\title{
UM ALGORITMO PARA SINTONIA DE CONTROLADORES ROBUSTOS PARA AMORTECIMENTO DE MODOS INTRA-PLANTA EM SISTEMAS DE POTÊNCIA
}

\begin{abstract}
Dissertação apresentada à Escola de Engenharia de São Carlos da Universidade de São Paulo, como parte dos requisitos para obtenção do título de Mestre em Engenharia Elétrica.
\end{abstract}

Orientador: Prof. Dr. Rodrigo Andrade Ramos 
AUTORIZO A REPRODUÇÃO E DIVULGAÇÃO TOTAL OU PARCIAL DESTE TRABALHO, POR QUALQUER MEIO CONVENCIONAL OU ELETRÔNICO, PARA FINS DE ESTUDO E PESQUISA, DESDE QUE CITADA A FONTE.

Ficha catalográfica preparada pela Seção de Tratamento da Informação do Serviço de Biblioteca - EESC/USP

Borges, Rafael Cruz
Um algoritmo para sintonia de controladores robustos
para amortecimento de modos intra-planta em sistemas de
potência / Rafael Cruz Borges i orientador Rodrigo
Andrade Ramos. -- São Carlos, 2009.
Dissertação (Mestrado-Programa de Pós-Graduação em
Engenharia Elétrica e Área de Concentraço em Sistemas
Elétricos de Potência) -- Escola de Engenharia de São
Carlos da Universidade de São Paulo, 2009.
l. Sistemas elétricos de potência. 2. Oscilações
eletromecânicas. 3. PSS. 4. Modos intra-planta.
5. Desigualdades matriciais lineares. I. Título.




\section{FOLHA DE JULGAMENTO}

\section{Candidato: Engenheiro RAFAEL CRUZ BORGES.}

Dissertação defendida e julgada em 06/07/2009 perante a Comissão Julgadora:

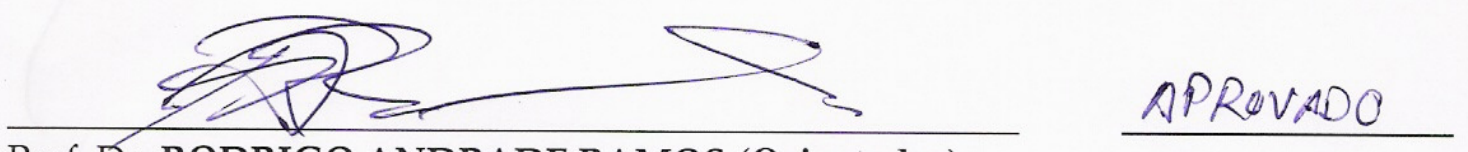

Prof. Dr. RODRIGO ANDRADE RAMOS (Orientador)

(Escola de Engenharia de São Carlos/USP)

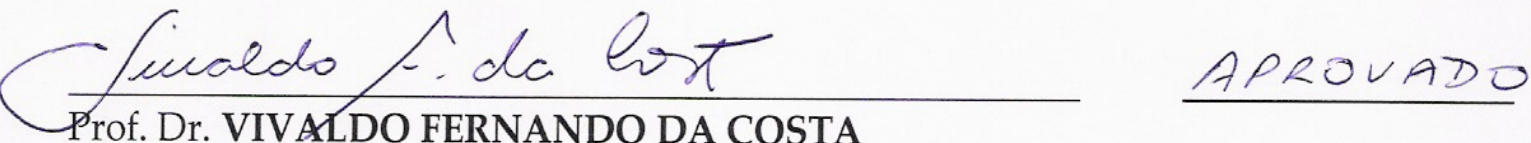

(Universidade Estadual de Campinas/UNICAMP)

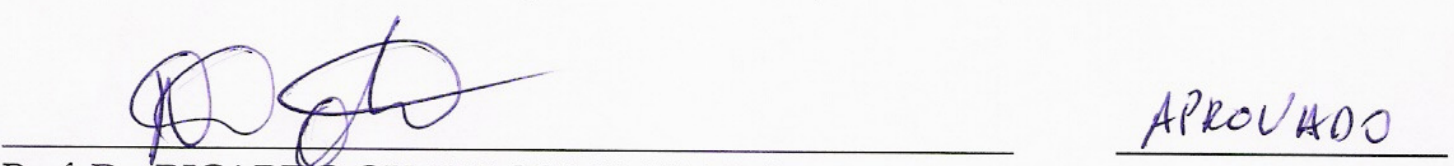

Prof. Dr. RICARDO QUADROS MACHADO

(Escola de Engenharia de São Carlos/USP)

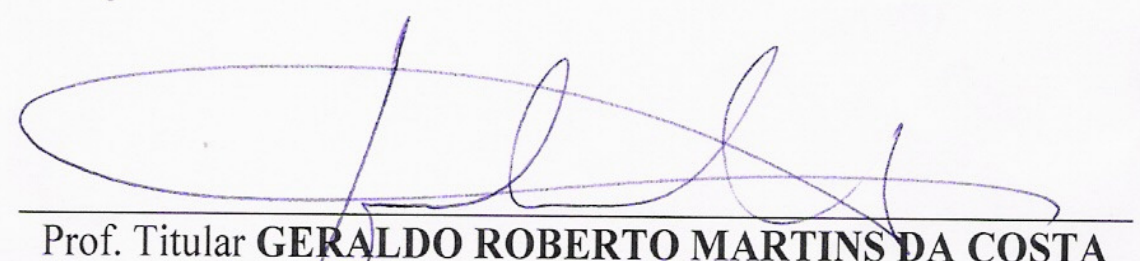

Coordenador do Progyama de Pós-Graduação em Engenharia Elétrica e

Presidente da Comissão de Pós-Graduação 
Ao meu pai Rubens, à minha mãe Silvia, à minha namorada Regiane, aos meus irmãos Régis, Renê e Remi, à minha avó Maria, à minha sogra Iraci e à memória dos avós João, Geni e Nilson. 


\section{AGRADECIMENTOS}

Agradeço em primeiro lugar a Deus por tudo de bom que aconteceu na minha vida, que me concedeu inúmeras oportunidades de crescimento profissional e principalmente saúde e força para vencer todos os momentos difíceis que aconteceram.

Ao professor Rodrigo Andrade Ramos pela orientação, confiança, compreensão e amizade, sempre pronto a encontrar as melhores soluções para o trabalho.

Agradeço ao meu pai e minha mãe que depositaram toda confiança, pelo apoio em todas as minhas decisões e sempre deram forças para a conclusão desse trabalho.

Agradeço a minha namorada Regiane por todo o incentivo, companheirismo e dedicação ao longo de toda essa trajetória e por todo o apoio nos momentos mais difíceis encontrados, e a dona Iraci pela dedicação e a ótima convivência.

Ao meu irmão Regis, minha cunhada Kelly e o sobrinho Reginho, que mesmo de longe sempre me apoiaram na realização deste trabalho.

A minha avó Maria por todo o empenho e apoio, que foi muito importante nos últimos anos.

Ao engenheiro Miguel Pedrosa da Construtora Norberto Odebrecht pela grande compreensão, confiança, oportunidade e amizade. Pela ótima convivência e amizade dos colegas engenheiros da Construtora: Edelvânio Ferraz, José Amin, Everton, Marcelo Castro, Paulo Mota e companheirismo do amigo Jair Souza.

Ao professores Newton Geraldo Bretas, João Bosco e Luís Fernando pela amizade e companheirismo.

Ao meu amigo Marcelo Castoldi pela grande ajuda na realização deste trabalho e também pela grande amizade.

Ao amigo Ricardo de Andrade pela grande amizade e convivência nos últimos anos. 
Aos amigos do LACO, Augusto Santos, Antônio Carlos, Carolina Rodrigues, Elmer Pablo, Fabíolo Amaral, Leandro Brolin, Carlisson, Marcelo Nanni, Moussa Mansour, Saulo Piereti, Raphael Augusto, Roman e aos demais integrantes pelo bom ambiente de trabalho.

A Universidade de São Paulo pelo ensino gratuito e de qualidade e a todos que de uma forma ou outra, contribuíram para a conclusão do trabalho. 
“Tentar e falhar é, pelo menos, aprender. Não chegar a tentar é sofrer a inestimável perda do que poderia ter sido". 


\section{RESUMO}

BORGES, R. C. (2009). Um algoritmo para sintonia de controladores robustos para amortecimento de modos intra-planta em sistemas de potência. Dissertação de MestradoEscola de Engenharia de São Carlos, Universidade de São Paulo, São Carlos, 2009.

O problema de modos intra-planta em sistemas de potência é caracterizado pela oscilação dos geradores de uma mesma usina uns contra os outros. Estes modos são geralmente bem amortecidos, mas uma sintonia inadequada dos parâmetros dos PSSs (Power System Stabilizers), visando fornecer um amortecimento aos modos locais, por exemplo, pode reduzir o amortecimento dos modos intra-planta. Esta possibilidade pode ser evitada por uma sintonia cuidadosa dos estabilizadores, em um modelo que seja capaz de representar os modos intra-planta. Este processo de sintonia pode ser tedioso e demorado, exigindo muitas horas de trabalho de um especialista. Neste trabalho, apresentamos um algoritmo computacional capaz de realizar esse processo, com uma intervenção mínima do projetista (reduzindo, portanto, o esforço do engenheiro projetista na sintonia do PSS e deixando que o computador faça de maneira eficiente) e aplicamos este algoritmo para encontrar uma sintonia adequada de PSSs para o amortecimento dos modos local e intra-planta coexistentes no mesmo sistema. Como mostrado neste trabalho, o algoritmo é capaz de sintonizar os PSSs para varias condições de operação de uma só vez, o que pode também resultar em uma melhor sintonia quando comparado com abordagens seqüenciais de projeto.

Palavras-Chave: Sistemas elétricos de potência, oscilações eletromecânicas, PSS, modos intra-planta, desigualdades matriciais lineares. 


\begin{abstract}
BORGES, R. C. (2009). An algorithm for robust controller tuning to damp intra-plant modes in power systems. Dissertation (M.S Degree)-Escola de Engenharia de São Carlos, Universidade de São Paulo, São Carlos, 2009.

The problem of intra-plant modes is characterized by the oscillation of the machines within a power station against each other. These modes are usually well-damped, but improper settings for the parameters for power system stabilizers (PSSs), aiming at enhancing the damping of local modes, for example, can reduce the damping of the intra-plant modes. This possibility must be avoided by a careful tuning of the stabilizers, over a model that is able to represent the intra-plant modes. This tuning process may be involved and time-consuming, requiring many hours of work from a specialist. In this paper, we present a computerized algorithm that is capable of performing this process with minimum intervention of the human designer (therefore alleviating the burden of PSS tuning for the engineer and placing most of it on the computer) and apply it to find a PSS tuning to damp both local and intra-plant modes of the same plant. As shown in the paper, the algorithm is capable of tuning PSSs for several operating conditions at once, which may also result in better tuning when compared to sequential approaches.
\end{abstract}

Key-Words: Electrical power system, Electromechanical oscillations, Power system stabilizers, Intra-plant Modes, Linear Matrix Inequalities. 


\section{SUMÁRIO}

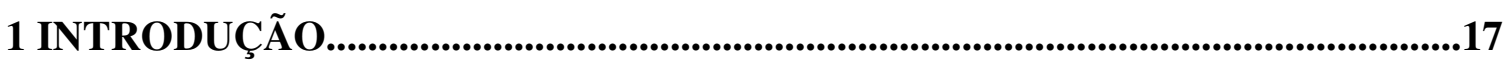

2 MODELAGEM DE UM SISTEMA DE POTÊNCIA................................................23

2.1 Modelagem de uma Máquina Síncrona................................................................23

2.2 Regulador Automático de Tensão....................................................................28

2.3 Modelo da Rede de Transmissão e das Cargas.........................................................29

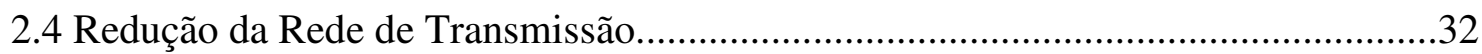

3 OSCILAÇÕES ELETROMECÂNICAS INTRA-PLANTA.......................................35

3.1 Resposta de um Sistema a Pequenas Perturbações..................................................35

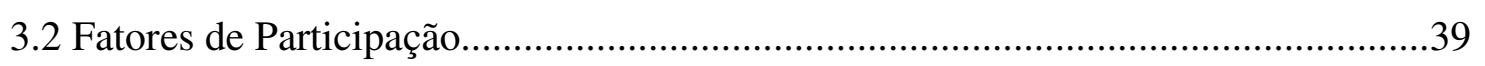

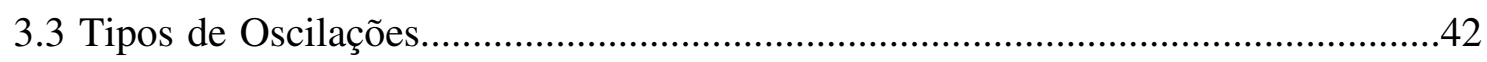

3.4 Exemplo de Oscilação Eletromecânica Intra-Planta................................................43

4 UM PROCEDIMENTO DE SINTONIA AUTOMÁtica DE PSS PARA AMORTECIMENTO DE MODOS INTRA-PLANTA..........................................46

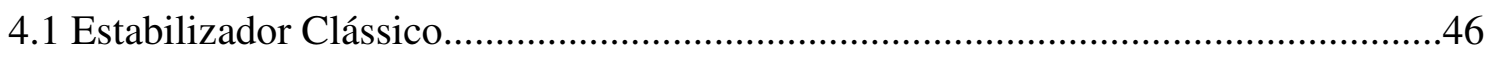

4.2 Proposta do Trabalho: Um Procedimento de Sintonia Automática de Pss para

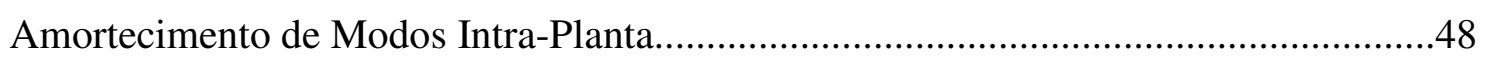

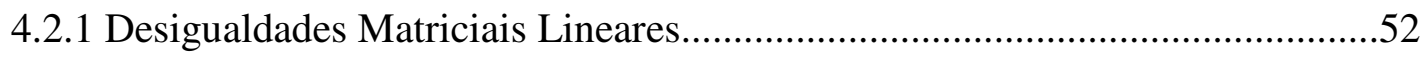

4.2.2 Estabilidade de Sistemas Lineares.............................................................53

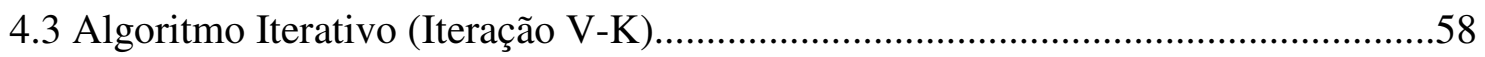

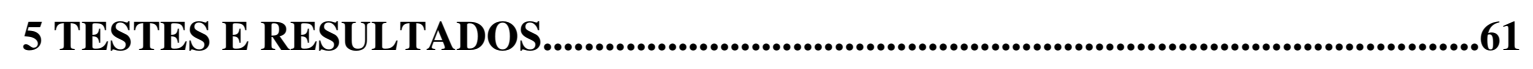

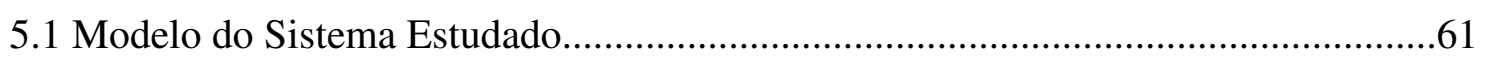

5.2 Aplicação do Algoritmo V-K para o Problema de Oscilação Intra-Planta................69

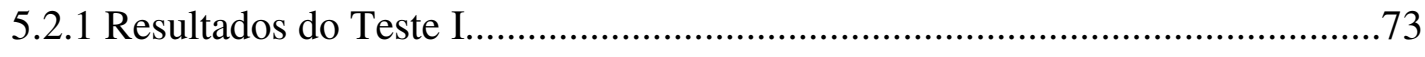

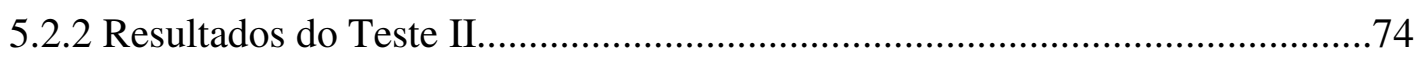

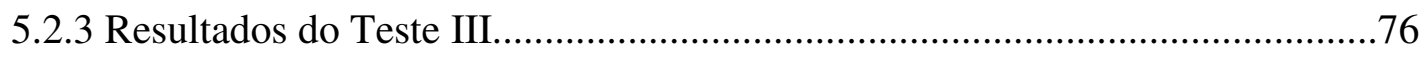

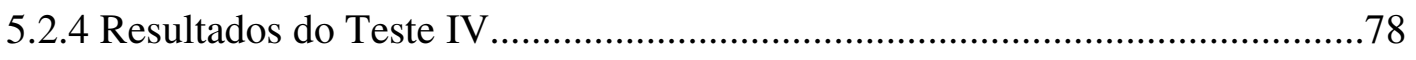


5.2.5 Resultados do Teste V. .80

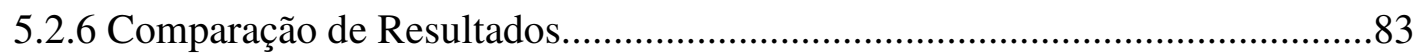

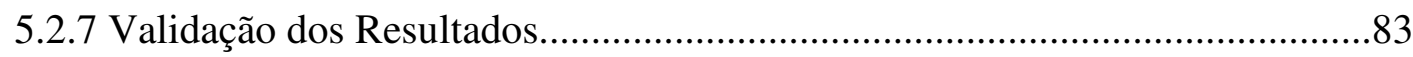

6 CONCLUSÕES E PERSPECTIVAS FUTURAS................................................87

REFERÊNCIAS BIBLIOGRÁFICAS.....................................................................90 


\section{LISTA DE FIGURAS}

Figura 2.1 - Representação ilustrativa da máquina síncrona de dois pólos.......................25

Figura 2.2 - Regulador Automático de Tensão.................................................................29

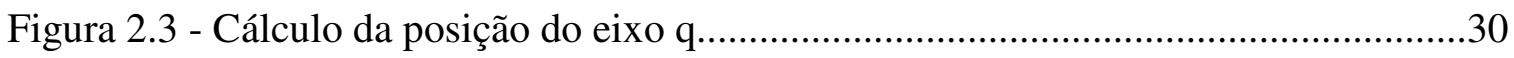

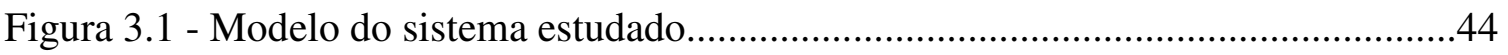

Figura 4.1 - Estrutura de controle do tipo rede avanço-atraso........................................47

Figura 4.2 - Diagrama do sistema a ser controlado......................................................52

Figura 4.3 - Setor cônico para garantia de amortecimento minimo...................................56

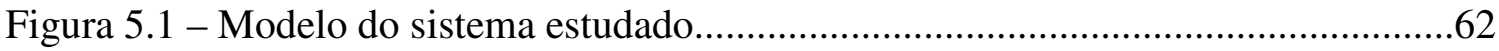

Figura 5.2 - Modelo agregado do sistema da figura 5.1...............................................66

Figura 5.3 - Simulação não linear do sistema com uma falta de $16 \mathrm{~ms}$ aplicado na barra $1 \mathrm{em} \mathrm{t}=2 \mathrm{~s}$ (potência incrementada em 12\% em relação ao caso base)............................84

Figura 5.4 - Simulação não linear do sistema com uma falta de $16 \mathrm{~ms}$ aplicado na barra $8 \mathrm{em} \mathrm{t}=2 \mathrm{~s}$ (potência incrementada em $16 \%$ em relação ao caso base)............................85

Figura 5.5 - Simulação não linear do sistema com uma falta em $16 \mathrm{~ms}$ aplicada na barra 8 em $\mathrm{t}=2 \mathrm{~s}$ (potência incrementada em $16 \%$ em relação ao caso base)

Figura 5.6 - Simulação não linear do sistema com uma falta de 16 ms aplicada na barra 1 $\mathrm{em} \mathrm{t}=2 \mathrm{~s}$ (potencia incrementada em $15 \%$ com relação ao caso base)

Figura 5.7 - Simulação não linear do sistema com uma falta de 16 ms aplicada na barra 1 em $\mathrm{t}=2 \mathrm{~s}$ (potencia incrementada em 15\% com relação ao caso base). 


\section{LISTA DE TABELAS}

Tabela 5.1 - Dados do sistema de transmissão..............................................................62

Tabela 5.2 - Parâmetros dos Geradores do Sistema.........................................................63

Tabela 5.3 - Dados do regulador de tensão.................................................................63

Tabela 5.4 - Autovalores do sistema em malha aberta...................................................64

Tabela 5.5 - Fator de participação do modo 1 e 2 ...........................................................65

Tabela 5.6 - Fator de participação do modo 7 e 8 ..........................................................65

Tabela 5.7 - Autovalores em malha fechada do sistema agregado.................................67

Tabela 5.8 - Autovalores em malha fechada com Kpss=6.......................................69

Tabela 5.9 - Autovalores em malha fechada com PSS dado por (5.2).............................71

Tabela 5.10 - Autovalores em malha fechada com PSS dado por (5.3)..........................74

Tabela 5.11 - Autovalores em malha fechada com PSS dado por (5.4)..........................75

Tabela 5.12 - Autovalores em malha fechada com PSS dado por (5.5).........................77

Tabela 5.13 - Autovalores em malha fechada com PSS dado por (5.6)...........................79

Tabela 5.14 - Autovalores em malha fechada com PSS dado por (5.7).........................82

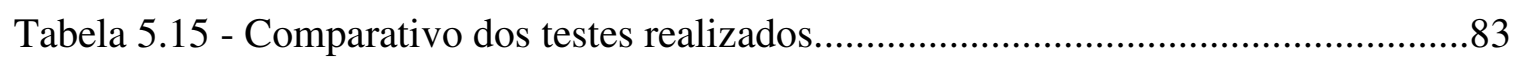




\section{LISTA DE ABREVIATURAS E SIGLAS}

$\begin{array}{ll}A V R & \text { - Automatic Voltage Regulator } \\ L M I & \text { - Linear Matrix Inequality } \\ B M I & \text { - Bilinear Matrix Inequality } \\ M V A r & \text { - Mega Volts Ampere } \\ M W & \text { - Mega Watts } \\ P S S & \text { - Power System Stabilizer } \\ \text { pu } & \text { - Por unidade } \\ \text { SEP } & \text { - Sistema Elétrico de Potência } \\ \text { PRP } & \text { - Posicionamento Regional de Pólos } \\ \text { FACTS } & \text { - Flexible alternating current transmission system }\end{array}$




\section{LISTA DE SÍMBOLOS}

$\delta_{i}$ - ângulo do rotor do gerador i, [rad]

$\omega_{i}$ - velocidade angular do rotor do gerador i, [p.u]

$\Delta \omega_{i}$ - desvio angular da velocidade do gerador i, [p.u]

$\omega_{0}-$ velocidade síncrona, $[\mathrm{rad} / \mathrm{s}]$

$E_{q i}^{\prime}$ - componente da tensão transitória ao longo do eixo direto do gerador i, [p.u]

$E_{F D i}$ - tensão de campo do gerador i, [p.u]

$H_{i}$ - constante de inércia do gerador i, [s]

$P_{m i}$ - potência mecânica de entrada do gerador i, [p.u]

$x_{d i}^{\prime}-$ reatância transitória do eixo direto do gerador i, [p.u]

$x_{q i}^{\prime}-$ reatância transitória do eixo em quadratura do gerador i, [p.u]

$I_{d i}$ - componente do eixo direto da corrente do estator do gerador i, [p.u]

$I_{q i}$ - componente do eixo em quadratura da corrente do estator do gerador i, [p.u]

$V_{d i}$ - componente do eixo direto da tensão no estator do gerador i, [p.u]

$V_{q i}$ - componente do eixo em quadratura da tensão no estator do gerador i, [p.u]

$x_{d i}$ - reatância síncrona do gerador i, [p.u]

$\tau_{d o i}^{\prime}$ - constante de tempo de circuito aberto transitória de eixo d do gerador i, [p.u]

$V_{T i}$ - tensão terminal do gerador i, [p.u]

$V_{\text {refi }}$ - tensão de referência para a barra terminal do gerador i, [p.u]

$V_{S i}$ - entrada de controle do regulador de tensão do gerador i, [p.u]

$K_{e i}$ - ganho do regulador de tensão do gerador i, [p.u]

$T_{e i}$ - constante de tempo do regulador de tensão do gerador i, [p.u]

$I$ - vetor com as correntes injetadas em cada barra do sistema

$V$ - vetor com as tensões nestes barramentos

$Y$ - matriz admitância modificada

$G$ - parte real da matriz admitância

$B$ - parte imaginária da matriz admitância 
$\lambda$ - autovalor

$v$ - autovetor

$f$ - freqüência em $[\mathrm{Hz}]$

$\zeta$ - fator de amortecimento

$K_{p s s}$ - ganho do PSS clássico

$T_{1}$ e $T_{2}$ - constantes de tempo do bloco avanço-atraso de fase do controlador

$T_{w}$ - constante de tempo do bloco washout do controlador

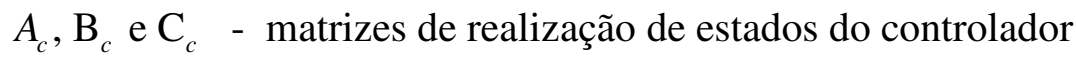

$\theta$ - ângulo do setor canônico no posicionamento regional de pólos

$\zeta_{0}$ - amortecimento mínimo

$s a t_{d}$ - saturação do eixo direto

$s a t_{q}$ - saturação do eixo em quadratura

$x_{p i}$ - reatância de potier do gerador i, [p.u]

$V_{f i}$ - medida da tensão terminal do gerador i, [p.u]

$T_{r i}$ - constante de tempo do processo de transdução da tensão terminal do gerador i, [s]

$V_{R i}$ - parte real da tensão terminal do gerador i, [p.u]

$V_{I i}$ - parte imaginária da tensão terminal do gerador i, [p.u]

$I_{R i}$ - parte real da corrente no estator do gerador i, [p.u]

$I_{I i}$ - parte imaginária da corrente no estator do gerador i, [p.u]

$w_{i}$ - autovetores à esquerda da matriz $\mathrm{A}$

$p_{k i}$ - fatores de participação

$\bar{x}$ - vetor de estados do sistema

$\bar{u}$ - vetor de entrada do sistema

$\bar{y}$ - vetor de saída do sistema

$x_{j}$ - representa desvios em relação a um valor de equilíbrio $\bar{x}$

$u_{j}$ - representa desvios em relação a um valor de equilíbrio $\bar{u}$

$y_{j}$ - representa desvios em relação a um valor de equilíbrio $\bar{y}$

$x_{c i}$ - vetor com as variáveis de estado do controlador

$A_{j}, \mathrm{~B}_{j}$ e $\mathrm{C}_{j}$ - matrizes obtidas pela linearização do sistema para o ponto de operação $\mathrm{j}$ 


\section{Capítulo 1}

\section{INTRODUÇÃO}

Devido ao aumento de carga nos Sistemas Elétricos de Potência (SEPs) nos últimos anos, houve a necessidade de se fazer a interconexão dos sistemas para se ter um melhor fornecimento de energia a essas cargas, ou seja, para se ter uma maior confiabilidade do sistema. A interligação do sistema resulta em um menor custo, pois permite menores reservas energéticas para o atendimento das cargas em horários de ponta e como consequiência um menor número de geradores funcionando à vazio (reserva girante), caso haja um aumento de carga inesperado.

Desde o início da operação interligada dos Sistemas Elétricos de Potência (SEPs), a estabilidade dos mesmos é vista como um problema fundamental para a operação do mesmo. Historicamente, o problema de estabilidade de maior foco e que dominou a atenção da indústria foi a estabilidade transitória (Rodrigues et al., 2007). No entanto, com o crescimento dos sistemas de potência e de suas interconexões, com o uso de novas tecnologias e com a operação do sistema em altas condições de carregamento, diferentes formas de instabilidade surgiram, tais como a instabilidade de tensão ou as oscilações de baixa freqüência (Kundur et al., 2004).

A estabilidade do SEP pode ser entendida como a capacidade que o sistema tem de retornar a uma condição de equilíbrio após a ocorrência de uma perturbação. Em outras palavras, se uma certa perturbação retira um elemento do estado desejado e, após a eliminação 
desta perturbação, o elemento retorna ao seu estado original (Kundur et al., 2004), então podemos dizer que o respectivo sistema é estável.

São várias as perturbações que podem ocorrer nos sistemas de potência, e os estudos de estabilidade nestes sistemas são geralmente classificados de acordo com a natureza de tais perturbações (Kundur et al., 2004). De maneira bastante geral, esta classificação está dividida em duas categorias principais: estabilidade a grandes perturbações e estabilidade a pequenas perturbações (Kundur et al., 2004).

A estabilidade a grandes perturbações pode ser entendida como a capacidade do sistema em encontrar um novo ponto de operação após a ocorrência de uma perturbação que afaste o sistema significativamente do ponto de equilíbrio gerado após a ocorrência da mesma. Uma perturbação desta natureza pode ser referente a um curto-circuito permanente em uma linha de transmissão importante para o sistema ou à perda de grandes unidades geradoras, por exemplo. $\mathrm{O}$ fato de que o estado do sistema se afasta de maneira significativa do ponto de equilíbrio correspondente requer que o sistema seja modelado, em estudos de estabilidade a grandes perturbações, por um conjunto de equações diferenciais não-lineares.

Por outro lado, a análise da estabilidade a pequenas perturbações (a qual será o foco desse trabalho de mestrado) pode ser entendida como a análise da resposta do sistema quando sujeito a perturbações de pequena magnitude (tais como variações normais diárias nas cargas), as quais não afastam significativamente o ponto de operação do sistema do equilíbrio correspondente. Neste caso, pode-se recorrer a uma linearização do modelo do sistema em torno do ponto de equilíbrio de interesse para representar a dinâmica deste sistema em resposta a tais perturbações, fato que produz grande simplificação nos procedimentos de análise e controle do sistema.

Este trabalho enfoca mais especificamente o problema de amortecimento de oscilações eletromecânicas de baixa freqüência, o qual pode ser enquadrado na categoria de estudos de 
estabilidade a pequenas perturbações e é um dos problemas mais pesquisados na área desde a década de 1960. A razão para persistência deste problema desde então é o fato de que os sistemas de potência estão operando cada vez mais próximos de seus limites, devido a uma série de restrições ambientais e econômicas. Em face a essas restrições de operação, as não linearidades existentes no comportamento dos componentes do SEP passam a ser cada vez mais significativas e os controladores que lidam com os mesmos (em sua maioria projetada com uso de técnicas lineares clássicas) ficaram menos eficazes (Rodrigues et al., 2007).

Pequenas perturbações podem gerar as oscilações eletromecânicas citadas no parágrafo anterior. Tais oscilações, quando não bem amortecidas, podem causar desgastes mecânicos nos geradores, afetar a transferência de potência das linhas de transmissão, e até mesmo interromper o fornecimento de energia elétrica em casos extremos, o que justifica a atenção significativa que este problema vem recebendo por parte de pesquisadores e engenheiros do setor elétrico há vários anos.

Existem diversos tipos de oscilações eletromecânicas e a resposta do sistema a uma pequena perturbação usualmente envolve uma combinação de um ou mais destes tipos. Em geral, uma oscilação com frequência e taxa de decaimento bem definida é denominada modo de oscilação no sistema de potência, e é usual classificar tais modos nas seguintes categorias (Rogers, 2000): modos locais, modos inter-área, modos torcionais, modos de controle ou das excitatrizes e modos intra-planta. Esta classificação dos tipos de oscilações será abordada em mais detalhes no capítulo 3, e este trabalho enfocará o último item da classificação acima: os modos intra-planta.

Dependendo de vários fatores (a maioria deles relacionados à condição operativa, à topologia e ao conjunto de parâmetros do sistema), o amortecimento natural desses modos pode ser baixo, o que é prejudicial à operação estável do sistema. Dentre as medidas corretivas que podem ser aplicadas para aumentar tal amortecimento, uma das mais comuns é 
a aplicação de controladores conhecidos como PSSs (do inglês, Power System Stabilizers) (Kundur, 2004), (Kundur et al., 2004). O aumento de amortecimento produzido por tais controladores faz com que o tempo durante o qual estes modos permanecem com influência significativa na dinâmica do sistema, após uma pequena perturbação, seja reduzido.

Os PSSs têm sido amplamente utilizados em SEP desde que foram propostos em (Demello e Concordia, 1969). Estes controladores fornecem amortecimento às oscilações eletromecânicas através de um sinal estabilizante adicionado ao regulador automático de tensão (ou AVR, do inglês, Automatic Voltage Regulator) do gerador.

O uso de PSSs tem sido objeto de vários estudos nos últimos anos, sendo que a maioria deles enfoca somente nas oscilações eletromecânicas dos modos locais e inter-área. Nestes estudos, a análise e o projeto de PSSs são efetuados na maioria das vezes modelando usinas geradoras através de uma máquina equivalente. Esta simplificação é adequada em boa parte dos casos, mas em algumas situações um modelo mais detalhado pode ser requerido. Um exemplo refere-se a usinas compostas por várias unidades geradoras que podem oscilar umas contra as outras, caracterizando os modos intra-planta já mencionados. Em alguns casos, estes modos podem ser um fator limitante em aplicações de PSSs (Crenshaw et al.,1983), (Schleif et al.,1979), e tais modos constituirão o foco principal deste trabalho de mestrado, conforme mencionado anteriormente.

Mesmo nos casos mais comuns, a aplicação de PSSs não é uma tarefa trivial. Os parâmetros destes controladores devem ser sintonizados para fornecerem aumento de amortecimento para múltiplos modos de oscilação que mudam de acordo com as condições operativas (Kundur, 2004), o que torna o processo de sintonia bastante complexo. As técnicas para sintonia dos parâmetros de PSSs têm evoluído a partir de um trabalho inicial apresentado em (Larsen e Swann, 1981), com vários tipos de abordagens, envolvendo resíduos de funções 
de transferência (Pagola et al.,1989) ou mesmo a teoria de controle robusto (Ramos et al.,2004), (Boukarim et al.,2000), para citar apenas alguns exemplos.

As abordagens mencionadas no parágrafo acima foram propostas tendo em mente os modos locais e inter-área, mas a maioria delas também pode ser aplicada em problemas de modos intra-planta. $\mathrm{O}$ amortecimento natural dos modos intra-planta é normalmente suficiente para que eles não apresentem problemas para a estabilidade do sistema. No entanto, quando os parâmetros do PSS são inadequados, esse amortecimento natural pode ser reduzido e, em casos extremos, os modos podem até mesmo ser desestabilizados (Rogers, 2000).

Para evitar este problema, todas as máquinas de uma mesma usina devem ser modeladas individualmente (de forma que o modelo possa representar as oscilações entre as mesmas) e um processo cuidadoso de sintonia dos PSSs deve ser conduzido, para encontrar um conjunto de parâmetros que aumente o amortecimento dos modos nos quais as máquinas participam, sejam eles intra-planta, local ou mesmo inter-área. Para dificultar ainda mais o processo, as frequiências e taxas de amortecimento desses modos são afetadas pelas variações das condições operativas, de forma que essas variações também precisam ser levadas em conta no projeto.

A combinação de todos esses fatores faz a sintonia do PSS um trabalho um tanto elaborado, mesmo para uma única estação geradora em que as máquinas participam em modos locais e intra-planta de uma só vez. Um engenheiro usando o método típico de tentativa-e-erro pode levar horas ou mesmo dias tentando encontrar um conjunto de parâmetros satisfatório, caso a variação nas condições operativas desta estação geradora seja bastante expressiva (como é o caso, por exemplo, das usinas despachadas para atender às condições de picos de carga no sistema).

Isto leva à idéia de substituir o processo de tentativa-e-erro envolvido no processo de sintonia do PSS feito pelo engenheiro por um processo realizado por um computador, o qual 
consegue realizar operações numéricas com bastante rapidez, mas não tem nenhum conhecimento prático ou empírico do problema. Para tanto, ele deve ser adequadamente programado para guiar sua procura por um conjunto de parâmetros de PSS em uma direção promissora, assim como um projetista deveria fazer. Algoritmos genéticos, por exemplo, vêm sendo empregados com sucesso como uma ferramenta para executar tal tarefa no contexto de sintonia simultânea de PSSs para amortecer os modos inter-área e local (Bomfim, 2000).

Neste trabalho, uma abordagem diferente é apresentada para executar uma sintonia computadorizada automática de parâmetros de PSSs, objetivando o aumento simultâneo do fator de amortecimento para modos local e intra-planta de um mesmo sistema, levando em conta diferentes condições de operação. O método é baseado num processo de otimização conhecido como iteração V-K (Oliveira et al.,2007), o qual utiliza algoritmos de resolução de desigualdades matriciais lineares (ou LMIs, do inglês Linear Matrix Inequalities) para encontrar uma sintonia adequada dos parâmetros dos PSS. A principal inovação apresentada neste trabalho de mestrado é a adaptação do algoritmo de iteração V-K para o tratamento de oscilações eletromecânicas intra-planta, as quais são raramente abordadas em trabalhos que objetivam o desenvolvimento de processos de sintonia automática de PSSs.

Este trabalho esta estruturado da seguinte forma ${ }^{1}$ : o capítulo 2 apresenta a modelagem do SEP que será utilizada neste trabalho; no capítulo 3 será feito uma abordagem sobre as oscilações eletromecânicas intra-planta; no capítulo 4 serão apresentados alguns problemas na utilização de estabilizadores clássicos para os modos intra-planta e, a partir dos mesmos, uma proposta de solução; no capítulo 5 serão apresentados os testes e resultados obtidos; e no capítulo 6 serão apresentadas as conclusões e as perspectivas futuras.

\footnotetext{
${ }^{1}$ Optou-se deliberadamente por não incluir no início do texto uma revisão bibliográfica detalhada sobre o tema de pesquisa. As referências estão dispostas ao longo do texto de forma a serem citadas dentro do contexto ao qual cada capítulo se refere. Acredita-se que tal formatação contribua para uma maior clareza sobre a conexão entre as referências citadas e o presente trabalho.
} 


\section{Capítulo 2}

\section{MODELAGEM DE UM SISTEMA DE POTÊNCIA}

Os sistemas elétricos de potência estão sujeitos a vários fenômenos físicos, e o estudo desses fenômenos requer uma modelagem matemática dos elementos que constituem este sistema. O grau de complexidade da modelagem matemática varia de acordo com as considerações e aproximações que serão utilizados. Devido a essa complexidade, proveniente da diversificação dos elementos do sistema, é conveniente recorrer a considerações físicas e aproximações para adequar a modelagem de acordo com o tipo de pesquisa em questão, de modo a simplificar a modelagem sem perder as informações do sistema estudado.

Neste capítulo será apresentada a modelagem do sistema elétrico utilizado no estudo proposto, e também as considerações e aproximações utilizadas para a obtenção desta. São apresentados os modelos das máquinas síncronas, dos reguladores de tensão, das cargas e da rede de transmissão. Este capítulo tem o objetivo de apresentar de forma geral a modelagem de cada um dos elementos citados, para posterior utilização no estudo dos modos de oscilações intra-planta.

\section{1 - Modelagem de uma Máquina Síncrona}

A máquina síncrona é um dos elementos mais importantes para efeito de estudos de estabilidade, o qual possui a função de fornecer energia elétrica às cargas, através do sistema 
de transmissão. Basicamente as máquinas síncronas são constituídas pelo estator (estrutura fixa) e o rotor (estrutura girante) e estão divididas em duas categorias: máquinas de pólos lisos (ou máquina de rotor cilíndrico) e máquinas de pólos salientes. A bobina do circuito de campo, o qual é fixa ao rotor, é alimentada por uma corrente contínua, e quando o rotor esta em movimento a uma velocidade constante, o mesmo faz com que o campo magnético gerado por este circuito induza uma tensão aproximadamente senoidal na bobina do circuito de armadura, fixa ao estator da máquina.

Para estudos de estabilidade de forma geral, as equações diferenciais de sétima ordem que representam a modelagem da máquina podem ser encontradas em (Anderson e Fouad, 1994). Nesta modelagem, considera-se que a máquina em estudo seja representada pelo modelo equivalente de dois pólos, mostrado na figura 2.1, e admite-se que a mesma esteja em condições balanceadas durante os transitórios. A dinâmica do rotor é representada por duas variáveis de estado (posição e velocidade angular, com relação a uma referência síncrona) e os transitórios elétricos, tanto do rotor quanto do estator, são modelados através de circuitos equivalentes, utilizando-se a transformação de Park. Através dessa transformação, as equações da máquina podem ser referenciadas aos eixos d (direto) e q (quadratura), os quais constituem uma referência girante. A vantagem dessa simplificação se deve ao fato de que alguns parâmetros da máquina, como as indutâncias próprias e mútuas entre o rotor e o estator se tornam constantes em relação a este referencial, o que se traduz em uma maior simplificação nas equações diferenciais. O efeito do fluxo principal do rotor, induzido pela tensão de campo, é modelado por um destes circuitos, enquanto que os demais se referem aos efeitos dos enrolamentos amortecedores e das correntes parasitas (que também causam amortecimento das eventuais oscilações provocadas por perturbações) no rotor. 


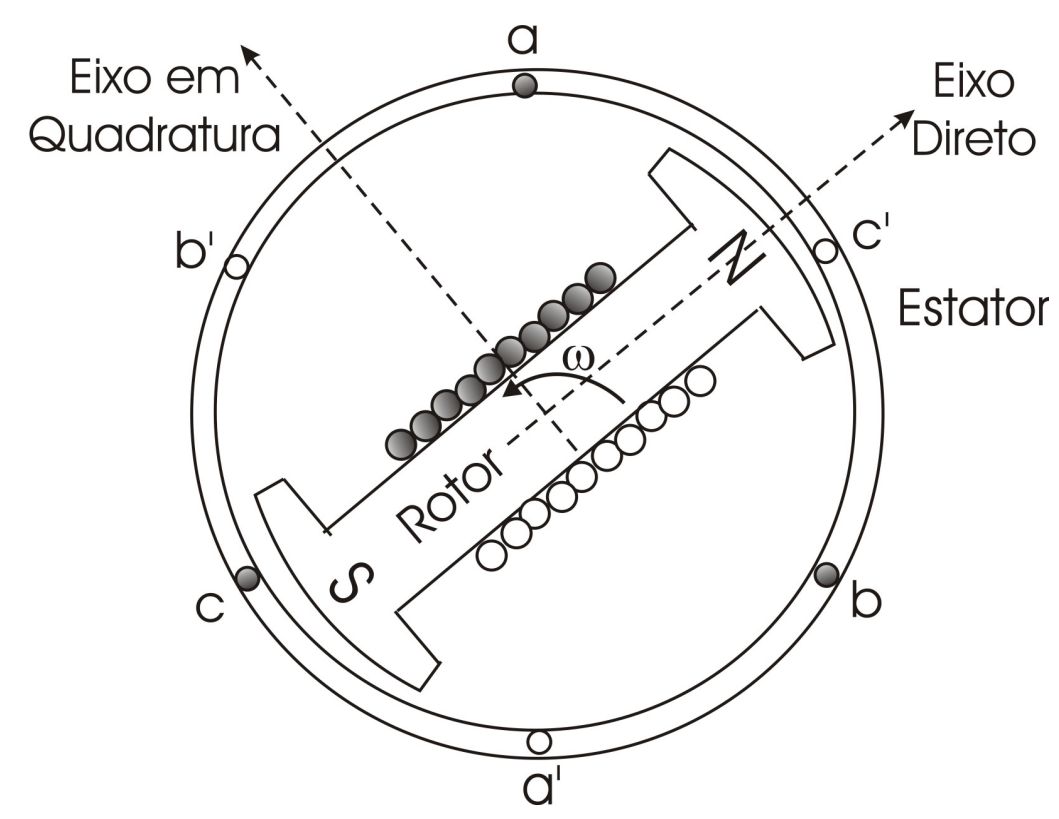

Figura 2.1 - Representação ilustrativa da máquina síncrona de dois pólos

Neste trabalho, toda a análise do problema de oscilações eletromecânicas intra-planta será feita com a construção do modelo através do software PACDYN. O efeito dos enrolamentos amortecedores foi desprezado no equacionamento utilizado neste trabalho, o que possibilitou uma redução da ordem da modelagem. O software PACDYN (desenvolvido pelo CEPEL), é especializado em estudos de estabilidade de sistemas elétricos de potência. Este é capaz de criar representações linearizadas do sistema em torno de um ponto de operação e, a partir destas representações, estudar localmente a estabilidade do sistema via, por exemplo, análise de autovalores e autovetores. Em estudos de estabilidade a pequenas perturbações a potência mecânica é considerada como sendo constante. Isso se deve ao fato de que as variações de $\mathbf{P}_{\mathbf{m}}$ dependem da atuação dos reguladores de velocidade. Esses reguladores apresentam constantes de tempo elevadas, fazendo com que as variações da potência mecânica sejam insignificantes durante a faixa de tempo de análise das oscilações eletromecânicas. Dessa maneira, o modelo da turbina do gerador não é incluído na modelagem da máquina síncrona. 
As equações diferenciais e algébricas, referidas aos eixos direto (d) e em quadratura (q) da máquina i, que descrevem modelo 2 utilizado pelo PACDYN são:

$$
\begin{aligned}
& \dot{\delta}_{\mathrm{i}}=\omega_{\mathrm{o}} \omega_{\mathrm{i}}-\omega_{\mathrm{o}} \\
& \dot{\omega}_{\mathrm{i}}=\frac{1}{2 \mathrm{H}_{\mathrm{i}}}\left[\mathbf{P}_{\mathrm{mi}}-\mathbf{V}_{\mathrm{di}} \mathbf{I}_{\mathrm{di}}-\mathbf{V}_{\mathrm{qi}} \mathbf{I}_{\mathrm{qi}}\right] \\
& \dot{\mathbf{E}}_{\mathrm{qi}}^{\prime}=\frac{1}{\tau_{\mathrm{doi}}^{\prime}}\left[\mathbf{E}_{\mathrm{FDi}}-\mathbf{E}_{\mathrm{qi}}^{\prime} \mathbf{s a t}_{\mathrm{d}}-\left(\mathbf{x}_{\mathrm{di}}-\mathbf{x}_{\mathrm{di}}^{\prime}\right) \mathbf{I}_{\mathrm{di}}\right] \\
& \mathbf{V}_{\mathrm{qi}}=\mathbf{E}_{\mathrm{qi}}^{\prime}-\left(\frac{\mathbf{x}_{\mathrm{di}}^{\prime}-\mathbf{x}_{\mathrm{pi}}}{\mathbf{s a t}_{\mathrm{di}}}+\mathbf{x}_{\mathrm{pi}}\right) \mathbf{I}_{\mathrm{di}} \\
& \mathbf{V}_{\mathrm{di}}=\mathbf{E}_{\mathrm{di}}^{\prime}+\left(\frac{\mathbf{x}_{\mathrm{qi}}^{\prime}-\mathbf{x}_{\mathrm{pi}}}{\mathbf{s a t}_{\mathrm{qi}}}+\mathbf{x}_{\mathrm{pi}}\right) \mathbf{I}_{\mathrm{qi}}
\end{aligned}
$$

onde $\boldsymbol{\delta}_{\mathbf{i}}, \boldsymbol{\omega}_{\mathbf{i}}$ e $\mathbf{E}_{\mathbf{q} \mathbf{i}}^{\prime}$ representam o ângulo, a velocidade angular do rotor e a componente da tensão interna de eixo em quadratura proporcional ao fluxo do enrolamento de campo. $\mathbf{V}_{\mathbf{d i}} \mathrm{e}$ $\mathbf{V}_{\mathbf{q} i}$ são as componentes de eixo d e q da tensão nos terminais do estator, $\omega_{\mathbf{o}}$ é a velocidade síncrona, $\mathbf{H}_{\mathrm{i}}$ é a constante de inércia do gerador, $\mathbf{P}_{\mathrm{mi}}$ é a potência mecânica de entrada do gerador, $\mathbf{x}_{\mathbf{d i}}^{\prime}$ e $\mathbf{x}_{\mathbf{q} \mathbf{i}}^{\prime}$ são as reatâncias transitórias de eixo $\mathbf{d}$ e $\mathbf{q}, \mathbf{I}_{\mathbf{d i}}$ e $\mathbf{I}_{\mathbf{q} \mathbf{i}}$ são correntes do estator de eixo d e $\mathbf{q}, \mathbf{E}_{\mathbf{F D i}}$ é uma tensão no estator, equivalente ao efeito da tensão de campo, $\mathbf{x}_{\text {di }}$ é a reatância síncrona e $\boldsymbol{\tau}_{\text {doi }}^{\prime}$ é a constante de tempo de circuito aberto transitória de eixo d, $\mathbf{x}_{\mathbf{p i}}$ é a reatância de potier, sat $_{\mathbf{d i}}$ e $\mathbf{s a t}_{\mathbf{q i}}$ são as saturações de eixo d e q.

Tem-se que pelo "default" do PACDYN, $\mathbf{s a t}_{\mathbf{d i}}=\mathbf{s a t}_{\mathbf{q i}}=1$ e com isso as equações (2.3)-(2.5) podem ser reescritas da seguinte forma:

$$
\dot{E}_{q i}^{\prime}=\frac{1}{\tau_{d o i}^{\prime}}\left[E_{F D i}-E_{q i}^{\prime}-\left(x_{d i}-x_{d i}^{\prime}\right) I_{d i}\right]
$$




$$
\begin{aligned}
& \mathbf{V}_{\mathrm{qi}}=\mathbf{E}_{\mathrm{qi}}^{\prime}-\mathbf{X}_{\mathrm{di}}^{\prime} \mathbf{I}_{\mathrm{di}} \\
& \mathbf{V}_{\mathrm{di}}=\mathbf{E}_{\mathrm{di}}^{\prime}+\mathbf{X}_{\mathrm{qi}}^{\prime} \mathbf{I}_{\mathrm{qi}}
\end{aligned}
$$

Substituindo as equações (2.7) e (2.8) na equação (2.2), as equações algébricas e diferenciais que descrevem o modelo, são:

$$
\begin{aligned}
& \dot{\delta}_{\mathrm{i}}=\omega_{0} \omega_{\mathrm{i}}-\omega_{\mathrm{o}} \\
& \dot{\omega}_{\mathrm{i}}=\frac{1}{2 \mathrm{H}_{\mathrm{i}}}\left[\mathbf{P}_{\mathrm{mi}}-\mathbf{E}_{\mathrm{di}}^{\prime} \mathbf{I}_{\mathrm{di}}-\mathbf{E}_{\mathrm{qi}}^{\prime} \mathbf{I}_{\mathrm{qi}}-\left(\mathbf{x}_{\mathrm{qi}}^{\prime}-\mathbf{x}_{\mathrm{di}}^{\prime}\right) \mathbf{I}_{\mathrm{di}} \mathbf{I}_{\mathrm{qi}}\right] \\
& \dot{\mathbf{E}}_{\mathrm{qi}}^{\prime}=\frac{1}{\tau_{\mathrm{doi}}^{\prime}}\left[\mathbf{E}_{\mathrm{FDi}}-\mathbf{E}_{\mathrm{qi}}^{\prime}-\left(\mathbf{x}_{\mathrm{di}}-\mathbf{x}_{\mathrm{di}}^{\prime}\right) \mathbf{I}_{\mathrm{di}}\right] \\
& \mathbf{V}_{\mathrm{qi}}=\mathbf{E}_{\mathrm{qi}}^{\prime}-\mathbf{x}_{\mathrm{di}}^{\prime} \mathbf{I}_{\mathrm{di}} \\
& \mathbf{V}_{\mathrm{di}}=\mathbf{E}_{\mathrm{di}}^{\prime}+\mathbf{x}_{\mathrm{qi}}^{\prime} \mathbf{I}_{\mathrm{qi}}
\end{aligned}
$$

Pode-se notar que o modelo considerado em questão é composto por equações algébricas e diferenciais ao mesmo tempo, que são referidos aos eixos $\mathbf{d}$ e $\mathbf{q}$ da máquina. Devido à dimensão do sistema e a variedade de tipos de cargas (indutivas, capacitivas, resistiva), e a presença de elementos não lineares no sistema, a modelagem das cargas tornase uma parte complexa de ser resolvido. Mas nesse trabalho as cargas serão modeladas como impedâncias constantes, e isso causa uma simplificação no modelo final e garante que um processo chamado de "redução de rede" possa ser aplicado, o qual será discutido mais adiante. 


\section{2- Regulador Automático de Tensão}

Existem diferentes tipos e modelos de Reguladores Automáticos de Tensão (ou AVRs, do inglês, Automatic Voltage Regulators), desenvolvidos ao longo dos anos em que os mesmos começaram a ser usados nos sistemas de potência. Estes reguladores fornecem uma ação corretiva proporcional ao desvio da tensão terminal da máquina em relação à tensão de referência $\mathbf{V}_{\text {ref. }}$ Para este trabalho será utilizado o modelo, que apresenta as seguintes equações resultantes referente ao gerador i:

$$
\begin{aligned}
& \dot{\mathbf{E}}_{\mathrm{FD}}=\frac{1}{T_{\mathrm{ei}}}\left[\mathrm{K}_{\mathrm{ei}}\left(\mathrm{V}_{\mathrm{refi}}-\mathrm{V}_{\mathrm{fi}}+\mathrm{V}_{\mathrm{Si}}\right)-\mathrm{E}_{\mathrm{FDi}}\right] \\
& \dot{\mathrm{V}}_{\mathrm{fi}}=\frac{1}{\mathrm{~T}_{\mathrm{ri}}}\left(\left|\mathbf{V}_{\mathrm{Ti}}\right|-\mathrm{V}_{\mathrm{fi}}\right)
\end{aligned}
$$

onde:

$$
\overrightarrow{\mathbf{V}}_{\mathrm{Ti}}=\mathbf{V}_{\mathrm{qi}}+\mathbf{j} \mathbf{V}_{\mathrm{di}}
$$

sendo que $\left|\mathbf{V}_{\mathbf{T i}}\right|$ é o módulo da tensão terminal, $\mathbf{V}_{\text {refi }}$ é a tensão de referência para a barra terminal, $\mathbf{V}_{\mathbf{S i}}$ é a entrada de controle do regulador (também chamada de sinal estabilizante), $\mathbf{K}_{\text {ei }}$ e $\mathbf{T}_{\mathbf{e}}$ são o ganho e a constante de tempo do regulador, respectivamente, $\mathbf{V}_{\mathrm{fi}}$ é a medida da tensão terminal e $\mathbf{T}_{\text {ri }}$ é a constante de tempo do processo de transdução da tensão terminal, normalmente constituído por um transformador de potencial seguido de um circuito retificador. Este regulador pode se representado pelo diagrama de blocos da figura 2.2. 


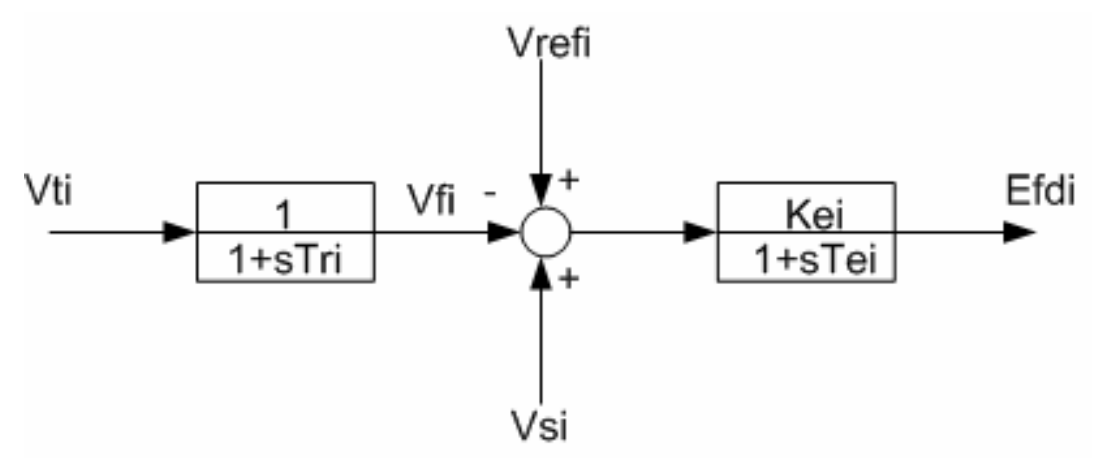

Figura 2.2- Regulador Automático de Tensão

\section{3 - Modelo da Rede de Transmissão e das Cargas}

Como dito anteriormente a modelagem das cargas dos sistemas elétricos de potência possui certa complexidade. Neste trabalho, as cargas serão modeladas como impedâncias constantes ligadas aos barramentos do sistema. Este artifício, além de simplificar o modelo final, garante que um processo de redução de rede (baseado num algoritmo de eliminação de Gauss) possa ser aplicado, para eliminar o conjunto de equações algébricas, resultando assim num modelo constituído apenas por um conjunto de equações diferenciais na forma de espaço de estados.

Admite-se que os transitórios que ocorrem nas linhas de transmissão são muito mais rápidos do que as oscilações eletromecânicas do rotor e que, portanto, tais transitórios podem ser desprezados. Logo, a rede de transmissão pode ser modelada como um circuito estático passivo através da equação algébrica matricial do tipo $\mathbf{I}=\mathbf{Y} \mathbf{V}$, onde I é o vetor com as correntes injetadas em cada barramento do sistema, $\mathbf{V}$ é um vetor com as tensões nestes barramentos e $\mathbf{Y}$ é a matriz admitância modificada, que inclui as admitâncias constantes das cargas. Esta equação fornece, para cada barramento, uma tensão $\mathbf{V}_{\mathbf{i}} \mid \boldsymbol{\beta}_{\mathbf{i}}$ em relação à 
referência angular comum (denominada eixo Real). Assim, nas barras de geração, a posição do eixo $\mathbf{q}$ (e conseqüentemente o ângulo $\boldsymbol{\delta}_{\mathbf{i}}$ ) da máquina é dada pela direção de uma tensão auxiliar $\mathbf{E}_{q d i}$, que pode ser calculada como mostrado na figura 2.3.

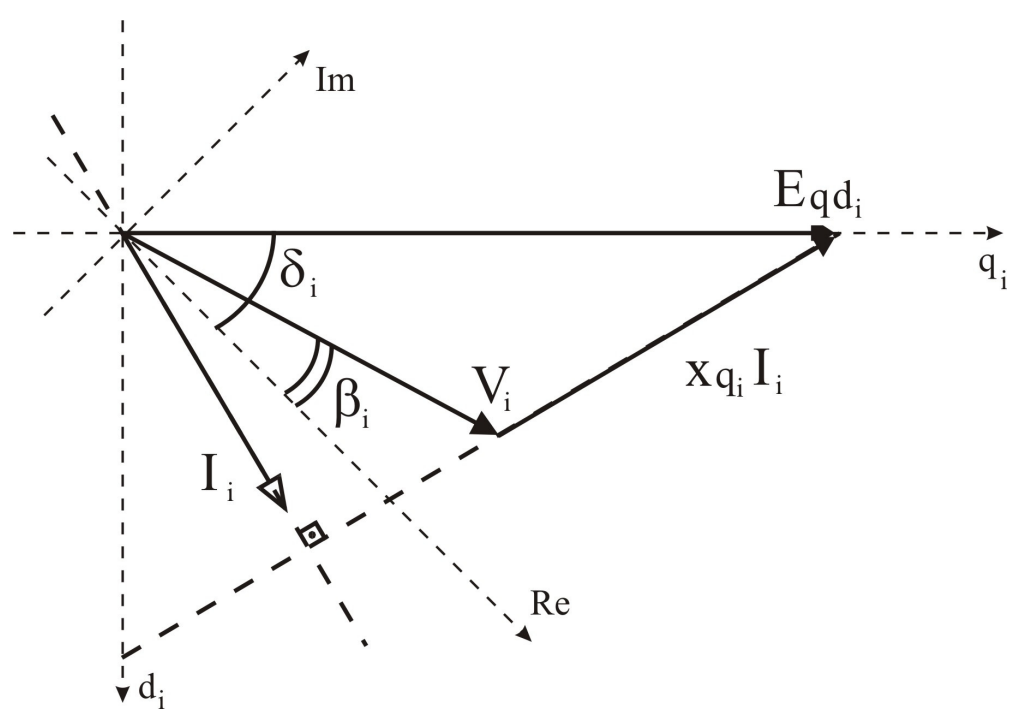

Figura 2.3 - Cálculo da posição do eixo q

Transportando as equações de cada máquina para a referência comum, obtém-se um novo conjunto de equações que ainda preserva a estrutura da rede de transmissão. Feito isto, as equações para a máquina i do sistema são as seguintes:

$$
\begin{aligned}
& \dot{\delta}_{\mathrm{i}}=\omega_{\mathrm{o}} \omega_{\mathrm{i}}-\omega_{\mathrm{o}} \\
& \dot{\omega}_{\mathrm{i}}=\frac{1}{2 \mathrm{H}_{\mathrm{i}}}\left[\begin{array}{l}
P_{\mathrm{mi}}-\mathrm{E}_{\mathrm{di}}^{\prime}\left(\mathrm{I}_{\mathrm{Ri}} \operatorname{sen}\left(\delta_{\mathrm{i}}\right)-\mathrm{I}_{\mathrm{Ii}} \cos \left(\delta_{\mathrm{i}}\right)\right)-\left(\mathrm{I}_{\mathrm{Ri}} \cos \left(\delta_{\mathrm{i}}\right)+\mathrm{I}_{\mathrm{Ii}} \operatorname{sen}\left(\delta_{\mathrm{i}}\right)\right) x \\
\mathbf{x}\left(\mathrm{E}_{\mathrm{qi}}^{\prime}+\left(\mathrm{x}_{\mathrm{qi}}^{\prime}-\mathbf{x}_{\mathrm{di}}^{\prime}\right)\left(\mathrm{I}_{\mathrm{Ri}} \operatorname{sen}\left(\delta_{\mathrm{i}}\right)-\mathrm{I}_{\mathrm{Ii}} \cos \left(\delta_{\mathrm{i}}\right)\right)\right)
\end{array}\right] \\
& \dot{\mathrm{E}}_{\mathrm{qi}}^{\prime}=\frac{1}{\tau_{\mathrm{doi}}^{\prime}}\left[\mathrm{E}_{\mathrm{FDi}}-\mathrm{E}_{\mathrm{qi}}^{\prime}-\left(\mathrm{x}_{\mathrm{di}}-\mathbf{x}_{\mathrm{di}}^{\prime}\right)\left(\mathrm{I}_{\mathrm{Ri}} \operatorname{sen}\left(\delta_{\mathrm{i}}\right)-\mathrm{I}_{\mathrm{Ii}} \cos \left(\delta_{\mathrm{i}}\right)\right)\right] \\
& \dot{\mathrm{E}}_{\mathrm{FD}}=\frac{1}{T_{\mathrm{ei}}}\left[\mathrm{K}_{\mathrm{ei}}\left(\mathrm{V}_{\mathrm{refi}}-\mathrm{V}_{\mathrm{fi}}+\mathrm{V}_{\mathrm{Si}}\right)-\mathrm{E}_{\mathrm{FDi}}\right]
\end{aligned}
$$




$$
\begin{aligned}
& \dot{V}_{\mathrm{fi}}=\frac{1}{T_{\mathrm{ri}}}\left(\left|\mathbf{V}_{\mathrm{Ti}}\right|-\mathbf{V}_{\mathrm{fi}}\right) \\
& \mathbf{V}_{\mathrm{Ri}}=\mathbf{E}_{\mathrm{qi}}^{\prime} \cos \left(\delta_{\mathrm{i}}\right)-\dot{\mathbf{x}}_{\mathrm{di}}^{\prime} \mathbf{I}_{\mathrm{Ii}} \\
& \mathbf{V}_{\mathrm{Ii}}=\mathbf{E}_{\mathrm{di}}^{\prime} \mathbf{E}_{\mathrm{qi}}^{\prime} \operatorname{sen}\left(\delta_{\mathrm{i}}\right)+\mathbf{x}_{\mathrm{di}}^{\prime} \mathbf{I}_{\mathrm{Ri}}
\end{aligned}
$$

sendo $\mathbf{V}_{\mathbf{R i}}$ e $\mathbf{V}_{\mathbf{I i}}$ as partes real e imaginária, respectivamente, da tensão terminal (com os eixos real $(\mathrm{Re})$ e imaginário $(\mathrm{Im})$ dados pela figura 2.3 e $\mathbf{I}_{\mathbf{R i}}$ e $\mathbf{I}_{\mathbf{I i}}$ as partes real e imaginária, respectivamente, da corrente do estator.

O modulo da tensão terminal $\left|\mathbf{V}_{\mathbf{T i}}\right|$ em cada barra de geração $i$ é dado por:

$$
\left|\mathbf{V}_{\mathrm{Ti}}\right|=\left|\mathbf{V}_{\mathrm{Ri}}+\mathbf{j} \mathrm{V}_{\mathrm{Ii}}\right|=\sqrt{\mathrm{V}_{\mathrm{Ri}}^{2}+\mathbf{j} \mathbf{V}_{\mathrm{Ii}}^{2}}
$$

Substituindo (2.22) e (2.23) em (2.24), tem-se:

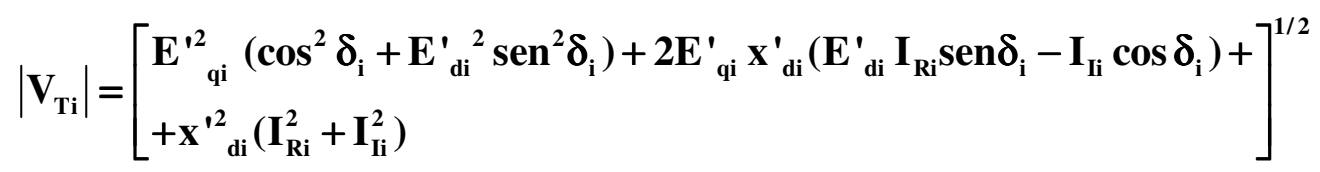

Colocando a equação do regulador de tensão da unidade i para este sistema de referência angular, tem-se:

$$
\begin{aligned}
& \dot{\mathbf{E}}_{\mathrm{FD}}=\frac{1}{T_{\mathrm{ei}}}\left[\mathrm{K}_{\mathrm{ei}}\left(\mathrm{V}_{\mathrm{refi}}-\mathrm{V}_{\mathrm{fi}}+\mathrm{V}_{\mathrm{Si}}\right)-\mathrm{E}_{\mathrm{FDi}}\right] \\
& \dot{\mathrm{V}}_{\mathrm{fi}}=\frac{1}{T_{\mathrm{ri}}}\left(\sqrt{\mathrm{V}_{\mathrm{Ri}}{ }^{2}+\mathrm{j} \mathrm{V}_{\mathrm{Ii}}{ }^{2}}-\mathrm{V}_{\mathrm{fi}}\right)
\end{aligned}
$$

Além do mais, a equação $\mathbf{I}=\mathbf{Y V}$ da rede de transmissão estabelece que a corrente injetada em cada barra de geração $i$ do sistema é dada por:

$$
I_{R i}+j I_{I i}=\sum_{k=1}^{n b} Y_{i k}\left(V_{R i}+j V_{I i}\right)
$$


onde $\mathrm{Y}_{\mathrm{ik}} \in \mathrm{C}$ são elementos da matriz $\mathbf{Y}$ e nb é o número total de barras do sistema. Fica claro, neste sistema de referência de ângulo, a relação entre as equações diferencias do gerador e as equações algébricas da rede de transmissão.

\section{4 - Redução da Rede de Transmissão}

O conjunto de equações que descreve a dinâmica da máquina síncrona juntamente com o regulador automático de tensão (equações (2.17)-(2.23)) é composto por equações algébricas e diferenciais. No entanto, para que se possam aplicar as técnicas lineares de controle, propostas neste trabalho, a modelagem do mesmo deve ser composta apenas por equações diferenciais. Para isso, as equações algébricas deverão ser eliminadas, através de um processo que chamamos de "redução de rede". Com a eliminação das equações o modelo passa a ser constituído apenas por um conjunto de equações diferenciais na forma de espaço de estados.

A redução de rede é feita através da inclusão das cargas, (os quais foram, neste trabalho, consideradas como impedância constante, para efeito de simplificação) na matriz $\mathbf{Y}_{\text {bus }}$. Ressalta-se que essa é uma simplificação usual em estudos de estabilidade a pequena perturbação. As barras de carga do sistema são então eliminadas através do processo de eliminação de Gauss, e, portanto, a rede de transmissão se reduz às barras internas dos geradores, obtendo-se uma matriz admitância modificada $\mathbf{Y}_{\mathbf{m}}$. Além disso, seria também possível incluir as reatâncias transitórias dos geradores na matriz $\mathbf{Y}_{\text {bus }}$ (de formar que a matriz $\mathbf{Y}_{\mathbf{m}}$ representasse a rede reduzida aos nós internos dos geradores), caso as reatâncias de eixo direto e em quadratura tenham valores numéricos coincidentes. Como será visto adiante, no 
entanto, os geradores do sistema estudado neste trabalho apresentam $\mathbf{x}_{\mathbf{d i}}^{\prime} \neq \mathbf{x}_{\mathbf{q i}}^{\prime}$ e, por esta razão, não foi possível incluir tais reatâncias na matriz $\mathbf{Y}_{\mathbf{m}}$. Um processo de redução modificado (envolvendo o conjunto de equações algébrico-diferenciais que inclui as equações do estator como restrições algébricas) foi então aplicado (CEPEL, 2002).

Com a redução da rede, as correntes injetadas nas barras de geração podem ser reescritas da seguinte forma:

$$
\begin{aligned}
& I_{\mathrm{Ri}}=\sum_{\mathrm{k}=1}^{\mathrm{n}}\left(\mathbf{E}_{\mathrm{qk}}^{\prime} \mathbf{G}_{\mathrm{ik}} \cos \left(\delta_{\mathrm{k}}\right)-\mathbf{E}_{\mathrm{qk}}^{\prime} \mathbf{B}_{\mathrm{ik}} \operatorname{sen}\left(\delta_{\mathrm{k}}\right)\right) \\
& \mathbf{I}_{\mathrm{Ii}}=\sum_{\mathrm{k}=1}^{\mathrm{n}}\left(\mathbf{E}_{\mathrm{qk}}^{\prime} \mathbf{G}_{\mathrm{ik}} \operatorname{sen}\left(\delta_{\mathrm{k}}\right)+\mathbf{E}_{\mathrm{qk}}^{\prime} B_{\mathrm{ik}} \cos \left(\delta_{\mathrm{k}}\right)\right)
\end{aligned}
$$

onde $\mathbf{G}_{\mathbf{i k}}$ e $\mathbf{B}_{\mathbf{i k}}$ são os elementos das matrizes condutância e susceptância respectivamente, ou seja, são as partes real e imaginária do elemento $\mathbf{Y}_{\text {mik }}$ da matriz $\mathbf{Y}_{\mathrm{m}}$ e n é o número de geradores do sistema.

Substituindo as equações (2.29) e (2.30) nas equações de (2.18) e (2.19), e (2.25) em (2.27), encontra-se um novo conjunto de equações diferenciais que descrevem o gerador i no sistema reduzido:

$$
\begin{aligned}
& \dot{\delta}_{\mathrm{i}}=\omega_{0} \omega_{\mathrm{i}}-\omega_{0}
\end{aligned}
$$

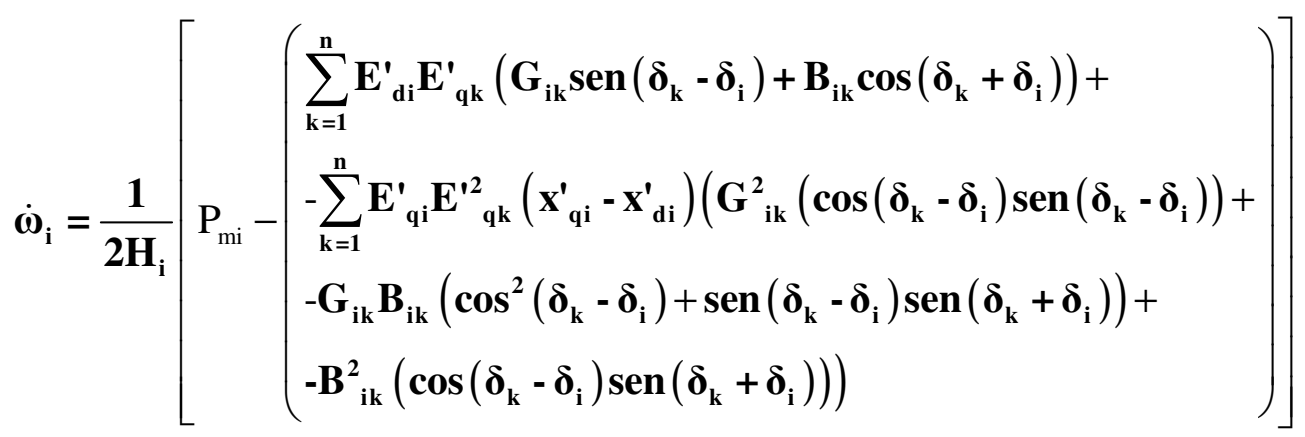

$$
\begin{aligned}
& \dot{\mathbf{E}}_{\mathrm{qi}}^{\prime}=\frac{1}{\tau_{\mathrm{doi}}^{\prime}}\left[\mathbf{E}_{\mathrm{FDi}}-\mathbf{E}_{\mathrm{qi}}^{\prime}+\left(\mathrm{x}_{\mathrm{di}}-\mathbf{x}_{\mathrm{di}}^{\prime}\right)\left(\sum_{\mathrm{k}=1}^{\mathrm{n}} \mathbf{E}_{\mathrm{qk}}^{\prime}\left(\mathrm{G}_{\mathrm{ik}} \operatorname{sen}\left(\delta_{\mathrm{k}}-\delta_{\mathrm{i}}\right)+\mathbf{B}_{\mathrm{ik}} \cos \left(\delta_{\mathrm{k}}-\delta_{\mathrm{i}}\right)\right)\right)\right]
\end{aligned}
$$




$$
\begin{aligned}
& \dot{E}_{\mathrm{FD}}=\frac{1}{T_{e i}}\left[K_{e i}\left(V_{\text {refi }}-V_{f i}+V_{S i}\right)-E_{F D i}\right]
\end{aligned}
$$

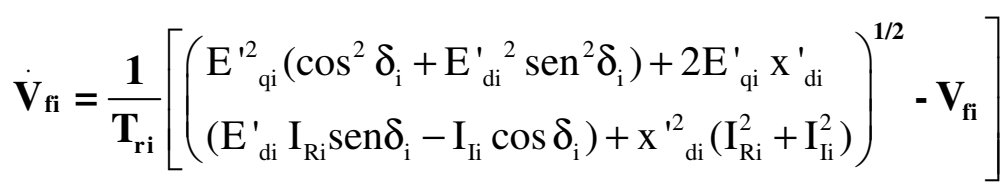

onde $\mathbf{I}_{\mathbf{R i}}$ e $\mathbf{I}_{\mathbf{I i}}$ são dadas pela equação (2.29) e (2.30), respectivamente.

As equações (2.31)-(2.35) descrevem um sistema de potência multimáquinas, as quais serão utilizadas no desenvolvimento deste trabalho. E será utilizado também na formulação do problema de oscilações eletromecânicas intra-planta o conceito de barramento infinito. Um barramento infinito é definido como uma barra do sistema capaz de manter sua tensão terminal constante, independente das condições de operação do sistema, e suprir qualquer quantidade de potência necessária para o restabelecimento do balanço de potência do sistema. Obviamente, este é um elemento idealizado, mas esta aproximação pode ser bastante precisa no caso de geradores conectados radialmente a sistemas com uma inércia equivalente muito superior à dos mesmos. Neste caso, podemos representar o sistema aos quais estes geradores se conectam radialmente através de um equivalente Thèvenin visto da barra terminal comum destes geradores (esta representação será usada neste trabalho para fins de projeto e simulação). Outra maneira bastante usual de se representar um barramento infinito é utilizar um gerador equivalente conectado à barra na qual se deseja obter o comportamento idealizado, e fazer com que a inércia deste gerador tenda ao infinito.

Uma das grandes dificuldades encontrada é a complexidade do equacionamento não linear do sistema para realizar o controle do mesmo. Logo é natural que algumas simplificações sejam feitas na fase de projeto de controladores. A simplificação mais comumente utilizada é a linearização do conjunto de equações que descreve o sistema, em torno de um ponto de operação de interesse, que será abordada no Capítulo 3. 


\section{Capítulo 3}

\section{OSCILAÇÕES ELETROMECÂNICAS INTRA-PLANTA}

Como dito nos capítulos anteriores, as pequenas perturbações podem excitar os modos de oscilações eletromecânicas, os quais reduzem a margem de estabilidade do sistema e podem, eventualmente, causar danos aos componentes do mesmo. Este capítulo tem como objetivo a conceituação e análise dos modos de oscilação eletromecânica intra-planta, os quais constituem o foco principal desta dissertação de mestrado. Nas seções seguintes, serão apresentados alguns conceitos importantes para o entendimento do problema de oscilações eletromecânicas em sistemas de potência e, posteriormente, uma descrição detalhada da natureza dos modos intra-planta.

\section{1 - Resposta de um Sistema a Pequenas Perturbações}

No estudo dos modos de oscilação eletromecânica do sistema, uma das preocupações é calcular as taxas de amortecimento destes modos. Logo pode-se determinar quais são os modos que apresentam um amortecimento abaixo do considerado "seguro" para o sistema e também quantos deles são considerados instáveis, para a partir deste ponto adotar medidas de controle para aumentar esse amortecimento e estabilizar os modos instáveis.

As técnicas comumente aplicadas neste tipo de estudo utilizam a linearização das equações que compõem a modelagem do sistema e através do cálculo dos autovalores e 
autovetores do respectivo modo linearizado. Com isso, consegue-se obter informações qualitativas a respeito do comportamento do sistema nas vizinhanças do ponto de operação em que o sistema foi linearizado. Essa abordagem leva em consideração que as perturbações ocorridas não afastam o sistema significativamente do seu ponto de operação original (desde que este ponto de operação seja estável). Dessa forma, a resposta será dominada pelos termos lineares. Esta abordagem linearizada geralmente leva a procedimentos de análise e projeto mais simples do que aqueles baseados em técnicas não lineares.

Para um melhor entendimento desta técnica de linearização, a mesma será apresentada adiante, para uma equação diferencial em sua forma geral. Considere que

$$
\dot{\mathbf{x}}=\mathbf{f}(\mathbf{x})
$$

representa o conjunto (2.31)-(2.35) de forma sintetizada. Definindo $\Delta \mathbf{x}=\mathbf{x}-\mathbf{x}_{\mathbf{e}}$, onde $\mathbf{x}_{\mathbf{e}}$ é um ponto de equilíbrio do sistema.

Para pequenos valores de $\Delta \mathbf{x}$ e expandindo f(x) em série de Taylor em torno do ponto de equilíbrio $\mathbf{x}_{\mathbf{e}}$, tem se:

$$
f(x) \approx f\left(x_{e}\right)+\left.\frac{\partial f}{\partial x}\right|_{x_{e}} \cdot\left(x-x_{e}\right)+\ldots . .
$$

é uma aproximação bastante precisa. Como $\mathbf{x}_{\mathbf{e}}$ foi admitido como sendo um ponto de equilíbrio, tem-se que $\mathrm{f}\left(\mathrm{x}_{\mathrm{e}}\right)=0 \rightarrow \dot{\mathrm{x}}(0)=0$, então

$$
\left.\mathrm{f}(\mathrm{x}) \approx \frac{\partial \mathrm{f}}{\partial \mathrm{x}}\right|_{\mathrm{x}_{\mathrm{e}}} \cdot \Delta \mathrm{x}+\ldots
$$

e admitindo-se que nenhuma trajetória de (3.1) não se afasta significativamente do ponto de equilíbrio $\mathbf{x}_{\mathrm{e}}$, tem-se que os termos de ordem superior a 1 podem ser desprezados, reduzindose a equação (3.3) a $\mathbf{f}(\mathbf{x}) \approx \mathbf{A} \boldsymbol{\Delta} \mathbf{x}$ onde $\mathbf{A}$ é a matriz Jacobiana de $\mathbf{f}(\mathbf{x})$ calculada em $\mathbf{x}_{\mathbf{e}}$. 
Mas

$$
\Delta \dot{\mathbf{x}}=\dot{\mathrm{x}}-\dot{\mathbf{x}_{\mathrm{e}}}=\dot{\mathrm{x}} \rightarrow \mathbf{f}(\mathbf{x})=\dot{\mathrm{x}}=\dot{\Delta \mathbf{x}}=\mathbf{A} \cdot \Delta \mathbf{x}
$$

Portanto, $\Delta \dot{\mathbf{x}}=\mathbf{A} . \Delta \mathbf{x}$ é uma representação aproximada de (3.1) em uma vizinhança de $\mathbf{x}_{\mathbf{e}}$.

Da teoria de sistemas lineares, sabe-se que a resposta do sistema (3.5) pode ser caracterizada através dos autovalores e autovetores da matriz A. Isso pode ser demonstrado supondo que a solução de (3.5) tem a seguinte forma:

$$
\Delta \mathbf{x}(\mathbf{t})=\sum_{\mathrm{i}=1}^{\mathrm{n}} \mathbf{c}_{\mathrm{i}} \mathbf{v}_{\mathrm{i}} \mathbf{e}^{\lambda_{\mathrm{i}} \mathrm{t}}
$$

onde $\mathbf{c}_{\mathbf{i}} \in \mathrm{C}, \boldsymbol{\lambda}_{\mathbf{i}} \in \mathrm{C}$ e $\mathbf{v}_{\mathbf{i}} \in \mathrm{C}^{\mathrm{n}}$ são constantes, $\mathrm{i}=1, \ldots, \mathrm{n}$ e té um parâmetro representando o tempo, $\boldsymbol{\lambda}_{\mathbf{i}} \mathrm{e} \mathbf{v}_{\mathbf{i}}$ são os autovalores e autovetores da matriz Jacobiana $\mathbf{A}$, respectivamente. Logo,

$$
\Delta \dot{x}(\mathbf{t})=\sum_{i=1}^{n} \lambda_{i} \mathbf{c}_{i} \mathbf{v}_{i} \mathbf{e}^{\lambda_{i} t}
$$

Sabendo-se que a matriz A é denotada por ( $\partial \mathrm{f} / \partial \mathrm{x})_{\mathrm{x}_{\mathrm{e}}}$ e ajustando as equações (3.5), (3.6) e (3.7), temos

$$
\sum_{i=1}^{n} \lambda_{i} \mathbf{c}_{i} \mathbf{v}_{i} e^{\lambda_{i} t}=A \sum_{i=1}^{n} c_{i} \mathbf{v}_{i} e^{\lambda_{i} t}
$$

Como $c_{i}$ e $\lambda_{i}$ são constantes, o problema se resume em

$$
\sum_{i=1}^{n} \lambda_{i} \mathbf{v}_{i}=\sum_{i=1}^{n} A v_{i}
$$


Analisando-se cada parcela dos somatórios em ambos os lados da equação (3.9), esta pode ser resolvida através do cálculo dos autovalores e autovetores à direita da matriz $\mathbf{A}$, ou seja, encontra-se $\lambda_{\mathbf{i}}$ e $v_{i}$ que satisfaçam a seguinte equação:

$$
\lambda_{\mathbf{i}} \mathbf{v}_{\mathbf{i}}=\mathrm{Av}_{\mathrm{i}} \quad, i=1, \ldots, n
$$

supondo-se que A tenha $n$ autovalores distintos. Com o cálculo dos autovalores e autovetores a direita da matriz A é possível obter uma base para as soluções de (3.5). Na maioria da literatura o termo "autovetores da direita" é referido simplesmente como "autovetores". Este texto também adotará essa nomenclatura.

A equação (3.6) mostra a relação dos autovalores com a resposta do sistema. Se os autovalores $\lambda_{\mathbf{i}}$ estiverem posicionados no semiplano esquerdo aberto do plano complexo (ou seja, tiverem parte real negativa), a resposta do sistema será atenuada pelos termos $\mathbf{e}^{\lambda_{\mathrm{i}} \mathrm{t}}$, o que caracteriza um sistema estável. Se a parte real de algum dos autovalores $\lambda_{i}$ for positiva, o respectivo termo $\mathbf{e}^{\lambda_{i} t}$ introduzirá um crescimento exponencial na resposta, caracterizando um sistema instável.

Cada autovalor $\lambda_{\mathrm{i}}=\boldsymbol{\sigma}_{\mathrm{i}}+\mathbf{j} \boldsymbol{\omega}_{\mathrm{i}}$ é denominado um "modo de resposta" ou um "modo de oscilação" (caso tenha parte imaginária diferente de zero) do sistema (3.5). A parte real do autovalor, está relacionada com o crescimento ou decaimento exponencial da resposta. Já a parte imaginária fornece a freqüência de oscilação do respectivo modo. Essa freqüência é dada em $\mathrm{Hz}$ por

$$
\mathbf{f}_{\mathrm{i}}=\frac{\omega_{\mathrm{i}}}{2 \pi}
$$

O fator de amortecimento $\zeta_{\mathbf{i}}$ de um autovalor $\lambda_{\mathbf{i}}$ é dado por 


$$
\zeta_{i}=\frac{-\sigma_{i}}{\sqrt{\sigma_{i}^{2}+\omega_{i}^{2}}}
$$

o que estabelece uma relação entre a freqüência de oscilação de um modo e seu respectivo decaimento. Pode ser notado em (3.12) que altos valores de $\zeta_{\mathrm{i}}$ indicam que a parte imaginária do respectivo autovalor é pequena em relação à sua parte real. Dessa forma, oscilações bem amortecidas em freqüências mais altas tendem a desaparecer mais rapidamente da resposta.

O significado dos autovetores na resposta do sistema, que pode ser observado na equação (3.6) é que, um autovetor $\mathbf{v}_{\mathbf{i}}$ associado a um modo de resposta $\lambda_{\mathbf{i}}$ fornece a distribuição deste modo pelas variáveis de estado, ou seja, determina a intensidade com que esse modo estará presente na resposta individual de cada variável de estado. Com isso, é possível utilizar os elementos dos autovetores $\mathbf{v}_{\mathbf{i}}$ para descobrir em qual (ou quais) variável (variáveis) de estado o modo de resposta $\lambda_{\mathbf{i}}$ é mais intenso. Neste tipo de análise, os elementos dos autovetores são denominados mode shapes. É bastante comum encontrarem representações em espaços de estados cujas variáveis (que pode ser relacionadas à grandeza físicas ou não) são medidas em diferentes unidades. Portanto, ao utilizar os autovetores para avaliar a intensidade relativa de um modo de resposta sobre as variáveis de estado do sistema, deve-se ter o cuidado de comparar sempre grandezas medidas em unidades iguais.

\section{2 - Fatores de Participação}

Uma alternativa ao uso dos mode shapes para determinação da relação entre os modos da resposta e as variáveis de estado é obtida com o emprego dos fatores de participação. Em sistemas de potência de grande porte, o fator de participação é importante para quantificar a 
participação de cada gerador em cada modo de resposta do sistema. Para entender estes fatores, precisamos entender o conceito de autovetores à esquerda. Os autovetores à esquerda da matriz A são definidos como o conjunto de vetores $\mathrm{w}_{\mathbf{i}} \in \mathrm{R}^{\mathrm{n}}$ que a seguinte equação seja satisfeita,

$$
\lambda_{\mathrm{i}} \mathrm{w}_{\mathrm{i}}=\mathrm{w}_{\mathrm{i}} \mathbf{A}, i=1, \ldots, n
$$

admitindo novamente que A tenha $n$ autovalores distintos. Das equações (3.10) e (3.13), podemos notar que se multiplicarmos tanto $\mathrm{w}_{\mathbf{i}}$ quanto $\mathrm{v}_{\mathbf{i}}$ por um escalar, a igualdade não é afetada, ou seja, podem-se multiplicar os autovetores à esquerda e à direita de uma matriz por escalares quaisquer, que os vetores resultantes continuarão sendo autovetores. Tendo isto em vista, é comum que os autovetores $\mathrm{w}_{\mathbf{i}}$ e $\mathrm{v}_{\mathbf{i}}$ sejam normalizados, associados ao mesmo modo de resposta, em que $\mathrm{w}_{\mathrm{i}} \mathrm{v}_{\mathrm{i}}=1$. Outra propriedade destes vetores é a ortogonalidade entre um autovetor à direita, associado a um determinado autovalor de uma matriz A, e qualquer autovetor à esquerda que seja associado a outro autovalor da mesma matriz. Em resumo, $\mathrm{w}_{\mathrm{j}} \mathrm{v}_{\mathrm{i}}=0$ se $\mathrm{i} \neq \mathrm{j}$.

Através dessas propriedades, pode-se mostrar que os autovetores à esquerda determinam as magnitudes da excitação dos modos de resposta devidas às condições iniciais (ou seja, as constantes $\mathrm{c}_{\mathrm{i}}$ em (3.6) e (3.7)). Para isso tem-se

$$
\begin{gathered}
\lambda_{\mathrm{i}} \mathrm{w}_{\mathrm{i}}=\mathrm{w}_{\mathrm{i}} \mathbf{A} \rightarrow \\
\rightarrow \lambda_{\mathrm{i}} \mathrm{w}_{\mathrm{i}} \Delta \mathrm{x}(0)=\mathrm{w}_{\mathrm{i}} \mathbf{A} \Delta \mathrm{x}(0) \rightarrow \\
\rightarrow \lambda_{\mathrm{i}} \mathrm{w}_{\mathrm{i}} \Delta \mathrm{x}(0)=\mathrm{w}_{\mathrm{i}} \Delta \dot{\mathrm{x}}(0) \rightarrow \\
\rightarrow \lambda_{\mathrm{i}} \mathrm{w}_{\mathrm{i}} \Delta \mathrm{x}(0)=\mathrm{w}_{\mathrm{i}} \sum_{\mathrm{i}=1}^{\mathrm{n}} \lambda_{\mathrm{i}} \mathrm{c}_{\mathrm{i}} \mathrm{v}_{\mathrm{i}}
\end{gathered}
$$


Sabendo-se das propriedades anteriores e aplicando-as na relação (3.17), tem-se

$$
\mathrm{w}_{\mathrm{i}} \Delta \mathrm{x}(0)=\mathrm{c}_{\mathrm{i}}
$$

o que mostra a relação existente dos autovetores à esquerda, entre as condições iniciais e a excitação dos modos da resposta.

Depois de definidos os autovetores à esquerda, voltaremos à análise dos fatores de participação. Torna-se necessário avaliar quais são as variáveis de estado mais influentes em um modo de resposta. $\mathrm{O}$ fator de participação é uma ferramenta muito importante no projeto de controladores, pois é usado para identificar quais são os geradores mais adequados para se fazer o controle do referido modo de resposta. Para isto, são utilizados os fatores de participação definidos em (Pérez-Arriaga et al., 1982),

$$
p_{k i}=\omega_{i k} v_{k i}
$$

onde $\omega_{i k}$ é o k-ésimo elemento do i-ésimo autovetor à esquerda $\mathbf{w}_{\mathbf{i}}$ e $v_{k i} \mathbf{o}$ k-ésimo elemento do i-ésimo autovetor à direita $v_{\mathbf{i}}$. E quando os autovetores são complexos conjugados pode ser calculado por: $p_{k i}=\frac{\left|v_{i k}\right|\left|\omega_{k i}\right|}{\sum_{\mathrm{k}=1}^{\mathrm{k}=\mathrm{n}}\left|v_{i k}\right|\left|\omega_{k i}\right|}$ obtido de (Sauer e Pai, 1998), onde a soma de todos os fatores participação é igual a um.

Com o cálculo dos autovalores e autovetores (à direita e à esquerda) do modelo linearizado, é possível analisar diversas características da resposta do sistema a uma pequena perturbação. Porém, o cálculo desses autovalores e autovetores é uma tarefa bastante complexa, pelo fato de que são inúmeras variáveis presente no sistema de potência, o que às vezes se torna inviável. A alternativa, então, é calcular apenas os modos da resposta de interesse, ou seja, aqueles em apresentarem um baixo amortecimento ou instáveis. 
Os geradores com alto fator de participação são, na maioria das vezes, candidatos para receber os controladores de amortecimento do tipo PSS (do inglês, Power System Stabilizer). A variável de estado com maior fator de participação normalizado pode ser a melhor escolha para a realimentação do sinal, mas, no entanto, esta pode não ser uma variável física mensurável. As velocidades angulares dos rotores têm sido extensamente usadas como sinal de realimentação em projeto de controladores de amortecimento do tipo PSS. No entanto, outras variáveis também podem ser utilizadas, tais como a freqüência na barra terminal ou a integral da potência acelerante (Rogers, 2000).

\section{3 - Tipos de Oscilações}

As pequenas variações nas cargas do sistema, que ocorrem continuamente ao longo do dia, podem excitar os modos de oscilação que são intrínsecos aos sistemas de potência. Tais modos de oscilação, chamados usualmente de oscilações eletromecânicas de baixa frequiência, podem ser observados no sistema como oscilações nos ângulos e velocidades dos rotores das máquinas e oscilações nos fluxos de potência ativa das linhas, e estas quando mal amortecidas podem trazer vários danos ao sistema elétrico.

Em geral, as oscilações eletromecânicas podem ser de modo local, modos inter-área, modos intra-planta, modos torcionais e modos de controle ou das excitatrizes.

Modos inter-área: Este fenômeno é observado em uma grande parte da rede. Ele envolve um grupo de geradores oscilando coerentemente contra outro grupo em uma área diferente, ocorrendo tipicamente na faixa de 0,1 a $0,7 \mathrm{~Hz}$ (Klein et al., 1991).

O modo inter-área envolve várias partes do sistema com comportamento dinâmico fortemente não linear. A característica do amortecimento do modo inter-área está ligada à 
capacidade de transmissão da linha de interligação participante do modo, à natureza das cargas do sistema e do fluxo de potência na conexão e na interação das cargas com a dinâmica dos geradores e seus controles associados (Pal e Chaudhuri, 2005).

Os modos torcionais, de controle ou das excitatrizes são causados pela interação dos controladores, quando estes são projetados de maneira inadequada, com a dinâmica do eixo do conjunto turbo-gerador e com o sistema de excitação (Kundur, 1994).

Cada uma dessas oscilações mencionadas pode ocorrer em condições particulares de operação do SEP. No entanto, é importante que os controladores projetados para amortecer tais oscilações o façam de maneira satisfatória, qualquer que seja o ponto de operação do sistema. Os modos locais e intra-planta serão discutidos na próxima seção. É importante ressaltar que apenas os modos intra-planta são abordados nessa dissertação de mestrado.

\section{4 - Exemplo de Oscilação Eletromecânica Intra-Planta}

Oscilações eletromecânicas de baixa freqüência são fenômenos comuns em sistemas elétricos de potência e, quando mal amortecidas, podem prejudicar a operação do mesmo. Por esta razão, usualmente são adicionados controladores conhecidos como Power System Stabilizers (PSSs) para aumentar o amortecimento destas oscilações.

O sistema da figura 3.1, que será o sistema estudado neste trabalho, ilustra dois tipos de oscilações que podem estar presentes nesta topologia do sistema (modo intra-planta e modo local). A figura 3.1 apresenta 4 (quatro) geradores idênticos conectados radialmente ao sistema (representados pelos geradores: G1,G2,G3,G4 e não participando, portanto, em qualquer modo inter-área), e que esta rede é grande o suficiente para ser representada por um barramento infinito. $\mathrm{O}$ barramento infinito é representado pela barra número 5. 


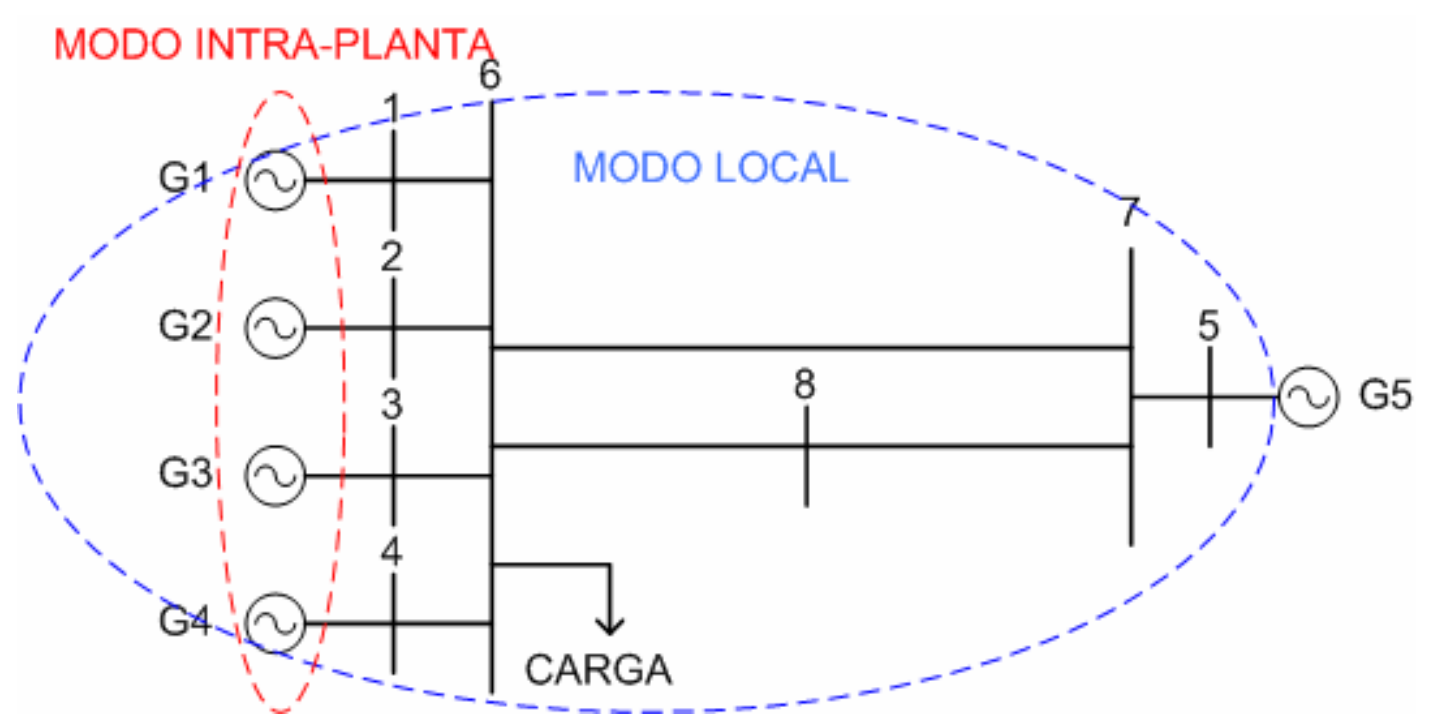

Figura 3.1- Modelo do Sistema Estudado

O modo local destacado na figura em cor azul, nos mostra qual a relação existente entre os geradores (G1, G2, G3 e G4) com o restante do sistema (representado pelo barramento infinito), ou seja, este modo de oscilação ocorre quando o grupo de geradores G1G4 oscila contra o restante do sistema, geralmente na faixa de freqüência de 0,7 a 2,0 Hz. Neste modo, o impacto das oscilações está localizado no gerador e na linha que conecta este à rede (Pal e Chaudhuri, 2005).

O modo intra-planta destacado em vermelho na figura acima, nos mostra que esse tipo de oscilação ocorre entre os geradores da mesma usina (representados por G1, G2, G3 e G4) uns oscilando contra os outros, e geralmente ocorrem na faixa de frequiência entre 2 e 3 Hz (Pal; Chaudhuri, 2005). Este tipo de modo é característico de usinas de geração de energia elétrica com várias máquinas operando em paralelo, e tais modos são geralmente bem amortecidos.

É prática usual representar múltiplas máquinas dentro de uma mesma usina por um modelo agregado com apenas um gerador equivalente, baseado no fato de que essas máquinas são normalmente muito similares. O modelo agregado contém as informações do modo local, 
caracterizado pela oscilação coerente de todas as máquinas da usina contra o restante do sistema. Entretanto, informações sobre as oscilações entre as máquinas dentro da planta são perdidas, devido à agregação que produz do modelo equivalente. Embora esta aproximação resulte em uma simplificação bastante desejada, ela pode em certos casos conduzir a resultados enganosos. Em (Rogers, 2000), por exemplo, foi mostrado que a utilização do modelo de uma máquina equivalente para representar unidades com várias máquinas no projeto de controladores de amortecimento pode levar, sob certas condições, à desestabilização dos modos intra-planta. Diante dessa consideração, pode-se concluir que é preciso ter cuidado na determinação do conjunto de parâmetros dos controladores de amortecimento instalados em diferentes máquinas que operam em paralelo dentro de uma mesma usina.

De fato, encontrar um conjunto de parâmetros de PSSs que seja efetivo no amortecimento dos modos intra-planta não é uma tarefa trivial, tendo em vista que o controlador projetado deve ainda ser robusto com relação às incertezas no ponto de operação do sistema e sua sintonia exige um exaustivo processo de tentativa-e-erro. Tal processo é atualmente realizado de forma empírica e manual pelo engenheiro projetista na indústria. No entanto, o objetivo deste trabalho é mostrar que este processo pode ser formulado como um procedimento de busca no espaço dos parâmetros dos PSSs, e que esta busca pode ser realizada de forma automática pelo computador, seguindo um algoritmo de otimização. O capítulo seguinte mostra como isso pode ser feito e aplica o algoritmo proposto para encontrar um conjunto de parâmetros de PSSs que seja adequado para o amortecimento de modos tanto locais quanto intra-planta, os quais constituem o foco principal deste trabalho. 


\section{Capítulo 4}

\section{UM PROCEDIMENTO DE SINTONIA AUTOMÁTICA DE PSS PARA AMORTECIMENTO DE MODOS INTRA PLANTA}

Conforme mencionado ao final do capítulo anterior, este capítulo apresentará a proposta de solução para melhorar o amortecimento dos modos de oscilação eletromecânicas, dos tipos intra-planta e local, através de um desenvolvimento de um procedimento automático, que pode ser realizado pelo computador, no qual a intervenção do engenheiro projetista é requerida somente na fase inicial, para fornecer os dados iniciais de projeto. Antes, porém, uma definição do tipo de controlador a ser projetado é apresentada de forma breve.

\section{1 - Estabilizador Clássico}

Atualmente, o uso das técnicas de controle clássico é predominante em projetos de controladores no sistema de potência. Essas técnicas permitem a análise de estabilidade e projeto de controladores para os modelos linearizados apresentados nas seções anteriores. Em geral, os controladores projetados por técnicas clássicas possuem uma estrutura de controle composta por redes de avanço-atraso de fase, ganho de realimentação, integradores, e outras funções que, podem ser implementadas na prática através de dispositivos microprocessados. 
A primeira metodologia de projeto de controladores de amortecimento em sistema de potência foi proposta em (DeMello e Concordia, 1969) (dando origem, portanto, aos primeiros controladores do tipo PSS) sendo baseada na compensação de fase no domínio da freqüência. Neste trabalho, os autores mostraram que o torque elétrico ocasionado pelo desbalanço de potência de uma máquina síncrona poderia ser decomposto em duas componentes: torque de amortecimento, em fase com o desvio da velocidade angular da máquina e o torque sincronizante em fase com o desvio angular do rotor. A estabilidade de um sistema de potência depende da existência de ambas componentes de torque para cada máquina síncrona do sistema (Kundur et al., 2004). Os problemas de estabilidade a pequenas perturbações estão relacionados à insuficiência de torque de amortecimento no sistema originada, por exemplo, pela ação dos reguladores automáticos de tensão (DeMello e Concordia, 1969).

O controlador proposto em (DeMello e Concordia, 1969) tinha por objetivo produzir uma componente de torque elétrico em fase com o desvio da velocidade angular, de modo que seja fornecido torque de amortecimento ao sistema. O sinal estabilizante gerado por esse controlador é adicionado a uma entrada do regulador automático de tensão do gerador. A estrutura deste controlador é mostrada na figura 4.1 .

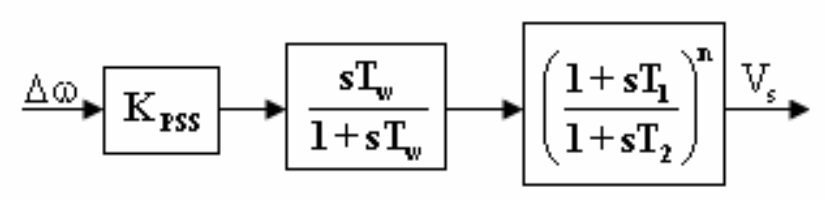

Figura 4.1 - Estrutura de controle do tipo rede de avanço-atraso

Alguns anos depois, este tipo de estabilizador passou a ser amplamente utilizado pelas empresas do setor de geração e transmissão de energia elétrica. A estrutura deste controlador é composta por um ganho de realimentação, um bloco washout (cuja função é eliminar a ação 
de controle durante o regime permanente) e blocos de avanço-atraso de fase utilizados para compensar o atraso de fase que ocorre entre a aplicação da entrada $\mathbf{V}_{\mathbf{s}}$ e o efeito produzido pela mesma no balanço de potências da máquina.

Conforme mencionado no capítulo anterior, encontrar um conjunto de parâmetros que define um PSS eficaz não é uma tarefa trivial, e requer um procedimento de tentativa-e-erro bastante exaustivo e tedioso (processo este que é usualmente chamado de sintonia).

Com o intuito de evitar que o engenheiro projetista tenha que realizá-lo manualmente, este trabalho propõe o desenvolvimento de um procedimento de projeto capaz de encontrar automaticamente uma sintonia satisfatória do PSS para amortecimento de modos intra-planta, utilizando uma ferramenta computacional baseada nas Desigualdades Matriciais Lineares (ou LMIs, do inglês Linear Matrix Inequalities). Esta proposta está descrita com mais detalhes na seção seguinte.

\section{2 - Proposta do Trabalho: Um Procedimento de Sintonia Automática de PSSs para Amortecimento de Modos Intra-Planta}

Para explicar como o algoritmo proposto neste trabalho pode tornar o trabalho do projetista mais fácil, inicialmente será introduzido um procedimento de modelagem típico que é comumente usado em estudos de estabilidade a pequenas perturbações e em projetos de PSSs, o qual servirá como base para a solução que será proposta nas próximas seções. A abordagem padrão da indústria na modelagem do sistema de potência para projetos de PSS é baseada em um conjunto de equações algébrico-diferenciais não-lineares na forma:

$$
\begin{array}{r}
\dot{\overline{\mathbf{x}}}=\mathbf{f}(\overline{\mathbf{x}}, \overline{\mathbf{u}}, \mathbf{z}, \lambda), \\
\mathbf{0}=\mathbf{h}(\overline{\mathbf{x}}, \overline{\mathbf{u}}, \mathbf{z}, \lambda),
\end{array}
$$




$$
\overline{\mathbf{y}}=\mathbf{g}(\overline{\mathbf{x}}, \overline{\mathbf{u}}, \mathbf{z}, \lambda)
$$

sendo $\overline{\mathbf{x}} \in R^{n}$ o estado do sistema, $\overline{\mathbf{u}} \in R^{p}$ a entrada de controle, $\overline{\mathbf{y}} \in R^{q}$ a saída medida (que pode ser utilizada para realimentação), $\mathbf{z} \in R^{m}$ o vetor de variáveis algébricas representando a rede de transmissão que acopla os diferentes geradores e $\lambda \in R^{l}$ um vetor de parâmetros, representando os níveis de carga e outras grandezas que definem a condição operativa do sistema. As restrições algébricas (4.2) podem ser eliminadas de (4.1)-(4.3) usando uma linearização deste grupo de equações e fazendo uma substituição das restrições algébricas linearizadas resultantes de (4.2) nas equações linearizadas resultantes de (4.1) e (4.3). O conjunto de equações resultantes por este processo tem a forma:

$$
\begin{gathered}
\dot{\mathbf{x}}_{j}=\mathbf{A}_{j} \mathbf{x}_{j}+\mathbf{B}_{j} \mathbf{u}_{j}, \\
\mathbf{y}_{j}=\mathbf{C}_{j} \mathbf{x}_{j}+\mathbf{D}_{j} \mathbf{u}_{j},
\end{gathered}
$$

Em (4.4)-(4.5), $\mathbf{x}_{j} \in R^{n}$ representa desvios em relação a um valor de equilíbrio $\overline{\mathbf{x}}_{j}$ de (4.1)-(4.3) correspondente a um valor particular de $\lambda$. De maneira análoga, $\mathbf{u}_{j} \in R^{p}$ e $\mathbf{y}_{j} \in R^{q}$ representam desvios de $\overline{\mathbf{u}}_{j}$ e $\overline{\mathbf{y}}_{j}$, respectivamente. É usual selecionar um número de condições operativas, definindo diferentes equilíbrios para $\overline{\mathbf{x}}_{j}$, de tal forma que estas condições representem as variações previstas na operação do sistema, e usar estas condições de operação para obter $L$ modelos linearizados na forma (4.4)-(4.5).

Para o modelo tratado neste trabalho, foram escolhidos PSSs baseados na medida de velocidade do rotor. Sendo assim, os sinais de saída da planta serão compostos pelas variações da velocidade do rotor de cada uma das 4 máquinas da figura 3.1. Dado que os sinais de entrada são compostos por sinais estabilizantes que são superpostos à tensão de referência dos Reguladores Automáticos de Tensão (ou AVRs, do inglês Automatic Voltage 
Regulators), não existe acoplamento direto entre o vetor de entrada de controle $\mathbf{u}_{j}$ e o vetor de saída $\mathbf{y}_{j}$, de forma que o termo $\mathbf{D}_{j} \mathbf{u}_{j}$ em (4.5) pode ser desconsiderado.

A estrutura tradicional da compensação de fase usado nos PSSs é dado pelo diagrama de bloco da figura 4.1, onde i são os geradores do sistema, é baseado em uma estrutura de realimentação de saída. Considerando o PSS com dois blocos de avanço e atraso de fase (que corresponde a $n=2$ na figura 4.1), e pode ser escrita na seguinte forma:

$$
\begin{aligned}
\dot{\mathbf{x}}_{c i} & =\left[\begin{array}{ccc}
-\alpha_{i} & 0 & 0 \\
\gamma_{i}-\alpha_{i} \beta_{i} & -\gamma_{i} & 0 \\
\alpha_{i} \beta_{i}^{2}-\beta_{i} \gamma_{i} & \gamma_{i}-\beta_{i} \gamma_{i} & -\gamma_{i}
\end{array}\right] \mathbf{x}_{c i}+\left[\begin{array}{c}
1 \\
\beta_{i} \\
\beta_{i}^{2}
\end{array}\right] \dot{y}_{i} \\
\mathbf{u}_{i} & =\left[\begin{array}{lll}
0 & 0 & K_{p s s i}
\end{array}\right] \mathbf{x}_{c i}
\end{aligned}
$$

onde

$$
\alpha_{i}=\frac{1}{T_{w i}}, \beta_{i}=\frac{T_{1 i}}{T_{2 i}}, \gamma_{i}=\frac{1}{T_{2 i}}
$$

Em (4.6)-(4.7), $\mathbf{x}_{c i}(t)$ é um vetor com variáveis de estados do $i$-ésimo controlador. A equação (4.6)-(4.7) pode ser escrita na seguinte forma compacta:

$$
\begin{aligned}
& \dot{\mathbf{x}}_{c i}=\mathbf{A}_{c i} \mathbf{x}_{c i}+\mathbf{B}_{c i} \dot{y}_{i}, \\
& \mathbf{u}_{i}=\mathbf{C}_{c i} \mathbf{x}_{c i},
\end{aligned}
$$

Embora a derivada da saída medida $\dot{y}_{j i}$ apareça como uma entrada para a formulação de espaço estado do controlador, não há necessidade da medição direta de tal derivada. Esta parcela aparece na formulação devido à presença do termo do washout $s T_{w i} / 1+s T_{w i}$ na função de transferência do PSS, o qual sintetiza uma aproximação para a derivada da saída medida. Todavia, a implementação atual dos controladores projetados será baseada apenas na saída medida, usando a relação. 


$$
\dot{y}_{j i}=\mathbf{C}_{j i} \mathbf{A}_{j} \mathbf{x}_{j}
$$

onde $\mathbf{C}_{j i}$ é a linha da matriz $\mathbf{C}_{j}$ que seleciona a $i$-ésima saída medida.

A partir do conjunto de equações (4.9)-(4.11) para cada gerador controlado, é possível agrupar todos estes $n c$ conjuntos de equações (nc sendo o numero de geradores controlados no sistema) em apenas um, dado por

$$
\begin{gathered}
\dot{\mathbf{x}}_{c}=\mathbf{A}_{c} \mathbf{x}_{c}+\mathbf{B}_{c} \mathbf{C}_{j} \mathbf{A}_{j} \mathbf{x}_{j}=\left[\begin{array}{ccc}
\mathbf{A}_{c 1} & \cdots & \mathbf{0} \\
\vdots & \ddots & \vdots \\
\mathbf{0} & \cdots & \mathbf{A}_{c n c}
\end{array}\right] \mathbf{x}_{c}+\left[\begin{array}{ccc}
\mathbf{B}_{c 1} & \cdots & \mathbf{0} \\
\vdots & \ddots & \vdots \\
\mathbf{0} & \cdots & \mathbf{B}_{c n c}
\end{array}\right] \mathbf{C}_{j} \mathbf{A}_{j} \mathbf{x}_{j}, \\
\mathbf{u}_{j}=\mathbf{C}_{c} \mathbf{x}_{c}=\left[\begin{array}{ccc}
\mathbf{C}_{c 1} & \cdots & \mathbf{0} \\
\vdots & \ddots & \vdots \\
\mathbf{0} & \cdots & \mathbf{C}_{c n c}
\end{array}\right] \mathbf{x}_{c}
\end{gathered}
$$

Fechando a malha do sistema, composto pelos modelos (4.4)-(4.5) e do controlador (4.12)-(4.13), pode ser descrito, em espaço de estados, por:

$$
\left[\begin{array}{c}
\dot{\mathbf{x}}_{j} \\
\dot{\mathbf{x}}_{c}
\end{array}\right]=\tilde{\mathbf{A}}_{j} \tilde{\mathbf{x}}_{j}=\left[\begin{array}{cc}
\mathbf{A}_{j} & \mathbf{B}_{j} \mathbf{C}_{c} \\
\mathbf{B}_{c} \mathbf{C}_{j} \mathbf{A}_{j} & \mathbf{A}_{c}
\end{array}\right]\left[\begin{array}{l}
\mathbf{x}_{j} \\
\mathbf{x}_{c}
\end{array}\right]
$$

para $j=1, \ldots, L$.

Sendo que as matrizes $\mathbf{A}_{j}, \mathbf{B}_{j} \mathbf{e} \mathbf{C}_{j}$ são obtidas pela linearização do modelo da figura 3.1 para uma condição de operação específica, $\tilde{\mathbf{x}}_{\mathbf{j}}(\mathbf{t}) \in \mathbf{R}^{\mathbf{n}+\mathbf{m}}$ é um vetor que contém os estados do sistema e do controlador, e $\mathbf{A}_{\mathbf{c}}, \mathbf{B}_{\mathbf{c}}$ e $\mathbf{C}_{\mathbf{c}}$ são as variáveis matriciais a serem determinadas pela técnica de controle adotada, e o sistema a ser controlado pode ser representado pela figura 4.2. 


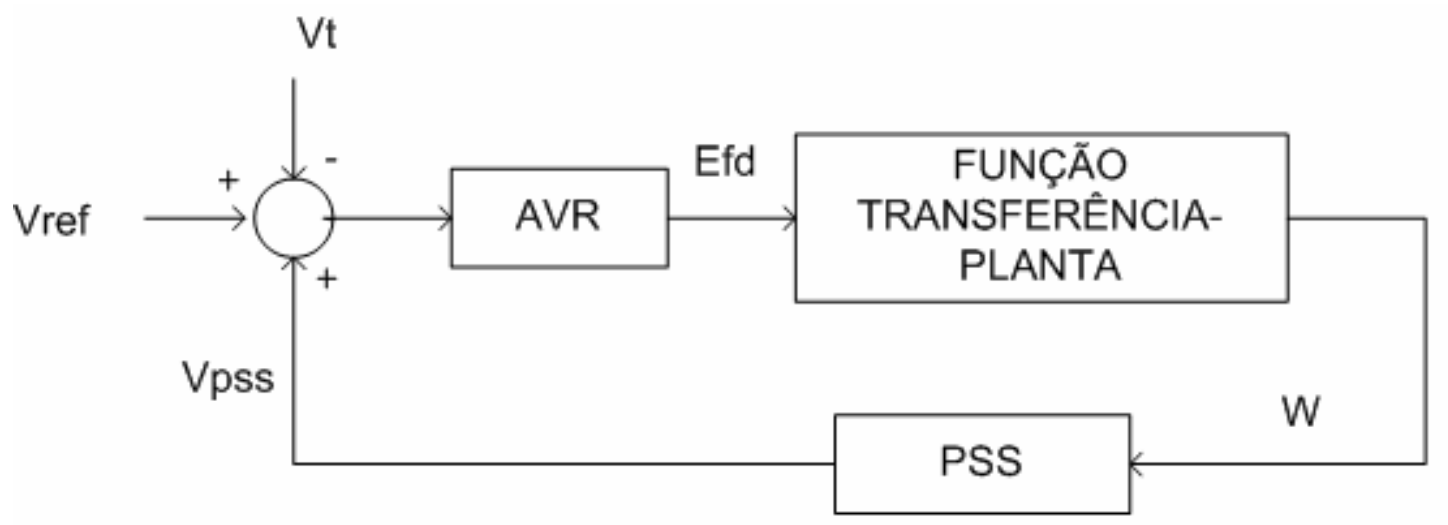

Figura 4.2- Diagrama do Sistema a ser Controlado

As seções seguintes apresentam uma definição para Desigualdades Matriciais Lineares (ou LMIs, do Inglês Linear Matrix Inequalities) e mostram como estas Desigualdades podem ser úteis na análise da dinâmica de sistemas lineares e no projeto de controladores para tais sistemas, dando ênfase em particular ao problema formulado nesta seção.

\subsection{1 - Desigualdades Matriciais Lineares}

De maneira geral, uma Desigualdade Matricial Linear ou LMI pode ser definida como segue (Boyd et al, 1994).

Definição 4.1 (LMI): Uma desigualdade matricial linear (ou LMI) tem a seguinte estrutura:

$$
\mathbf{F}(\mathbf{x})=\mathbf{F}_{\mathbf{0}}+\sum_{\mathrm{i}=1}^{\mathrm{m}} \mathbf{x}_{\mathrm{i}} \mathbf{F}_{\mathrm{i}}>\mathbf{0}
$$


onde $\mathbf{x}=\left(\mathbf{x}_{1}, \mathbf{x}_{2}, \ldots, \mathbf{x}_{\mathbf{m}}\right)$ é o vetor de variáveis de decisão e $\mathbf{F}_{\mathbf{i}} \in \mathbf{R}^{\mathrm{nxn}}$ para $\mathbf{i}=\mathbf{1}, \mathbf{2}, \ldots, \mathbf{m}$, são matrizes simétricas conhecidas.

A LMI $\mathbf{F}(\mathbf{x})>\mathbf{0}$ deve ser definida positiva para todo $\mathbf{x} \neq \mathbf{0}$, ou seja, $\mathbf{x}^{\mathrm{T}} \mathbf{F}(\mathbf{x}) \mathbf{x}>\mathbf{0}$ para todo $\mathbf{x} \neq \mathbf{0}$. Em algumas aplicações é possível encontrar a LMI (4.15) na forma semidefinida positiva, ou seja, $\mathbf{F}(\mathbf{x}) \geq \mathbf{0}$. Quando há necessidade de se trabalhar com múltiplas LMIs, a seguinte formulação pode ser utilizada, através de matrizes diagonais em bloco:

$$
F_{1}(x) \geq 0, \ldots, F_{k}(x) \geq 0 \Leftrightarrow \operatorname{diag}\left(F_{1}(x), \ldots, F_{k}(x)\right) \geq 0
$$

Normalmente, em problemas de controle, as LMIs não são formuladas na forma canônica (4.15), mas sim, na forma de variáveis matriciais. A seção seguinte apresenta como a estabilidade de um sistema linear invariante no tempo pode ser garantida a partir da resolução de uma desigualdade matricial bastante conhecida: a Desigualdade de Lyapunov.

\subsection{2 - Estabilidade de Sistemas Lineares}

A estabilidade da resposta de um sistema linear invariante no tempo pode ser expressa simplesmente pela condição necessária e suficiente de que todos os autovalores possuam parte real negativa, como foi mostrado na seção 3.1. Por outro lado, uma maneira alternativa de determinar a estabilidade de um sistema linear é através da teoria desenvolvida por Lyapunov para sistemas lineares. Considere um conjunto de sistemas lineares na forma:

$$
\dot{\tilde{\mathbf{x}}}_{\mathbf{j}}(\mathbf{t})=\tilde{\mathbf{A}}_{\mathbf{j}} \tilde{\mathbf{x}}_{\mathbf{j}}(\mathbf{t}), \mathrm{j}=1, \ldots, \mathrm{L}
$$

onde $\tilde{\mathbf{x}}_{\mathbf{j}} \in \mathbf{R}^{\mathbf{n}+\mathbf{m}}$ e $\tilde{\mathbf{A}}_{\mathbf{j}} \in \mathbf{R}^{(\mathbf{n}+\mathbf{m}) \times(\mathbf{n}+\mathbf{m})}$ é uma matriz precisamente conhecida. Note que a equação (4.17) pode representar um modelo de sistema de potência linearizado em torno de L pontos 
representativos de sua operação ao longo de um determinado período, conforme mostrado no capítulo 3.

De acordo com Lyapunov, a estabilidade desse sistema linear pode ser analisada a partir de uma função energia:

$$
\mathbf{V}\left(\tilde{\mathbf{x}}_{\mathbf{j}}\right)=\tilde{\mathbf{x}}_{\mathbf{j}}^{\mathbf{T}} \mathbf{P}_{\mathbf{j}} \tilde{\mathbf{x}}_{\mathbf{j}}
$$

onde $\mathbf{P}$ é uma matriz real, simétrica e definida positiva.

A função $\mathbf{V}\left(\tilde{\mathbf{x}}_{\mathbf{j}}\right)$ é quadrática e satisfaz as condições $\mathbf{V}(\mathbf{0})=\mathbf{0}$ e $\mathbf{V}\left(\tilde{\mathbf{x}}_{\mathbf{j}}\right)>\mathbf{0}$ para todo $\tilde{\mathbf{x}}_{\mathbf{j}} \neq \mathbf{0}$, ou seja, $\mathbf{V}\left(\tilde{\mathbf{x}}_{\mathbf{j}}\right)$ é definida positiva. Se existir $\mathbf{P}_{\mathbf{j}}$ tal que $\dot{\mathbf{V}}\left(\tilde{\mathbf{x}}_{\mathbf{j}}\right)$ seja definida negativa para todo $\tilde{\mathbf{x}}_{\mathbf{j}} \neq \mathbf{0}$, então, todas as trajetórias dos estados do sistema tendem para a origem $\tilde{\mathbf{x}}_{\mathbf{j}}=\mathbf{0}$ à medida que $\mathbf{t} \rightarrow \infty$ e, dessa forma, o sistema pode ser dito assintoticamente estável (Vidyasagar, 1993). A derivada da função $\mathbf{V}\left(\tilde{\mathbf{x}}_{\mathbf{j}}\right)$ em relação aos estados do sistema é:

$$
\dot{\mathbf{V}}\left(\tilde{\mathbf{x}}_{\mathbf{j}}\right)=\dot{\tilde{\mathbf{x}}}_{\mathbf{j}}^{\mathrm{T}} \mathbf{P}_{\mathbf{j}} \tilde{\mathbf{x}}_{\mathbf{j}}+\tilde{\mathbf{x}}_{\mathbf{j}}^{\mathrm{T}} \mathbf{P}_{\mathbf{j}} \dot{\tilde{\mathbf{x}}}_{\mathbf{j}} \rightarrow \dot{\mathbf{V}}\left(\tilde{\mathbf{x}}_{\mathbf{j}}\right)=\tilde{\mathbf{x}}_{\mathbf{j}}^{\mathrm{T}}\left(\tilde{\mathbf{A}}_{\mathbf{j}}^{\mathrm{T}} \mathbf{P}_{\mathbf{j}}+\mathbf{P}_{\mathbf{j}} \tilde{\mathbf{A}}_{\mathbf{j}}\right) \tilde{\mathbf{x}}_{\mathbf{j}}
$$

Portanto, pela teoria de estabilidade de Lyapunov, a condição necessária e suficiente para que o sistema (4.17) seja assintoticamente estável é que exista uma matriz $\mathbf{P}_{\mathbf{j}}=\mathbf{P}_{\mathbf{j}}^{\mathbf{T}}$ de modo que as desigualdades matriciais lineares

$$
\mathbf{P}_{\mathbf{j}}>\mathbf{0} \text { e } \tilde{\mathbf{A}}_{\mathbf{j}}{ }^{\mathrm{T}} \mathbf{P}_{\mathbf{j}}+\mathbf{P}_{\mathbf{j}} \tilde{\mathbf{A}}_{\mathbf{j}}<\mathbf{0}
$$

sejam satisfeitas (Boyd et al., 1994). Lyapunov também mostrou que essas desigualdades matriciais lineares poderiam ser resolvidas arbitrando-se uma matriz qualquer Q (simétrica e definida positiva) e resolvendo-se o sistema linear $\tilde{\mathbf{A}}_{\mathbf{j}}{ }^{\mathrm{T}} \mathbf{P}_{\mathbf{j}}+\mathbf{P}_{\mathbf{j}} \tilde{\mathbf{A}}_{\mathbf{j}}=-\mathbf{Q}$. Dessa forma, $\mathbf{a}$ estabilidade do sistema pode ser investigada sem a necessidade de se calcular diretamente os autovalores da matriz $\tilde{\mathbf{A}}_{\mathbf{j}}$. 
Portanto, utilizando a desigualdade de Lyapunov para caracterizar a estabilidade do sistema em malha fechada (4.14), o problema de projeto de controladores de amortecimento por realimentação de saída para o sistema (4.4)-(4.5) consiste em encontrar matrizes $\mathbf{A}_{\mathbf{c}}$, $\mathbf{B}_{\mathbf{c}}$, $\mathbf{C}_{\mathbf{c}}$ e $\tilde{\mathbf{P}}_{\mathbf{j}}=\tilde{\mathbf{P}}_{\mathbf{j}}^{\mathbf{T}}$ de tal forma que

$$
\begin{aligned}
& \mathbf{P}_{j}^{T}=\mathbf{P}_{j} \succ \mathbf{0} \\
& \tilde{\mathbf{A}}_{\mathbf{j}}{ }^{\mathbf{T}} \tilde{\mathbf{P}}_{\mathbf{j}}+\tilde{\mathbf{P}}_{\mathbf{j}} \tilde{\mathbf{A}}_{\mathbf{j}}<\mathbf{0}
\end{aligned}
$$

sejam atendidas. Em outras palavras, o problema de projeto consiste em estabelecer uma estrutura de controle por realimentação de saída definida pelas matrizes $\mathbf{A}_{\mathbf{c}}, \mathbf{B}_{\mathbf{c}}$ e $\mathbf{C}_{\mathbf{c}}$ que posicione todos os autovalores (ou pólos) do sistema em malha fechada $\tilde{\mathbf{A}}_{\mathbf{j}}$ no semi-plano esquerdo do plano complexo, processo chamado de Posicionamento Regional de Pólos (PRP).

O PRP consiste na imposição dos pólos do sistema em malha fechada em uma determinada região do plano complexo. Através dessa técnica é possível analisar se o controlador projetado garante um desempenho mínimo para o sistema em malha fechada no ponto de operação considerado, de modo que o sistema tenha um fator de amortecimento mínimo considerado "seguro".

Com isso os autovalores da matriz $\tilde{\mathbf{A}}_{\mathbf{j}}$ deverão estar no setor cônico para um fator de amortecimento mínimo $\zeta_{\min }$ representado na figura 4.3 abaixo. Um valor de $\zeta_{0}=0.05$ é normalmente considerado como um valor seguro para esta margem. 


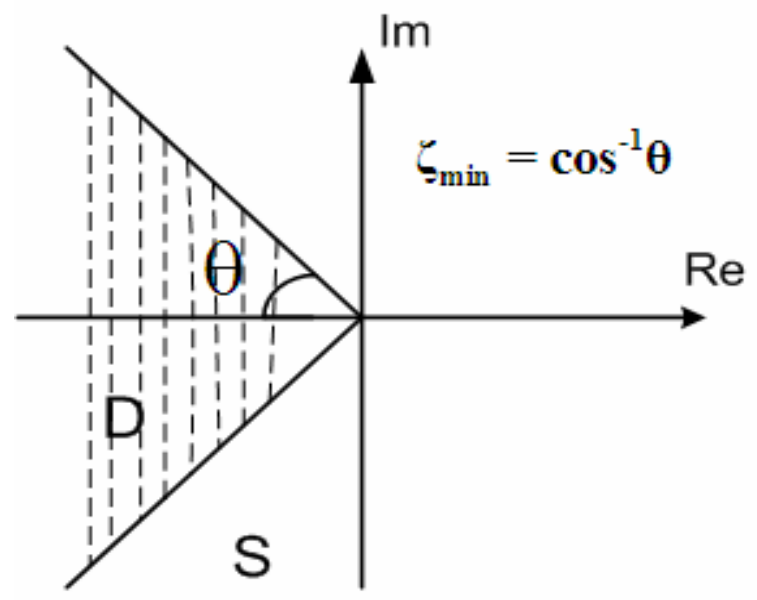

Figura 4.3 - Setor cônico para garantia de amortecimento mínimo

Caso todos os autovalores da matriz $\overline{\mathrm{A}}_{\mathrm{j}}$ estejam contidos na região definida na figura 4.3, isso implica que todos os autovalores da matriz $\tilde{\mathbf{A}}_{\mathbf{j}}$ estão contidos no semiplano esquerdo aberto do plano complexo (Davison \& Ramesh, 1970). Ou seja,

$$
\begin{gathered}
\lambda\left(\overline{\mathbf{A}}_{\mathrm{j}}\right) \subset \mathrm{S} \Rightarrow \lambda\left(\tilde{\mathrm{A}}_{\mathrm{j}}\right) \subset \mathrm{D} \text { e } \\
\overline{\mathrm{A}}_{\mathrm{j}}=\tilde{\mathrm{A}}_{\mathrm{j}} \otimes\left(\begin{array}{cc}
\operatorname{sen} \theta & -\cos \theta \\
\cos \theta & \operatorname{sen} \theta
\end{array}\right)=\left(\begin{array}{cc}
\operatorname{sen} \theta \tilde{\mathrm{A}}_{\mathrm{j}} & -\cos \theta \tilde{\mathrm{A}}_{\mathrm{j}} \\
\cos \theta \tilde{\mathrm{A}}_{\mathrm{j}} & \operatorname{sen} \theta \tilde{\mathrm{A}}_{\mathrm{j}}
\end{array}\right)
\end{gathered}
$$

Portanto, de acordo com a teoria de Lyapunov discutida anteriormente, é possível definir uma matriz $\overline{\mathbf{P}}_{\mathbf{j}}=\left[\begin{array}{cc}\tilde{\mathbf{P}}_{\mathbf{j}} & \mathbf{0} \\ \mathbf{0} & \tilde{\mathbf{P}}_{\mathbf{j}}\end{array}\right]$ tal que a equação (4.21)-(4.22) sejam satisfeitas. Sendo assim, a existência de uma matriz $\overline{\mathbf{P}}_{\mathbf{j}}=\left[\begin{array}{cc}\tilde{\mathbf{P}}_{\mathbf{j}} & \mathbf{0} \\ \mathbf{0} & \tilde{\mathbf{P}}_{\mathbf{j}}\end{array}\right]$ tal que 


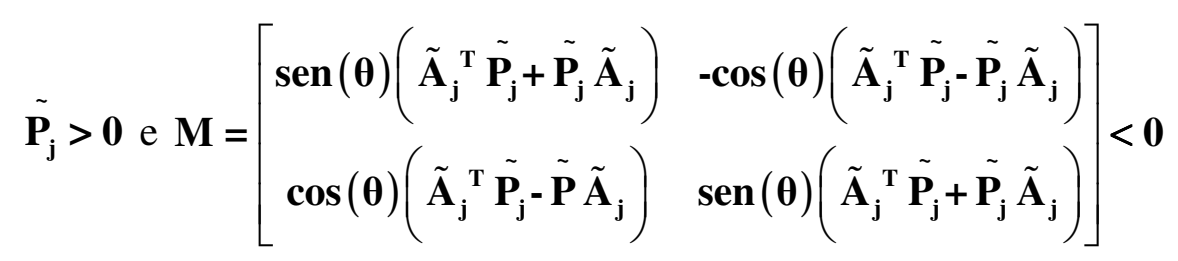

implica que todos os autovalores da matriz $\tilde{\mathbf{A}}_{\mathbf{j}}$ pertencem à região definida na figura 4.3 , e o sistema representado pela equação (4.18) apresenta pólos com fator de amortecimento maior ou igual a $\zeta_{\min }=\cos ^{-1} \theta$.

Depois de selecionar a localização dos estabilizadores, os projetistas das indústrias geralmente executam um projeto seqüencial dos PSSs, o que significa que cada um dos controladores (4.9)-(4.10) são projetados um de cada vez. Após o primeiro controlador ser projetado, ele é incluído no modelo do sistema e seus efeitos são analisados. Com o novo modelo que inclui o primeiro controlador projetado, um segundo pode ser então projetado, atualizando o modelo que inclui o primeiro (assim analisando seu efeito no novo projeto). $\mathrm{O}$ processo é repetido até que o desempenho desejado do sistema seja obtido.

Mesmo no caso da Figura 3.1, onde o PSS é projetado para o modelo agregado (e, portanto o mesmo PSS seria implementado em todos os 4 geradores de uma só vez), haveria ainda a necessidade de verificar os efeitos da colocação desses PSSs similares sobre os modos intra-planta, para várias condições de operação distintas. Obviamente isso é um processo muito demorado, e a proposta deste trabalho é reduzir substancialmente o tempo que o engenheiro tem que se dedicar ao mesmo, atribuindo ao computador à tarefa da procura dos parâmetros do PSS.

As desigualdades (4.21) são restrições de positividade nas matrizes $\mathbf{P}_{j}$ e, portanto, não são tão simples de resolver. Felizmente, foram recentemente desenvolvidos algoritmos para resolver desigualdades lineares similares a (4.21) Esses algoritmos são chamados de solvers 
de LMIs e alguns deles podem ser obtidos como partes de pacotes de softwares bem conhecidos como (Sturn, 1999), por exemplo.

Contudo, esses algoritmos de resolução não podem ser diretamente aplicados para encontrar as matrizes $\mathbf{A}_{c}, \mathbf{B}_{c}, \mathbf{C}_{c}$ e $\mathbf{P}_{j}$ em (4.25), porque essas desigualdades não são lineares em relação aos elementos dessas matrizes. Existem vários produtos cruzados entre as matrizes $\mathbf{P}_{j}$ e $\mathbf{A}_{c}, \mathbf{B}_{c}$ e $\mathbf{C}_{c}$ em (4.25), e, por esta razão, (4.25), são classificadas como Desigualdades Matriciais Bilineares (ou BMIs, do inglês Bilinear Matrix Inequalities). O problema de encontrar a solução de (4.25), pertence ao conjunto de problemas de factibilidade com restrições não-convexas.

Este trabalho propõe o uso de um algoritmo iterativo para a solução do problema BMI dado por (4.21) e (4.25). A idéia é usar o método conhecido como iterações V-K (Oliveira et al., 2007). A idéia básica do algoritmo de iteração V-K é que, fixando alternadamente as matrizes $\tilde{\mathbf{P}}_{\mathbf{j}}$ e $\tilde{\mathbf{A}}_{\mathbf{j}}$, a desigualdade em (4.22) torna-se uma LMI e portando podendo ser aplicado o Algoritmo Iterativo VK. Pretende-se utilizar tal idéia no desenvolvimento do procedimento de projeto de PSSs mencionado na seção 4.1, sendo esta a principal contribuição do presente trabalho.

\section{3 - Algoritmo Iterativo (Iteração V-K)}

O algoritmo conhecido como iteração $\mathrm{V}-\mathrm{K}$ pode ser definido nos seguintes passos:

1) Inicializar $\circ$ algoritmo $\operatorname{com} \mathbf{A}_{\mathbf{c}}, \mathbf{B}_{\mathbf{c}}$ e $\mathbf{C}_{\mathbf{c}}$, correspondente aos PSSs projetados para condições nominais; 
2) Com $\mathbf{A}_{\mathbf{c}}, \mathbf{B}_{\mathbf{c}}$ e $\mathbf{C}_{\mathbf{c}}$ fixos, minimizar $\sigma$ encontrando $\mathbf{P}_{j}$, $j=1, \ldots, L$, sujeito as LMIs

$$
\tilde{\mathbf{P}}_{\mathbf{j}}>0 \text { e } \mathbf{M}=\left[\begin{array}{lr}
\operatorname{sen}(\theta)\left(\tilde{\mathbf{A}}^{\mathrm{T}} \tilde{\mathbf{P}}+\tilde{\mathbf{P}} \tilde{\mathbf{A}}\right) & -\cos (\theta)\left(\tilde{\mathbf{A}}^{\mathrm{T}} \tilde{\mathbf{P}}-\tilde{\mathbf{P}} \tilde{\mathbf{A}}\right) \\
\cos (\theta)\left(\tilde{\mathbf{A}}^{\mathrm{T}} \tilde{\mathbf{P}}-\tilde{\mathbf{P}} \tilde{\mathbf{A}}\right) & \operatorname{sen}(\boldsymbol{\theta})\left(\tilde{\mathbf{A}}^{\mathrm{T}} \tilde{\mathbf{P}}+\tilde{\mathbf{P}} \tilde{\mathbf{A}}\right)
\end{array}\right]-\sigma \mathrm{I}<\mathbf{0}
$$

3) (Teste de convergência 1): $\boldsymbol{\sigma} \leq 0$, pare e utilize a função de transferência do PSS sintonizado de $\mathbf{A}_{\mathbf{c}}, \mathbf{B}_{\mathbf{c}} e$ $\mathbf{C}_{\mathbf{c}}$; Senão, continuar no passo 4 ;

4) Com $\mathbf{P}_{j}$ fixo, $j=1, \ldots, L$, minimizar $\sigma$ encontrando $\mathbf{A}_{\mathbf{c}}, \mathbf{B}_{\mathbf{c}}$ ' e $\mathbf{C}_{\mathbf{c}}$, sujeito as LMIs (4.26);

5) Teste de convergência 2): Se $\sigma \leq 0$, pare e utilize a função de transferência do PSS sintonizado de $\mathbf{A}_{\mathbf{c}}, \mathbf{B}_{\mathbf{c}}$ e $\mathbf{C}_{\mathbf{c}}$; Senão, volte para o passo 2 .

É fácil ver que qualquer solução de (4.26) com valores negativos de $\sigma$ corresponde a encontrar uma solução de (4.25). Além disso, a seqüência de valores de $\sigma$ gerados por este algoritmo iterativo é obviamente não crescente. Por outro lado, como esse algoritmo trata um problema de factibilidade não convexa, nenhuma demonstração de convergência global pode ser dada, e os resultados podem mudar de acordo com os valores iniciais fornecidos para o algoritmo.

Esta desvantagem pode ser contornada no caso do projeto de PSSs tendo em vista que a realização do projeto de tais controladores para condições de operação nominais é razoavelmente simples (devido ao fato de que a compensação de fase requerida é unicamente determinada). Dessa forma, o projeto para condições nominais pode ser realizado pelo engenheiro projetista sem maiores dificuldades, e o resultado de tal projeto pode ser usado para suprir os valores iniciais para o algoritmo apresentado. É razoável supor que os 
60

parâmetros do controlador nominal estejam próximos, no espaço de parâmetros, do conjunto que define PSSs eficazes para o amortecimento dos modos em todas as demais condições de operação. Espera-se, com isso, que seja atingida convergência do processo para uma solução factível na grande maioria dos casos, embora não haja ainda garantia ou prova de convergência do algoritmo. É fácil também ver que este processo é equivalente a realização da sintonia computadorizada de um conjunto de PSSs para amortecimento de múltiplos modos de oscilação (no caso deste trabalho, modos locais e intra-planta) em múltiplas condições de operação. 


\section{Capítulo 5}

\section{TESTES E RESULTADOS}

Este capítulo apresenta os resultados dos testes realizados para avaliar o desempenho do algoritmo proposto nesta dissertação de mestrado. Os testes foram realizados no sistema da figura 5.1, que também pode ser encontrado em (Rogers,2000). O algoritmo foi implementado usando o YALMIP (Löfberg, 2004) e resolvido usando o pacote SeDuMi (Sturn, 1999). O programa PacDyn foi usado para obter os modelos linearizados para os pontos de operação, e também no projeto de PSSs para o caso base usando um procedimento de sintonia baseado na técnica de resíduos (Pagola et al., 1989). Todos os testes foram realizados num computador equipado com processador Core Duo Pentium IV 794MHz com $2 \mathrm{~Gb}$ de memória RAM. Detalhes sobre os aspectos numéricos dos testes são fornecidos nas respectivas seções.

\section{1 - Modelo do Sistema Estudado}

Esta seção apresenta os resultados dos testes realizados no sistema da figura 5.1, cujos dados do sistema de transmissão e os dados dos geradores se encontram nas tabelas abaixo. Optou-se por apresentar tais dados no corpo do texto (e não na forma de Apêndice, como é usual em trabalhos desta natureza), para que o leitor possa relacionar de maneira mais direta os dados e a topologia do sistema com os resultados obtidos.

Os dados de linha do sistema, referentes às resistências e reatâncias, são apresentados na tabela 5.1. Todos os valores estão em p.u. na base $\mathrm{S}_{\mathrm{BASE}}=137,5 \mathrm{MVA}$. As potências ativa e reativa da carga são, respectivamente, iguais a 907,5MW e 20,6MVA. 


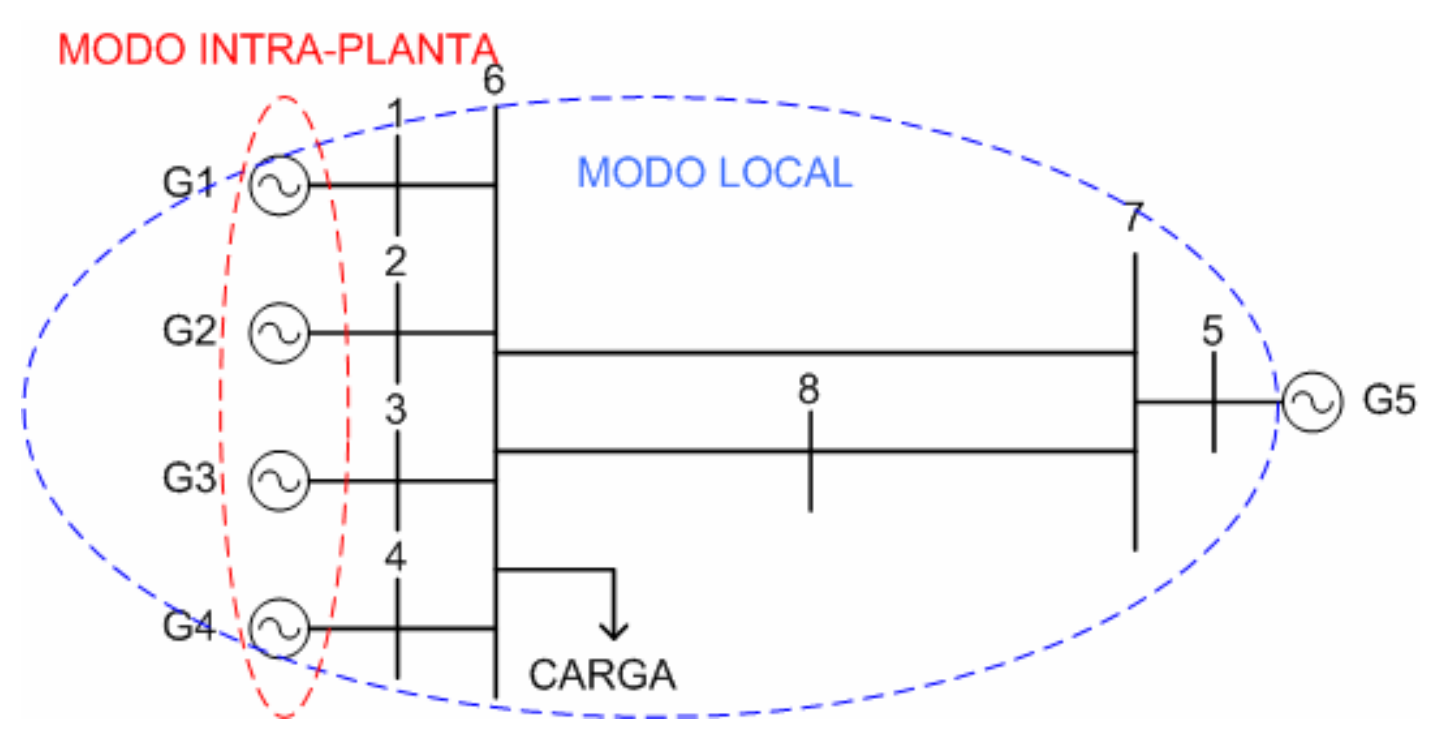

Figura 5.1- Modelo do Sistema Estudado

Tabela 5.1-Dados do sistema de transmissão

\begin{tabular}{|c|c|c|c|}
\hline $\begin{array}{c}\text { Barra de } \\
\text { Origem }\end{array}$ & $\begin{array}{c}\text { Barra de } \\
\text { Destino }\end{array}$ & $\begin{array}{c}\text { Resistência } \\
\text { [p.u.] }\end{array}$ & $\begin{array}{c}\text { Reatância } \\
\text { [p.u.] }\end{array}$ \\
\hline \hline 1 & 6 & 0 & 0.0576 \\
\hline 2 & 6 & 0 & 0.0576 \\
\hline 3 & 6 & 0 & 0.0576 \\
\hline 4 & 6 & 0 & 0.0576 \\
\hline 5 & 7 & 0 & 0.0576 \\
\hline 6 & 7 & 0.0085 & 0.072 \\
\hline 6 & 8 & 0.00425 & 0.036 \\
\hline 8 & 7 & 0.00425 & 0.036 \\
\hline
\end{tabular}

A tabela 5.2 apresenta os parâmetros dos geradores, também referidos à base $\mathrm{S}_{\text {BASE }}=137,5 \mathrm{MVA}$, e as potências ativas e reativas em p.u. dos geradores são $P_{1}=P_{2}=P_{3}=P_{4}=1,21$ e $Q_{1}=Q_{2}=Q_{3}=Q_{4}=0,18$ respectivamente, relativos à base mencionada. 
Tabela 5.2 - Parâmetros dos Geradores do Sistema

\begin{tabular}{|c|c|c|c|c|c|}
\hline Gerador & $\mathrm{x}_{\mathrm{d}}$ & $\mathrm{x}_{\mathrm{q}}$ & $\mathrm{x}_{\mathrm{d}}^{\prime}$ & $\tau_{\mathrm{do}}^{\prime}$ & $\mathrm{H}$ \\
\hline \hline 1 & 1.81 & 1.76 & 0.30 & 7.8 & 3.58 \\
\hline 2 & 1.81 & 1.76 & 0.30 & 7.8 & 3.58 \\
\hline 3 & 1.81 & 1.76 & 0.30 & 7.8 & 3.58 \\
\hline 4 & 1.81 & 1.76 & 0.30 & 7.8 & 3.58 \\
\hline
\end{tabular}

Os dados dos reguladores de tensão encontram-se na tabela 5.3.

Tabela 5.3- Dados do regulador de tensão

\begin{tabular}{|c|c|c|c|}
\hline Gerador & $\mathrm{Ke}$ & $\begin{array}{c}\mathrm{Te} \\
{[\mathrm{s}]}\end{array}$ & $\begin{array}{c}\mathrm{Tr} \\
{[\mathrm{s}]}\end{array}$ \\
\hline \hline 1 & 212 & 0.05 & 0.02 \\
\hline 2 & 212 & 0.05 & 0.02 \\
\hline 3 & 212 & 0.05 & 0.02 \\
\hline 4 & 212 & 0.05 & 0.02 \\
\hline
\end{tabular}

Os autovalores em malha aberta do sistema da figura 5.1 estão representados na tabela 5.4. Estes resultados foram obtidos através da construção do modelo linearizado com o auxílio do software PACDYN.

Nessas condições, o sistema possui todos seus autovalores com parte real menor que zero o que mostra que ele se comporta de maneira estável. No entanto, tanto o modo local (destacado em azul na tabela abaixo para correspondência com a legenda usada na Figura 5.1) quanto os modos intra-planta (destacados em vermelho, para a mesma correspondência) possuem um amortecimento menor que 3\%, o que indica baixa margem de estabilidade a pequenas perturbações ou, em outras palavras, que o sistema opera numa condição onde variações paramétricas ou topológicas de pequena grandeza têm grandes riscos de produzir instabilidade. 
Tabela 5.4- Autovalores do sistema em malha aberta.

\begin{tabular}{|c|c|c|c|}
\hline Modos & Real & Imaginária & Amortecimento $(\%)$ \\
\hline 1 & $-0,18$ & 11,06 & 1,6 \\
\hline 2 & $-0,18$ & $-11,06$ & 1,6 \\
\hline 3 & $-0,18$ & 11,06 & 1,6 \\
\hline 4 & $-0,18$ & $-11,06$ & 1,6 \\
\hline 5 & $-0,18$ & 11,06 & 1,6 \\
\hline 6 & $-0,18$ & $-11,06$ & 1,6 \\
\hline 7 & $-0,22$ & 7,83 & 2,79 \\
\hline 8 & $-\mathbf{0 , 2 2}$ & $-7,83$ & 2,79 \\
\hline 9 & $-6,87$ & 13,62 & 45,01 \\
\hline 10 & $-6,87$ & $-13,62$ & 45,01 \\
\hline 11 & $-56,26$ & 0 & 100 \\
\hline 12 & $-51,42$ & 0 & 100 \\
\hline 13 & $-51,42$ & 0 & 100 \\
\hline 14 & $-51,42$ & 0 & 100 \\
\hline 15 & $-15,46$ & 0 & 100 \\
\hline 16 & $-15,46$ & 0 & 100 \\
\hline 17 & $-15,46$ & 0 & 100 \\
\hline 18 & $-3,42$ & 0 & 100 \\
\hline 19 & $-3,42$ & 0 & 100 \\
\hline 20 & $-3,42$ & 0 & 100 \\
\hline
\end{tabular}

Conforme comentado anteriormente, o amortecimento mínimo considerado como indicativo de uma margem segura para a estabilidade a pequenas perturbações num sistema de potência é de pelo menos $5 \%$.

Como mostrado no capítulo 3, através da análise do fator de participação é possível identificar quais geradores são mais participativos nos respectivos modos de resposta, e também é possível saber quais dos modos de respostas correspondem a oscilações de natureza intra-planta ou local. Os fatores de participação dos modos 1 e 2 (os quais constituem um par complexo conjugado de autovalores) podem ser vistos na tabela 5.5. 
Tabela 5.5- Fator de participação do modo 1 e 2.

\begin{tabular}{|c|c|c|c|c|}
\hline \multicolumn{5}{|c|}{ Modo de Resposta: $-0,18 \pm \mathbf{j} 11,06$} \\
\hline Módulo & Nome da & Barr & & Variável de Estado \\
\hline 1.0000 & Barra4 & & 4 & $\omega_{4}$ \\
\hline 1.0000 & Barra4 & & 4 & $\delta_{4}$ \\
\hline 0.7062 & Barra3 & $\#$ & 3 & $\delta_{3}$ \\
\hline 0.7062 & Barra3 & $\#$ & 3 & $\omega_{3}$ \\
\hline 0.09222 & Barra1 & $\#$ & 1 & $\delta_{1}$ \\
\hline 0.09222 & Barra1 & $\#$ & 1 & $\omega_{1}$ \\
\hline 0.06330 & Barra2 & $\#$ & 2 & $\delta_{2}$ \\
\hline 0.06330 & Barra2 & $\#$ & 2 & $\omega_{2}$ \\
\hline
\end{tabular}

A análise da Tabela 5.5 permite concluir que os modos 1 e 2 representam modos de oscilação eletromecânica intra-planta, onde tem-se o gerador G4 com a maior participação nas variáveis de ângulo e velocidade angular, oscilando principalmente contra o gerador G3.

Um procedimento semelhante permitiu classificar os demais modos apresentados na Tabela 5.4. Pode-se observar pelos fatores de participação dos modos 7 e 8 , dados na tabela 5.6, que os mesmos representam modos de oscilação eletromecânica local. Neste caso temos os geradores G1, G2, G3 e G4 oscilando contra o restante do sistema.

Tabela 5.6- Fator de participação do modo 7 e 8.

\begin{tabular}{|c|ccc|c|}
\hline \multicolumn{5}{|c|}{ Modo de Resposta: -0,22 $\pm 7,83$} \\
\hline Módulo & Nome da & Barra & Variável de Estado \\
\hline 1.0000 & Barra3 & $\#$ & 3 & $\omega_{3}$ \\
\hline 1.0000 & Barra3 & $\#$ & 3 & $\delta_{3}$ \\
\hline 1.0000 & Barra1 & $\#$ & 1 & $\omega_{1}$ \\
\hline 1.0000 & Barra1 & $\#$ & 1 & $\delta_{1}$ \\
\hline 1.0000 & Barra4 & $\#$ & 4 & $\omega_{4}$ \\
\hline 1.0000 & Barra4 & $\#$ & 4 & $\delta_{4}$ \\
\hline 1.0000 & Barra2 & $\#$ & 2 & $\omega_{2}$ \\
\hline 1.0000 & Barra2 & $\#$ & 2 & $\delta_{2}$ \\
\hline
\end{tabular}


Para melhorar o amortecimento dos modos intra-planta e local, foi projetado o controlador de amortecimento do tipo PSS. Em (Rogers, 2000), mostrou se que a utilização do modelo de uma máquina equivalente, para representar unidades com várias máquinas no projeto de controladores de amortecimento, pode levar à desestabilização dos modos intraplanta. Construindo-se um modelo agregado para o sistema estudado, que pode ser representado pela figura 5.2, o projeto de um PSS para o mesmo pode resultar nos seguintes parâmetros (Rogers, 2000):

$$
\frac{y_{P S S}}{\Delta \omega}=\frac{1.41 s}{(1+1.41 s)} \frac{(1+0.4 s)}{(1+0.3 s)}
$$

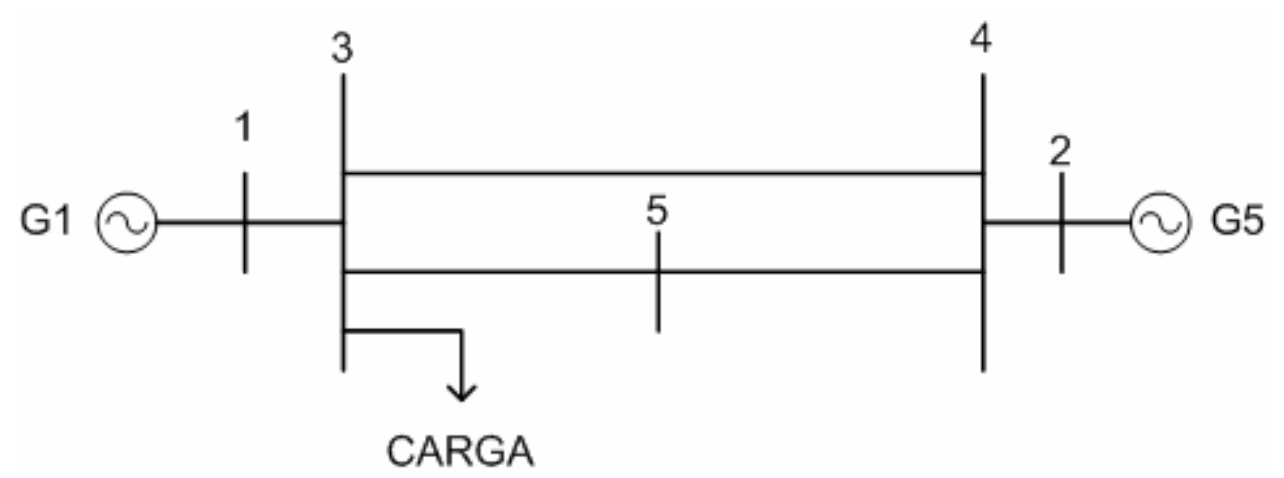

Figura 5.2- Modelo Agregado do Sistema da Figura 5.1.

A Tabela 5.7 mostra os autovalores em malha fechada do sistema da figura 5.2, quando o PSS dado por (5.1) é colocado no gerador G1, em que a barra 4 é considerado um barramento infinito. 
Tabela 5.7- Autovalores em malha fechada do sistema agregado.

\begin{tabular}{|c|c|c|}
\hline Real & Imaginária & Amortecimento(\%) \\
\hline$-0,78$ & 12,62 & 6,20 \\
\hline$-0,78$ & $-12,62$ & 6,20 \\
\hline$-6,72$ & 4,69 & 82,01 \\
\hline$-6,72$ & $-4,69$ & 82,01 \\
\hline$-54,74$ & 0 & 100 \\
\hline$-4,04$ & 0 & 100 \\
\hline$-0,74$ & 0 & 100 \\
\hline
\end{tabular}

Pode-se observar que o modelo agregado possui todos seus autovalores com parte real menor que zero, sugerindo que o sistema se comportaria de maneira estável, e que o modo local apresentaria um amortecimento maior que 5\%. Sendo assim, o engenheiro projetista poderia ser levado a concluir que o sistema operaria com boa margem de estabilidade a pequenas perturbações e que não haveria problemas relacionados a oscilações eletromecânicas.

No entanto, para usinas com várias unidades geradoras operando em paralelo (como é o caso do sistema da Figura 5.1, o qual foi representado de forma agregada pelo modelo da Figura 5.2), o PSS projetado através do modelo agregado deve ser implementado em cada uma destas unidades individualmente, para garantir que todas as máquinas contribuam para o amortecimento das oscilações eletromecânicas no sistema. No entanto, mesmo no caso em que as múltiplas unidades geradoras que são idênticas, a implementação do PSS projetado através do modelo agregado pode não ser efetiva no amortecimento dos modos intra-planta. A Tabela 5.8 ilustra este fato, mostrando os autovalores em malha fechada do sistema, quando o PSS dado por (5.1) é colocado em cada uma das 4 máquinas representadas na Figura 5.1.

Pode ser visto claramente na Tabela 5.8 que este PSS estabiliza o modo local com uma taxa de amortecimento satisfatória, consequiência de seu projeto baseado no modelo agregado. Todavia, quando são avaliados os modos intra-planta, pode ser observado que o PSS dado por 
68

(5.1) não amortece satisfatoriamente o sistema. Na verdade, se for feita uma comparação dos autovalores do sistema em malha aberta (Tabela 5.4) com os autovalores em malha fechada (depois da inserção do PSS, dado pela Tabela 5.8), é possível verificar que os modos intraplanta (que inicialmente eram pouco amortecidos, porém estáveis) foram desestabilizados pela aplicação do PSS.

Uma forma de evitar este problema é utilizar o modelo completo com as 4 máquinas modeladas individualmente, e não o modelo agregado, no projeto de PSSs para tais máquinas. Se este modelo for utilizado, qualquer técnica de sintonia manual empírica pode ser aplicada para assegurar que ambos os modos (local e intra-planta) sejam adequadamente amortecidos pelos PSSs projetados. O problema neste caso, entretanto, é a complexidade envolvida quando é necessário tratar múltiplos modos de oscilação de uma só vez. Esta complexidade é ainda aumentada pelo fato de que as características destes modos variam com as mudanças nas condições de operação do sistema. Por todas estas razões, conforme mencionado anteriormente neste trabalho, propõe-se a utilização do algoritmo de iteração V-K para a sintonia automática destes PSSs, cuja viabilidade será demonstrada na seção seguinte. 
Tabela 5.8- Autovalores em malha fechada com Kpss=6.

\begin{tabular}{|c|c|c|}
\hline Real & Imaginária & Amortecimento(\%) \\
\hline 0,63 & \begin{tabular}{|l|}
13,58 \\
\end{tabular} & $-4,61$ \\
\hline 0,63 & $-13,58$ & $-4,61$ \\
\hline 0,63 & 13,58 & $-4,61$ \\
\hline 0,63 & $-13,58$ & $-4,61$ \\
\hline 0,63 & 13,58 & $-4,61$ \\
\hline 0,63 & $-13,58$ & $-4,61$ \\
\hline$-2,83$ & 13,38 & 20,73 \\
\hline$-2,83$ & $-13,38$ & 20,73 \\
\hline$-4,00$ & $\mathbf{7 , 0 2}$ & 49,55 \\
\hline$-4,00$ & $-7,02$ & 49,55 \\
\hline$-2,15$ & $\mathbf{0 , 5 5}$ & 96,84 \\
\hline$-2,15$ & $-0,55$ & 96,84 \\
\hline$-2,15$ & $\mathbf{0 , 5 5}$ & 96,84 \\
\hline$-2,15$ & $-0,55$ & 96,84 \\
\hline$-2,15$ & $\mathbf{0 , 5 5}$ & 96,84 \\
\hline$-2,15$ & $-0,55$ & 96,84 \\
\hline$-56,31$ & $\mathbf{0}$ & 100 \\
\hline$-51,45$ & $\mathbf{0}$ & 100 \\
\hline$-51,45$ & $\mathbf{0}$ & 100 \\
\hline$-51,45$ & $\mathbf{0}$ & 100 \\
\hline$-19,35$ & $\mathbf{0}$ & 100 \\
\hline$-19,35$ & $\mathbf{0}$ & 100 \\
\hline$-19,35$ & $\mathbf{0}$ & 100 \\
\hline$-3,75$ & $\mathbf{0}$ & 100 \\
\hline$-0,87$ & $\mathbf{0}$ & 100 \\
\hline$-\mathbf{0 , 8 7}$ & $\mathbf{0}$ & 100 \\
\hline$-\mathbf{0 , 8 7}$ & $\mathbf{0}$ & 100 \\
\hline$-0,74$ & $\mathbf{0}$ & 100 \\
\hline
\end{tabular}

\section{2 - Aplicação do Algoritmo V-K para o Problema de Oscilação Intra-}

\section{Planta}

Nesta seção, o algoritmo apresentado no capítulo 4 é aplicado para sintonizar PSSs para o sistema da Figura 5.1. Dado que os geradores neste sistema são perfeitamente idênticos, é possível utilizar PSSs com os mesmos parâmetros em cada um deles para 
amortecimento tanto dos modos intra-planta quanto do modo local dos quais estes geradores participam.

Primeiramente foi projetado um PSS e analisou-se para quais pontos de operação o mesmo forneceria o amortecimento satisfatório, quando implementado em cada uma das 4 máquinas do sistema da Figura 5.1. Os seguintes pontos de operação foram analisados: o caso base dado na seção 5.1 e variações de $\pm 2 \%, \pm 4 \%, \pm 6 \%, \pm 8 \%, \pm 10 \%, \pm 12 \%, \pm 14 \%$ e $\pm 16 \%$ e $\pm 18 \%$ na potência da carga com relação a este caso base.

O programa PacDyn foi usado para obter os modelos linearizados na forma (4.4)-(4.5) para os pontos de operação mencionados acima, e também no projeto do PSS para o caso base usando um procedimento de sintonia baseado na técnica de resíduos (Pagola et al., 1989). O PSS projetado tem a seguinte função de transferência:

$$
y_{j i}=4.9 \frac{10 s}{1+10 s}\left(\frac{1+0.292 s}{1+0.029 s}\right)^{2}
$$

Quando este PSS projetado para o caso base é aplicado para as máquinas, o resultado dos autovalores do sistema em malha fechada pode ser visto na Tabela 5.9. É possível notar que o PSS é bastante eficiente sob condições para as quais o mesmo foi projetado, mas não alcança a margem de estabilidade a pequenas perturbações satisfatória de $\zeta_{0}=0,05$ quando o sistema opera sob algumas condições operativas diferentes. Observa-se que este PSS não fornece um amortecimento satisfatório de $5 \%$ para as variações de $+16 \%$ e $+18 \%$ da potência da carga. Com base nesta constatação, verifica-se a necessidade de sintonizar o PSS projetado para o caso base para que o mesmo produza amortecimento mínimo de $5 \%$ para todas as condições de operação consideradas na Tabela 5.9. Esta tarefa não é simples, pois a faixa de pontos de operação considerada é bastante ampla e um simples aumento de ganho do PSS dado por (5.2) não é suficiente para atingir tal objetivo. 
Tabela 5.9- Autovalores em malha fechada com o PSS dado por (5.2).

\begin{tabular}{|c|c|c|c|c|}
\hline Condição & Modos & Real & Imaginária & Amortecimento (\%) \\
\hline \multirow{2}{*}{$\begin{array}{c}\text { Não-nominal } \\
+2 \%\end{array}$} & Intra-Planta & $-3,53$ & $\pm 38,72$ & 9,09 \\
\hline & Local & $-0,35$ & $\pm 4,76$ & 7,28 \\
\hline \multirow{2}{*}{$\begin{array}{c}\text { Não-nominal } \\
+4 \% \\
\end{array}$} & Intra-Planta & $-3,50$ & $\pm 38,79$ & 8,98 \\
\hline & Local & $-0,33$ & $\pm 4,78$ & 6,92 \\
\hline \multirow{2}{*}{$\begin{array}{c}\text { Não-nominal } \\
+6 \%\end{array}$} & Intra-Planta & $-3,47$ & $\pm 38,85$ & 8,89 \\
\hline & Local & $-0,32$ & $\pm 4,80$ & 6,58 \\
\hline \multirow{2}{*}{$\begin{array}{c}\text { Não-nominal } \\
+8 \% \\
\end{array}$} & Intra-Planta & $-3,44$ & $\pm 38,92$ & 8,80 \\
\hline & Local & $-0,30$ & $\pm 4,81$ & 6,24 \\
\hline \multirow{2}{*}{$\begin{array}{c}\text { Não-nominal } \\
+10 \% \\
\end{array}$} & Intra-Planta & $-3,41$ & $\pm 38,98$ & 8,71 \\
\hline & Local & $-0,28$ & $\pm 4,83$ & 5,88 \\
\hline \multirow{2}{*}{$\begin{array}{c}\text { Não-nominal } \\
+12 \%\end{array}$} & Intra-Planta & $-3,38$ & $\pm 39,03$ & 8,63 \\
\hline & Local & $-0,27$ & $\pm 4,84$ & 5,54 \\
\hline \multirow{2}{*}{$\begin{array}{c}\text { Não-nominal } \\
+14 \% \\
\end{array}$} & Intra-Planta & $-3,36$ & $\pm 39,08$ & 8,56 \\
\hline & Local & $-0,25$ & $\pm 4,85$ & 5,19 \\
\hline \multirow{2}{*}{$\begin{array}{c}\text { Não-nominal } \\
+16 \%\end{array}$} & Intra-Planta & $-3,34$ & $\pm 39,12$ & 8,49 \\
\hline & Local & $-0,24$ & $\pm 4,86$ & 4,87 \\
\hline \multirow{2}{*}{$\begin{array}{c}\text { Não-nominal } \\
+18 \%\end{array}$} & Intra-Planta & $-3,17$ & $\pm 39,45$ & 8,02 \\
\hline & Local & $-0,23$ & $\pm 4,85$ & 4,63 \\
\hline \multirow{2}{*}{ Nominal } & Intra-Planta & $-3,57$ & $\pm 38,64$ & 9,20 \\
\hline & Local & $-0,36$ & $\pm 4,75$ & 7,63 \\
\hline \multirow{2}{*}{$\begin{array}{c}\text { Não-nominal } \\
-2 \% \\
\end{array}$} & Intra-Planta & $-3,61$ & $\pm 38,55$ & 9,32 \\
\hline & Local & $-0,38$ & $\pm 4,73$ & 7,98 \\
\hline \multirow{2}{*}{$\begin{array}{c}\text { Não-nominal } \\
-4 \%\end{array}$} & Intra-Planta & $-3,65$ & $\pm 38,47$ & 9,45 \\
\hline & Local & $-0,39$ & $\pm 4,71$ & 8,33 \\
\hline \multirow{2}{*}{$\begin{array}{c}\text { Não-nominal } \\
-6 \% \\
\end{array}$} & Intra-Planta & $-3,70$ & $\pm 38,38$ & 9,60 \\
\hline & Local & $-0,41$ & $\pm 4,69$ & 8,67 \\
\hline \multirow{2}{*}{$\begin{array}{c}\text { Não-nominal } \\
-8 \% \\
\end{array}$} & Intra-Planta & $-3,75$ & $\pm 38,27$ & 9,75 \\
\hline & Local & $-0,42$ & $\pm 4,67$ & 9,02 \\
\hline \multirow{2}{*}{$\begin{array}{c}\text { Não-nominal } \\
-10 \%\end{array}$} & Intra-Planta & $-3,80$ & $\pm 38,17$ & 9,92 \\
\hline & Local & $-0,44$ & $\pm 4,65$ & 9,35 \\
\hline \multirow{2}{*}{$\begin{array}{c}\text { Não-nominal } \\
-12 \%\end{array}$} & Intra-Planta & $-3,86$ & $\pm 38,05$ & 10,1 \\
\hline & Local & $-0,45$ & $\pm 4,63$ & 9,68 \\
\hline \multirow{2}{*}{$\begin{array}{c}\text { Não-nominal } \\
-14 \%\end{array}$} & Intra-Planta & $-3,93$ & $\pm 37,92$ & 10,30 \\
\hline & Local & $-0,46$ & $\pm 4,60$ & 10,00 \\
\hline \multirow{2}{*}{$\begin{array}{c}\text { Não-nominal } \\
-16 \%\end{array}$} & Intra-Planta & $-3,99$ & $\pm 37,78$ & 10,52 \\
\hline & Local & $-0,47$ & $\pm 4,58$ & 10,31 \\
\hline \multirow{2}{*}{$\begin{array}{c}\text { Não-nominal } \\
-18 \% \\
\end{array}$} & Intra-Planta & $-4,07$ & $\pm 37,63$ & 10,75 \\
\hline & Local & $-0,49$ & \pm 4.56 & 10,60 \\
\hline
\end{tabular}


A partir de então, foram realizados 5 testes:

a) Teste I: foram considerados o caso base e variações de $\pm 8 \%$ e $\pm 16 \%$ na potência da carga. O objetivo deste teste foi a realização de uma sintonia robusta com relação à variação nas condições do sistema e a obtenção de um parâmetro inicial de comparação do desempenho do algoritmo proposto;

b) Teste II: foram considerados o caso base e variações de $\pm 10 \%$ e $\pm 18 \%$ na potência da carga. O objetivo deste teste foi avaliar o efeito do aumento da faixa de variação de carga (o qual produz uma dificuldade significativamente maior para o projeto dos respectivos PSSs) sobre o desempenho do algoritmo;

c) Teste III: foram considerados o caso base e variações de $\pm 6 \%, \pm 10 \%, \pm 14 \%$ e $\pm 18 \%$ na potência da carga. O objetivo deste teste foi avaliar o efeito do aumento do número de pontos de operação (o qual também pode produzir uma dificuldade significativa para o projeto dos respectivos PSSs) sobre o desempenho do algoritmo;

d) Teste IV: foram considerados o caso base e variações de $\pm 2 \%, \pm 4 \%, \pm 6 \%, \pm 8 \%$, $\pm 10 \%, \pm 12 \%, \pm 14 \%$ e $\pm 16 \%$ na potência da carga. O objetivo deste teste também foi avaliar o efeito do aumento do número de pontos de operação sobre o desempenho do algoritmo, de forma que a comparação entre os testes I, II, III e IV pudesse indicar uma tendência de crescimento do tempo computacional requerido pelo algoritmo no que se refere tanto ao acréscimo do número de pontos de operação ao projeto quanto à faixa de variação nas quais estes pontos de operação são considerados; e

e) Teste V: foram considerados novamente o caso base e variações de $\pm 2 \%, \pm 4 \%$, $\pm 6 \%, \pm 8 \%, \pm 10 \%, \pm 12 \%, \pm 14 \%$ e $\pm 16 \%$ na potência da carga. Neste teste, porém, 
foi imposta uma estrutura tradicional de PSS com pólos e zeros reais, e também foram impostos limites sobre os parâmetros Kpss e $\gamma_{i}=\frac{1}{T_{2 i}}$, de forma a restringilos a valores que sejam fisicamente aceitáveis. Embora os demais testes tenham gerado valores fisicamente implementáveis para tais parâmetros, não havia nos mesmos garantia de que isso seria conseguido. Já no Teste $\mathrm{V}$ a imposição dos limites assegura tal garantia, e o objetivo deste teste é verificar o efeito do acréscimo destas restrições adicionais sobre o desempenho computacional do algoritmo.

Os parâmetros do PSS dado por (5.2) foram usados como condições iniciais para o algoritmo dado no capítulo 4 em cada um dos testes de I a V descritos no parágrafo anterior. Em todos estes testes, um amortecimento mínimo de $\zeta_{0}=0,05$ foi usado para definir o parâmetro $\theta$ e a constante de tempo do bloco washout foi fixada em $10 \mathrm{~s}$. O algoritmo foi implementado usando o YALMIP (Löfberg, 2004) e resolvido usando o pacote SeDuMi (Sturn, 1999). A seguir, apresentam-se os resultados de cada um destes 5 testes.

\subsection{1 - Resultados do Teste I}

No primeiro teste, o algoritmo convergiu para uma solução factível depois de 6 iterações, gastando aproximadamente 26 minutos para todo o processo ser completado. Considerando que um projetista experiente precisaria de um tempo consideravelmente maior do que este para resolver o mesmo problema, fica evidente o ganho de produtividade obtido com a aplicação do algoritmo proposto nesta dissertação de mestrado. 
O PSS sintonizado ao final do Teste I pelo algoritmo proposto tem a seguinte função de transferência:

$$
y_{j i}=8 \frac{10 s}{1+10 s}\left(\frac{59.6 s^{2}+442 s+661.9}{s^{2}+76.56 s+1236.3}\right)
$$

A aplicação deste PSS para todas as 4 máquinas do sistema da Figura 5.1 resultou nos autovalores em malha fechada mostrados na Tabela 5.10. Nesta tabela, é possível ver que essa sintonia do PSS garante que a taxa de amortecimento de todos os modos é maior que $\zeta_{0}=0,05$, não só para a condição do caso base, mas também para uma condição de operação (correspondente a $+16 \%$ de carga local com relação ao caso base) em que os modos não eram bem amortecidos pelo PSS dado em (5.2), como pode ser visto na comparação das Tabelas 5.9 e 5.10.

Tabela 5.10- Autovalores em malha fechada com o PSS dado por (5.3).

\begin{tabular}{|c|c|c|c|c|}
\hline Condição & Modos & Real & Imaginária & Amortecimento (\%) \\
\hline $\begin{array}{c}\text { Não-nominal } \\
+8 \%\end{array}$ & Intra-Planta & $-\mathbf{3 , 9 4}$ & $\mathbf{\pm 3 8 , 1 4}$ & $\mathbf{1 0 , 2 8}$ \\
\cline { 2 - 5 } & Local & $\mathbf{- 0 , 3 1}$ & $\mathbf{\pm 4 , 8 1}$ & $\mathbf{6 , 4 1}$ \\
\hline $\begin{array}{c}\text { Não-nominal } \\
+16 \%\end{array}$ & Intra-Planta & $\mathbf{- 3 , 8 4}$ & $\pm \mathbf{3 8 , 3 5}$ & $\mathbf{9 , 9 7}$ \\
\cline { 2 - 5 } & Local & $\mathbf{- 0 , 2 5}$ & $\mathbf{\pm 4 , 8 6}$ & $\mathbf{5 , 0 5}$ \\
\hline \multirow{2}{*}{\begin{tabular}{c} 
Nominal \\
\cline { 2 - 5 }
\end{tabular}} & Intra-Planta & $-\mathbf{4 , 0 7}$ & $\pm \mathbf{3 7 , 8 7}$ & $\mathbf{1 0 , 6 9}$ \\
\cline { 2 - 5 } & Local & $\mathbf{- 0 , 3 7}$ & $\mathbf{\pm 4 , 7 4}$ & $\mathbf{7 , 8 0}$ \\
\hline $\begin{array}{c}\text { Não-nominal } \\
-8 \%\end{array}$ & Intra-Planta & $-\mathbf{- 4 , 2 5}$ & $\mathbf{\pm 3 7 , 5 0}$ & $\mathbf{1 1 , 2 6}$ \\
\cline { 2 - 5 } & Local & $\mathbf{- 0 , 4 3}$ & $\mathbf{\pm 4 , 6 6}$ & $\mathbf{9 , 1 7}$ \\
\hline \multirow{2}{*}{$\begin{array}{c}\text { Não-nominal } \\
-16 \%\end{array}$} & Intra-Planta & $-\mathbf{4 , 4 9}$ & $\mathbf{3 7 , 0 0}$ & $\mathbf{1 2 , 0 4}$ \\
\cline { 2 - 5 } & Local & $\mathbf{- 0 , 4 8}$ & $\mathbf{\pm 4 , 5 7}$ & $\mathbf{1 0 , 4 2}$ \\
\hline
\end{tabular}

\subsection{2 - Resultados do Teste II}

No segundo teste, o algoritmo convergiu para uma solução factível depois de 32 iterações, gastando aproximadamente 1 hora e 32 minutos para todo o processo ser 
completado. Este aumento significativo do tempo computacional gasto para a obtenção de uma solução satisfatória deve-se fundamentalmente à inclusão do ponto de operação correspondente a $+18 \%$ de carga com relação ao valor do caso base no conjunto de condições de operação consideradas no projeto. Embora o número de condições de operação consideradas no projeto permaneça o mesmo com relação ao Teste I, a faixa de pontos de operação foi aumentada e agora inclui o ponto correspondente a $+18 \%$ mencionado, que é um ponto de alto carregamento e que, por essa razão, apresenta características bastante distintas dos demais.

O PSS sintonizado pelo algoritmo proposto no Teste II tem a seguinte função de transferência:

$$
y_{j i}=10 \frac{10 s}{1+10 s}\left(\frac{37.3 s^{2}+303.5 s+291.8}{s^{2}+73.9 s+1075.3}\right)
$$

A aplicação deste PSS para todas as 4 máquinas do sistema da Figura 5.1 resulta nos autovalores em malha fechada mostradas na Tabela 5.11. Observa-se que um amortecimento de 5,04\% para o modo local é conseguido na condição de operação correspondente a $+18 \%$ da carga nominal, o que não era possível com o PSS dado por (5.2).

Tabela 5.11- Autovalores em malha fechada com o PSS dado por (5.4).

\begin{tabular}{|c|c|c|c|c|}
\hline Condição & Modos & Real & Imaginária & Amortecimento (\%) \\
\hline \multirow{2}{*}{$\begin{array}{l}\text { Não-nominal } \\
+10 \%\end{array}$} & Intra-Planta & $-4,60$ & $\pm 33,63$ & 13,54 \\
\hline & Local & $-0,31$ & $\pm 4,82$ & 6,35 \\
\hline \multirow{2}{*}{$\begin{array}{c}\text { Não-nominal } \\
+18 \%\end{array}$} & Intra-Planta & $-4,52$ & $\pm 33,82$ & 13,20 \\
\hline & Local & $-0,25$ & \pm 4.87 & 5,04 \\
\hline \multirow[b]{2}{*}{ Nominal } & Intra-Planta & $-4,72$ & $\pm 33,32$ & 14,04 \\
\hline & Local & $-0,38$ & $\pm 4,73$ & 8,00 \\
\hline \multirow{2}{*}{$\begin{array}{c}\text { Não-nominal } \\
-10 \% \\
\end{array}$} & Intra-Planta & $-4,91$ & $\pm 32,88$ & 14,76 \\
\hline & Local & $-0,44$ & $\pm 4,62$ & 9,59 \\
\hline \multirow{2}{*}{$\begin{array}{c}\text { Não-nominal } \\
-18 \%\end{array}$} & Intra-Planta & $-5,12$ & $\pm 32,37$ & 15,62 \\
\hline & Local & $-0,49$ & $\pm 4,53$ & 10,69 \\
\hline
\end{tabular}


$\mathrm{O}$ fato de que o problema de sintonia correspondente ao Teste II ser significativamente mais complicado do que aquele relativo ao Teste I e de que o algoritmo proposto foi capaz de encontrar uma solução satisfatória para este problema em um tempo perfeitamente aceitável (por tratar-se de um procedimento offline) é certamente encorajador. Vale ressaltar que mesmo um projetista experiente levaria um tempo no mínimo igual ao tomado pelo algoritmo proposto na resolução do problema correspondente ao Teste II e, por esta razão, ainda se justifica a aplicação do algoritmo proposto em termos de ganho de produtividade, pois o engenheiro projetista pode dedicar-se a outras tarefas igualmente importantes para seu empregador enquanto o algoritmo realiza a sintonia do PSS.

\subsection{3 - Resultados do Teste III}

No terceiro teste, o algoritmo convergiu para uma solução factível depois de 35 iterações, gastando aproximadamente 3 horas e 17 minutos para todo o processo ser completado. Embora a mesma faixa de variação nas condições de operação usada no Teste II (entre $-18 \%$ e $+18 \%$ da carga local correspondente ao caso base) tenha sido mantida no Teste III, neste último foi utilizado um número maior de pontos de operação dentro desta faixa (9 pontos de operação no total).

O PSS sintonizado pelo algoritmo proposto no Teste III tem a seguinte função de transferência:

$$
y_{j i}=15 \frac{10 s}{1+10 s}\left(\frac{37.8 s^{2}+448.7 s+239.4}{s^{2}+114.1 s+2358.5}\right)
$$


A aplicação deste PSS para todas as 4 máquinas do sistema da Figura 5.1 resulta nos autovalores em malha fechada mostradas na Tabela 5.12, garantindo a taxa de amortecimento mínima desejada para todos os modos de resposta.

Tabela 5.12- Autovalores em malha fechada com o PSS dado por (5.5).

\begin{tabular}{|c|c|c|c|c|}
\hline Condição & Modos & Real & Imaginária & Amortecimento (\%) \\
\hline \multirow{2}{*}{$\begin{array}{c}\text { Não-nominal } \\
+6 \%\end{array}$} & Intra-Planta & $-8,93$ & $\pm 34,09$ & 25,33 \\
\hline & Local & $-0,33$ & $\pm 4,78$ & 6,99 \\
\hline \multirow{2}{*}{$\begin{array}{c}\text { Não-nominal } \\
+10 \% \\
\end{array}$} & Intra-Planta & $-8,89$ & $\pm 34,22$ & 25,14 \\
\hline & Local & $-0,30$ & $\pm 4,81$ & 6,33 \\
\hline \multirow{2}{*}{$\begin{array}{l}\text { Não-nominal } \\
+14 \%\end{array}$} & Intra-Planta & $-8,85$ & $\pm 34,34$ & 24,96 \\
\hline & Local & $-0,27$ & $\pm 4,84$ & 5,66 \\
\hline \multirow{2}{*}{$\begin{array}{c}\text { Não-nominal } \\
+18 \% \\
\end{array}$} & Intra-Planta & $-8,82$ & $\pm 34,45$ & 24,81 \\
\hline & Local & $-0,24$ & \pm 4.87 & 5,00 \\
\hline \multirow[b]{2}{*}{ Nominal } & Intra-Planta & $-9,00$ & $\pm 33,84$ & 25,69 \\
\hline & Local & $-0,38$ & $\pm 4,72$ & $\mathbf{7 , 9 7}$ \\
\hline \multirow{2}{*}{$\begin{array}{c}\text { Não-nominal } \\
-6 \%\end{array}$} & Intra-Planta & $-9,09$ & $\pm 33,55$ & 26,15 \\
\hline & Local & $-0,42$ & $\pm 4,65$ & 8,92 \\
\hline \multirow{2}{*}{$\begin{array}{c}\text { Não-nominal } \\
-10 \% \\
\end{array}$} & Intra-Planta & $-9,16$ & $\pm 36,30$ & 26,52 \\
\hline & Local & $-0,44$ & $\pm 4,60$ & $\mathbf{9 , 5 2}$ \\
\hline \multirow{2}{*}{$\begin{array}{c}\text { Não-nominal } \\
-14 \% \\
\end{array}$} & Intra-Planta & $-9,25$ & $\pm 33,03$ & 26,96 \\
\hline & Local & $-0,46$ & $\pm 4,56$ & 10,07 \\
\hline \multirow{2}{*}{$\begin{array}{c}\text { Não-nominal } \\
-18 \% \\
\end{array}$} & Intra-Planta & $-9,35$ & $\pm 32,70$ & 27,48 \\
\hline & Local & $-0,48$ & $\pm 4,51$ & 10,56 \\
\hline
\end{tabular}

Cabe salientar que a inclusão de um número maior de condições de operação gera dificuldades significativas para a realização da sintonia manual de PSSs, pois para cada novo conjunto de parâmetros gerado pelo processo empírico de tentativa-e-erro característico da sintonia manual, é necessário verificar o amortecimento mínimo obtido em cada um dos pontos de operação considerados. Embora seja simples, esta verificação consome um tempo significativo quando realizada de maneira manual, fazendo com que o processo de sintonia manual seja bastante tedioso e demande um número elevado de horas trabalhadas por parte do engenheiro projetista. Por outro lado, o algoritmo proposto realiza a sintonia de maneira 
automática e, como comentado anteriormente, deixa o projetista livre para a realização de outras atividades, resultando novamente em ganho de produtividade.

\subsection{4 - Resultados do Teste IV}

No quarto teste, o algoritmo convergiu para uma solução factível depois de 9 iterações, gastando aproximadamente 1 horas e 7 minutos para todo o processo ser completado. Neste teste, a faixa de variação dos pontos de operação foi reduzida para a mesma utilizada no Teste I (ou seja, de $-16 \%$ a $+16 \%$ de carga local com relação ao caso base), mas o número de pontos de operação foi aumentado para 17 (ou seja, um aumento de mais de três vezes com relação ao Teste I e de quase duas vezes com relação ao Teste III).

O PSS sintonizado pelo algoritmo proposto no Teste IV tem a seguinte função de transferência:

$$
y_{j i}=12 \frac{10 s}{1+10 s}\left(\frac{43.7 s^{2}+347.2 s+480.1}{s^{2}+77 s+1453.5}\right)
$$

A aplicação deste PSS para todas as 4 máquinas do sistema da Figura 5.1 resulta nos autovalores em malha fechada mostrados na Tabela 5.13.

O tempo gasto pelo algoritmo proposto para atingir uma solução satisfatória para o problema correspondente ao Teste IV é um forte indicativo de que o fator que mais influencia o desempenho computacional deste algoritmo é a presença de pontos de operação com alto carregamento, e não a inclusão de um número maior de pontos de operação, como poderia ser inferido pelo fato de um número maior de pontos de operação requerer um número maior de cálculos realizados pelo algoritmo. 
Tabela 5.13- Autovalores em malha fechada com o PSS dado por (5.6).

\begin{tabular}{|c|c|c|c|c|}
\hline Condição & Modos & Real & Imaginária & Amortecimento (\%) \\
\hline \multirow{2}{*}{$\begin{array}{l}\text { Não-nominal } \\
+2 \%\end{array}$} & Intra-Planta & $-5,00$ & $\pm 38,63$ & 12,86 \\
\hline & Local & $-0,36$ & $\pm 4,76$ & 7,46 \\
\hline \multirow{2}{*}{$\begin{array}{l}\text { Não-nominal } \\
+4 \%\end{array}$} & Intra-Planta & $-4,97$ & $\pm 38,71$ & 12,74 \\
\hline & Local & $-0,34$ & $\pm 4,78$ & 7,10 \\
\hline \multirow{2}{*}{$\begin{array}{c}\text { Não-nominal } \\
+6 \%\end{array}$} & Intra-Planta & $-4,94$ & $\pm 38,78$ & 12,64 \\
\hline & Local & $-0,32$ & $\pm 4,79$ & 6,76 \\
\hline \multirow{2}{*}{$\begin{array}{c}\text { Não-nominal } \\
+8 \% \\
\end{array}$} & Intra-Planta & $-4,91$ & $\pm 38,84$ & 12,55 \\
\hline & Local & $-0,31$ & $\pm 4,81$ & 6,42 \\
\hline \multirow{2}{*}{$\begin{array}{l}\text { Não-nominal } \\
+10 \%\end{array}$} & Intra-Planta & $-4,88$ & $\pm 38,90$ & 12,45 \\
\hline & Local & $-0,29$ & $\pm 4,82$ & 6,06 \\
\hline \multirow{2}{*}{$\begin{array}{c}\text { Não-nominal } \\
+12 \%\end{array}$} & Intra-Planta & $-4,86$ & $\pm 38,96$ & 12,37 \\
\hline & Local & $-0,28$ & $\pm 4,84$ & 5,72 \\
\hline \multirow{2}{*}{$\begin{array}{c}\text { Não-nominal } \\
+14 \% \\
\end{array}$} & Intra-Planta & $-4,83$ & $\pm 39,01$ & 12,29 \\
\hline & Local & $-0,26$ & $\pm 4,85$ & 5,37 \\
\hline \multirow{2}{*}{$\begin{array}{c}\text { Não-nominal } \\
+16 \%\end{array}$} & Intra-Planta & $-4,81$ & $\pm 39,06$ & 12,22 \\
\hline & Local & $-0,25$ & $\pm 4,86$ & 5,05 \\
\hline \multirow{2}{*}{ Nominal } & Intra-Planta & $-5,04$ & $\pm 38,55$ & 12,97 \\
\hline & Local & $-0,37$ & $\pm 4,74$ & $\mathbf{7 , 8 0}$ \\
\hline \multirow{2}{*}{$\begin{array}{c}\text { Não-nominal } \\
-2 \% \\
\end{array}$} & Intra-Planta & $-5,09$ & $\pm 38,47$ & 13,11 \\
\hline & Local & $-0,39$ & $\pm 4,72$ & 8,15 \\
\hline \multirow{2}{*}{$\begin{array}{c}\text { Não-nominal } \\
-4 \% \\
\end{array}$} & Intra-Planta & $-5,13$ & $\pm 38,38$ & 13,24 \\
\hline & Local & $-0,40$ & $\pm 4,70$ & 8,49 \\
\hline \multirow{2}{*}{$\begin{array}{c}\text { Não-nominal } \\
-6 \%\end{array}$} & Intra-Planta & $-5,17$ & $\pm 38,28$ & 13,39 \\
\hline & Local & $-0,41$ & $\pm 4,68$ & 8,83 \\
\hline \multirow{2}{*}{$\begin{array}{c}\text { Não-nominal } \\
-8 \% \\
\end{array}$} & Intra-Planta & $-5,22$ & $\pm 38,17$ & 13,56 \\
\hline & Local & $-0,43$ & $\pm 4,66$ & 9,17 \\
\hline \multirow{2}{*}{$\begin{array}{c}\text { Não-nominal } \\
-10 \% \\
\end{array}$} & Intra-Planta & $-5,28$ & $\pm 38,06$ & 13,74 \\
\hline & Local & $-0,44$ & $\pm 4,64$ & 9,49 \\
\hline \multirow{2}{*}{$\begin{array}{c}\text { Não-nominal } \\
-12 \% \\
\end{array}$} & Intra-Planta & $-5,34$ & $\pm 37,94$ & 13,93 \\
\hline & Local & $-0,45$ & $\pm 4,62$ & 9,81 \\
\hline \multirow{2}{*}{$\begin{array}{c}\text { Não-nominal } \\
-14 \% \\
\end{array}$} & Intra-Planta & $-5,40$ & $\pm 37,80$ & 14,15 \\
\hline & Local & $-0,47$ & $\pm 4,59$ & 10,13 \\
\hline \multirow{2}{*}{$\begin{array}{c}\text { Não-nominal } \\
-16 \%\end{array}$} & Intra-Planta & $-5,47$ & $\pm 37,66$ & 14,37 \\
\hline & Local & $-0,48$ & $\pm 4,57$ & 10,42 \\
\hline
\end{tabular}


Observa-se que o tempo gasto pelo algoritmo para encontrar uma solução para o problema relativo ao Teste IV, composto por 17 pontos de operação na faixa entre $-16 \%$ a $+16 \%$ de carga local com relação ao caso base, é menor do que aquele necessário para que o mesmo algoritmo encontre uma solução para o problema referente ao Teste II, composto por 5 pontos de operação $-18 \%$ a $+18 \%$ de carga local com relação ao caso base. Trata-se novamente de uma vantagem óbvia do algoritmo proposto com relação à sintonia manual, na qual uma quantidade elevada de pontos de operação pode requerer dias para que um engenheiro projetista complete uma sintonia de PSS.

\subsection{5 - Resultados do Teste V}

No quinto e último teste, o algoritmo convergiu para uma solução factível depois de 37 iterações, gastando aproximadamente 4 horas e 32 minutos para todo o processo ser completado. Foram mantidos os mesmos 17 pontos de operação do Teste IV, mas no Teste V foram utilizados limites nos parâmetros Kpss e $\gamma_{i}=\frac{1}{T_{2 i}}$, conforme mencionado anteriormente. Os limites utilizados foram $1<$ Kpss $<30$ e $24,85<\gamma_{i}=\frac{1}{T_{2 i}}<35$, respectivamente.

O PSS sintonizado pelo algoritmo proposto no Teste IV tem a seguinte função de transferência:

$$
y_{j i}=5,25 \frac{10 s}{1+10 s}\left(\frac{1+0.289 s}{1+0.0287 s}\right)^{2}
$$


Após a aplicação deste PSS para todas as 4 máquinas do sistema da Figura 5.1 resulta nos autovalores em malha fechada mostradas na Tabela 5.14 .

O aumento do tempo computacional gasto para a obtenção de uma sintonia satisfatória dos PSSs no Teste V, com relação ao Teste IV, deve-se fundamentalmente à redução significativa do espaço de busca gerada pela imposição da estrutura tradicional com pólos e zeros reais. Embora não haja impedimento, do ponto de vista prático, à implementação de controladores com pólos e zeros complexos, a utilização da estrutura tradicional pode ser preferida em alguns casos, especialmente aqueles em que o hardware disponível para implementação esteja adaptado para esta estrutura tradicional.

Apesar de ter havido aumento do tempo computacional na comparação com o Teste IV, o tempo gasto no teste V não é proibitivo e, portanto a imposição da estrutura tradicional de PSS, associada à imposição de limites nos parâmetros Kpss e $\gamma_{i}=\frac{1}{T_{2 i}}$, pode ser uma alternativa de projeto interessante, pois garante que o PSS sintonizado será fisicamente implementável e terá uma estrutura compatível com qualquer hardware existente para implementação do mesmo. 
Tabela 5.14- Autovalores em malha fechada com o PSS dado por (5.7).

\begin{tabular}{|c|c|c|c|c|}
\hline Condição & Modos & Real & Imaginária & Amortecimento (\%) \\
\hline \multirow{2}{*}{$\begin{array}{c}\text { Não-nominal } \\
+2 \%\end{array}$} & Intra-Planta & $-5,00$ & $\pm 38,63$ & 12,86 \\
\hline & Local & $-0,36$ & $\pm 4,76$ & 7,46 \\
\hline \multirow{2}{*}{$\begin{array}{c}\text { Não-nominal } \\
+4 \%\end{array}$} & Intra-Planta & $-4,97$ & $\pm 38,71$ & 12,74 \\
\hline & Local & $-0,34$ & $\pm 4,78$ & 7,10 \\
\hline \multirow{2}{*}{$\begin{array}{c}\text { Não-nominal } \\
+6 \%\end{array}$} & Intra-Planta & $-4,94$ & $\pm 38,78$ & 12,64 \\
\hline & Local & $-0,32$ & $\pm 4,79$ & 6,76 \\
\hline \multirow{2}{*}{$\begin{array}{c}\text { Não-nominal } \\
+8 \%\end{array}$} & Intra-Planta & $-4,91$ & $\pm 38,84$ & 12,55 \\
\hline & Local & $-0,31$ & $\pm 4,81$ & 6,42 \\
\hline \multirow{2}{*}{$\begin{array}{c}\text { Não-nominal } \\
+10 \%\end{array}$} & Intra-Planta & $-4,88$ & $\pm 38,90$ & 12,45 \\
\hline & Local & $-0,29$ & $\pm 4,82$ & 6,06 \\
\hline \multirow{2}{*}{$\begin{array}{c}\text { Não-nominal } \\
+12 \%\end{array}$} & Intra-Planta & $-4,86$ & $\pm 38,96$ & 12,37 \\
\hline & Local & $-0,28$ & $\pm 4,84$ & 5,72 \\
\hline \multirow{2}{*}{$\begin{array}{c}\text { Não-nominal } \\
+14 \%\end{array}$} & Intra-Planta & $-4,83$ & $\pm 39,01$ & 12,29 \\
\hline & Local & $-0,26$ & $\pm 4,85$ & 5,37 \\
\hline \multirow{2}{*}{$\begin{array}{c}\text { Não-nominal } \\
+16 \%\end{array}$} & Intra-Planta & $-4,81$ & $\pm 39,06$ & 12,22 \\
\hline & Local & $-0,25$ & $\pm 4,86$ & 5,05 \\
\hline \multirow{2}{*}{ Nominal } & Intra-Planta & $-5,04$ & $\pm 38,55$ & 12,97 \\
\hline & Local & $-0,37$ & $\pm 4,74$ & 7,80 \\
\hline \multirow{2}{*}{$\begin{array}{c}\text { Não-nominal } \\
-2 \% \\
\end{array}$} & Intra-Planta & $-5,09$ & $\pm 38,47$ & 13,11 \\
\hline & Local & $-0,39$ & $\pm 4,72$ & 8,15 \\
\hline \multirow{2}{*}{$\begin{array}{c}\text { Não-nominal } \\
-4 \% \\
\end{array}$} & Intra-Planta & $-5,13$ & $\pm 38,38$ & 13,24 \\
\hline & Local & $-0,40$ & $\pm 4,70$ & 8,49 \\
\hline \multirow{2}{*}{$\begin{array}{c}\text { Não-nominal } \\
-6 \%\end{array}$} & Intra-Planta & $-5,17$ & $\pm 38,28$ & 13,39 \\
\hline & Local & $-0,41$ & $\pm 4,68$ & 8,83 \\
\hline \multirow{2}{*}{$\begin{array}{c}\text { Não-nominal } \\
-8 \%\end{array}$} & Intra-Planta & $-5,22$ & $\pm 38,17$ & 13,56 \\
\hline & Local & $-0,43$ & $\pm 4,66$ & 9,17 \\
\hline \multirow{2}{*}{$\begin{array}{c}\text { Não-nominal } \\
-10 \%\end{array}$} & Intra-Planta & $-5,28$ & $\pm 38,06$ & 13,74 \\
\hline & Local & $-0,44$ & $\pm 4,64$ & 9,49 \\
\hline \multirow{2}{*}{$\begin{array}{c}\text { Não-nominal } \\
-12 \% \\
\end{array}$} & Intra-Planta & $-5,34$ & $\pm 37,94$ & 13,93 \\
\hline & Local & $-0,45$ & $\pm 4,62$ & $\mathbf{9 , 8 1}$ \\
\hline \multirow{2}{*}{$\begin{array}{c}\text { Não-nominal } \\
-14 \% \\
\end{array}$} & Intra-Planta & $-5,40$ & $\pm 37,80$ & 14,15 \\
\hline & Local & $-0,47$ & $\pm 4,59$ & 10,13 \\
\hline \multirow{2}{*}{$\begin{array}{c}\text { Não-nominal } \\
-16 \% \\
\end{array}$} & Intra-Planta & $-5,47$ & $\pm 37,66$ & 14,37 \\
\hline & Local & $-0,48$ & $\pm 4,57$ & 10,42 \\
\hline
\end{tabular}




\subsection{6 - Comparação de Resultados}

A tabela 5.15 mostra uma comparação de resultados entre todos os testes efetuados, a partir da qual as conclusões apresentadas nas subseções 5.2.1 a 5.2.5 podem ser sumarizadas.

Tabela 5.15- Comparativo dos testes realizados.

\begin{tabular}{|c|c|c|c|c|c|}
\hline Teste & I & II & III & IV & V \\
\hline $\mathbf{N}^{\mathbf{0}}$ de Pontos de Operação & 5 & 5 & 9 & 17 & 17 \\
\hline Faixa de Operação & $\pm 16 \%$ & $\pm 18 \%$ & $\pm 18 \%$ & $\pm 16 \%$ & $\pm 16 \%$ \\
\hline $\mathbf{N}^{\mathbf{0}}$ de Iterações & 6 & 32 & 35 & 9 & 37 \\
\hline Tempo (minutos) & 26 & 92 & 197 & 67 & 272 \\
\hline
\end{tabular}

\subsection{7 - Validação dos Resultados}

É prática comum validar os resultados das análises e projetos baseados em modelos linearizados através de simulações não lineares dos respectivos sistemas em malha fechada. Sendo assim, para validar os resultados obtidos pelos processos lineares envolvidos no algoritmo proposto, uma série de simulações não lineares do sistema em malha fechada, com os PSSs dados por (5.3-5.7), foram realizadas. A Figura 5.3 mostra a resposta dos geradores para um curto-circuito trifásico na barra 1 (aplicado em 2s e com duração 16 ms - lembrando que esta curta duração é utilizada para garantir que o sistema não se afaste significativamente da condição de equilíbrio, caracterizando assim uma pequena perturbação) com o PSS dado por (5.3) quando o sistema é operado na condição não-nominal de $+12 \%$ apresentada na Tabela 5.10. 


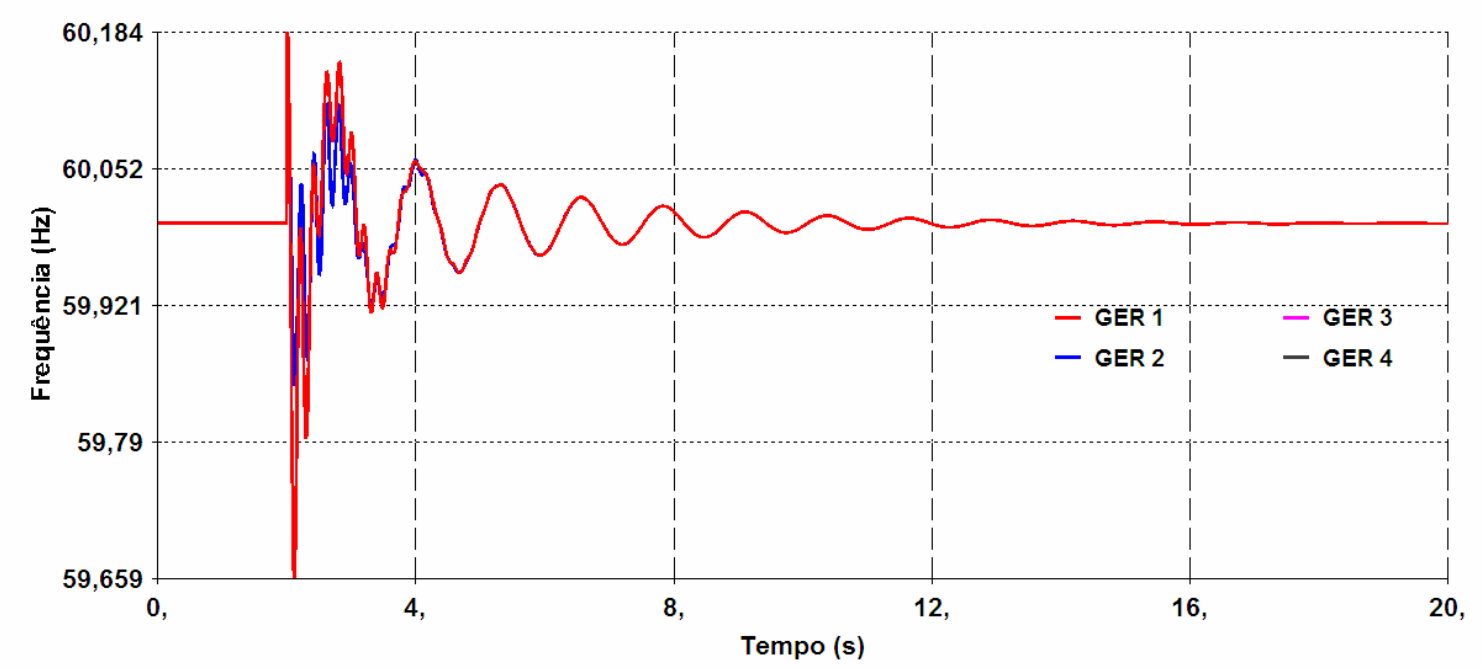

Figura 5.3- Simulação não linear do sistema com uma falta de $16 \mathrm{~ms}$ aplicado na barra $1 \mathrm{em} \mathrm{t}=2 \mathrm{~s}$ (potência incrementada em $12 \%$ em relação ao caso base).

Depois que a falta é removida, o sistema retorna para sua configuração original e é possível distinguir, no início do transitório, a presença de ambos os modos locais e intraplanta. O gerador 1 se comporta diferentemente dos outros geradores, o que indica a presença das oscilações intra-planta deste gerador contra os demais dentro da mesma usina. No entanto, esta diferença entre a resposta do gerador 1 com a dos demais desaparece rapidamente da resposta (resultado do bom amortecimento conseguido para o modo intra-planta correspondente), e os 4 geradores começam a oscilar coerentemente contra o resto do sistema, ficando então bem caracterizado o modo local respectivo, com menor (mais ainda satisfatório) amortecimento do que o modo intra-planta, conforme esperado pelos resultados da Tabela 5.10 .

As Figuras 5.4 e 5.5 mostram as respostas dos geradores para um curto-circuito trifásico na barra 8 com o PSS dado por (5.4) e (5.5) respectivamente, quando o sistema é operado na condição não-nominal de $+16 \%$ apresentada nas Tabelas 5.11 e 5.12 . Note que a localização da falta aplicada tende a afetar todos os geradores de forma equânime, de maneira que não sejam estimuladas oscilações intra-planta. Depois da falta ser removida o sistema retorna a sua configuração inicial e, de fato, é possível notar que todos os geradores oscilam 
coerentemente contra o resto do sistema, caracterizando assim o modo local. Os resultados das Figuras 5.4 e 5.5 também confirmam que os modos locais são bem amortecidos pelos PSSs ajustados pelo algoritmo proposto.

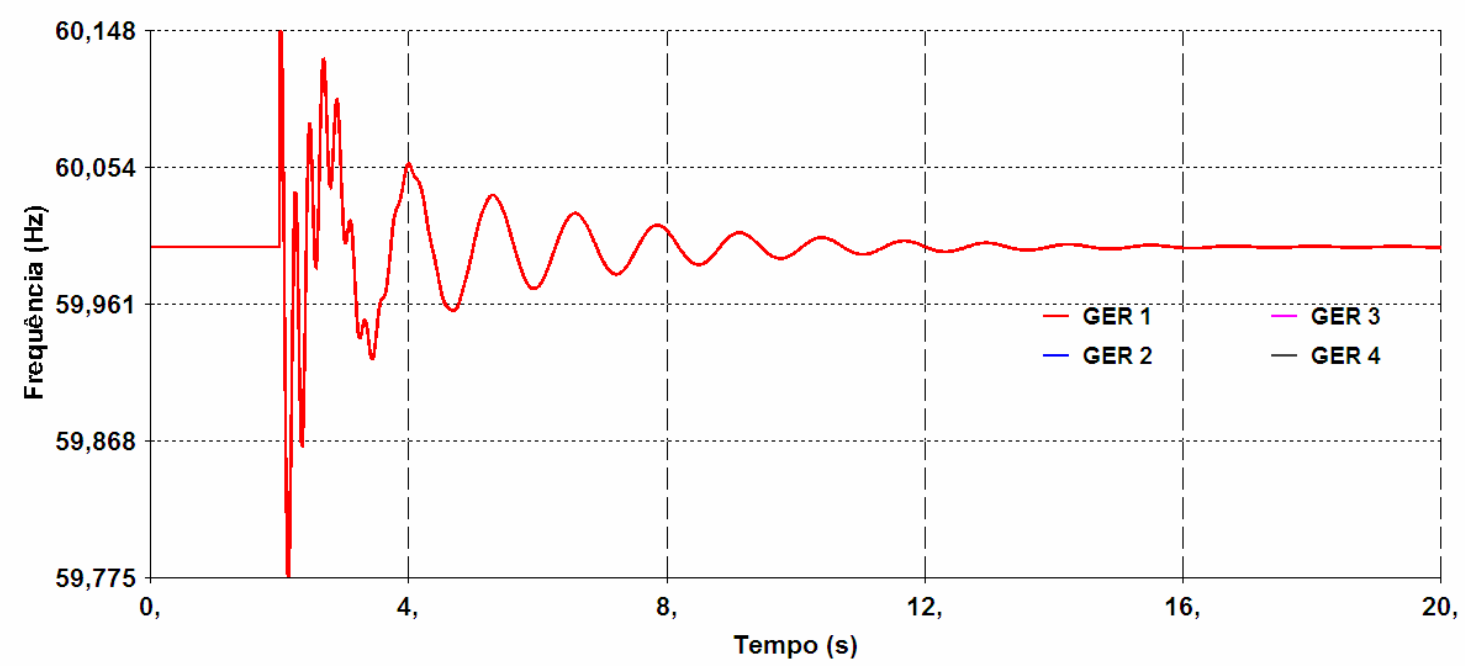

Figura 5.4- Simulação não linear do sistema com uma falta de $16 \mathrm{~ms}$ aplicado na barra $8 \mathrm{em} \mathrm{t}=2 \mathrm{~s}$ (potência incrementada em $16 \%$ em relação ao caso base).

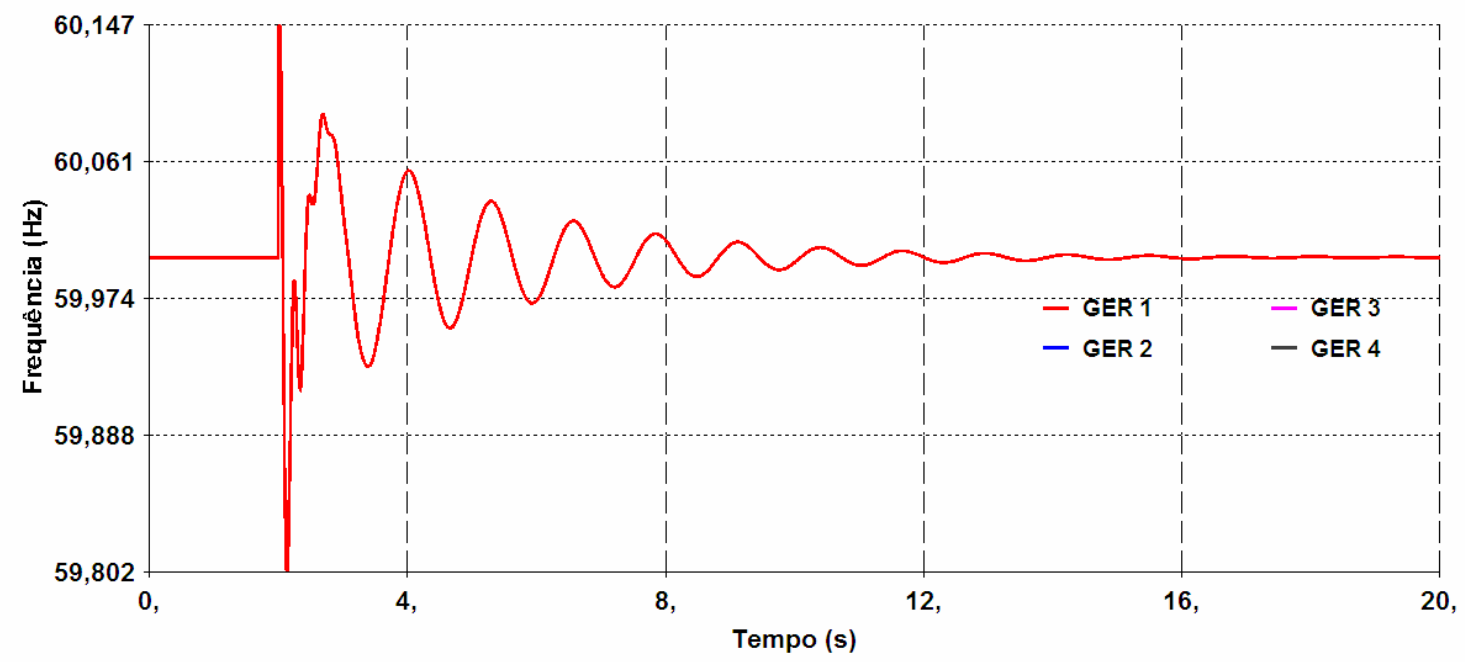

Figura 5.5- Simulação não linear do sistema com uma falta em 16ms aplicada na barra 8 em t=2s (potência incrementada em 16\% em relação ao caso base).

As Figuras 5.6 e 5.7 mostram a resposta do sistema com a mesma perturbação descrita na Figura 5.3, com os PSSs dados por (5.6) e (5.7) respectivamente. Nota-se, novamente, que 
os resultados previstos pelas ferramentas lineares utilizadas no projeto destes PSSs são confirmados pelas simulações não lineares apresentadas.

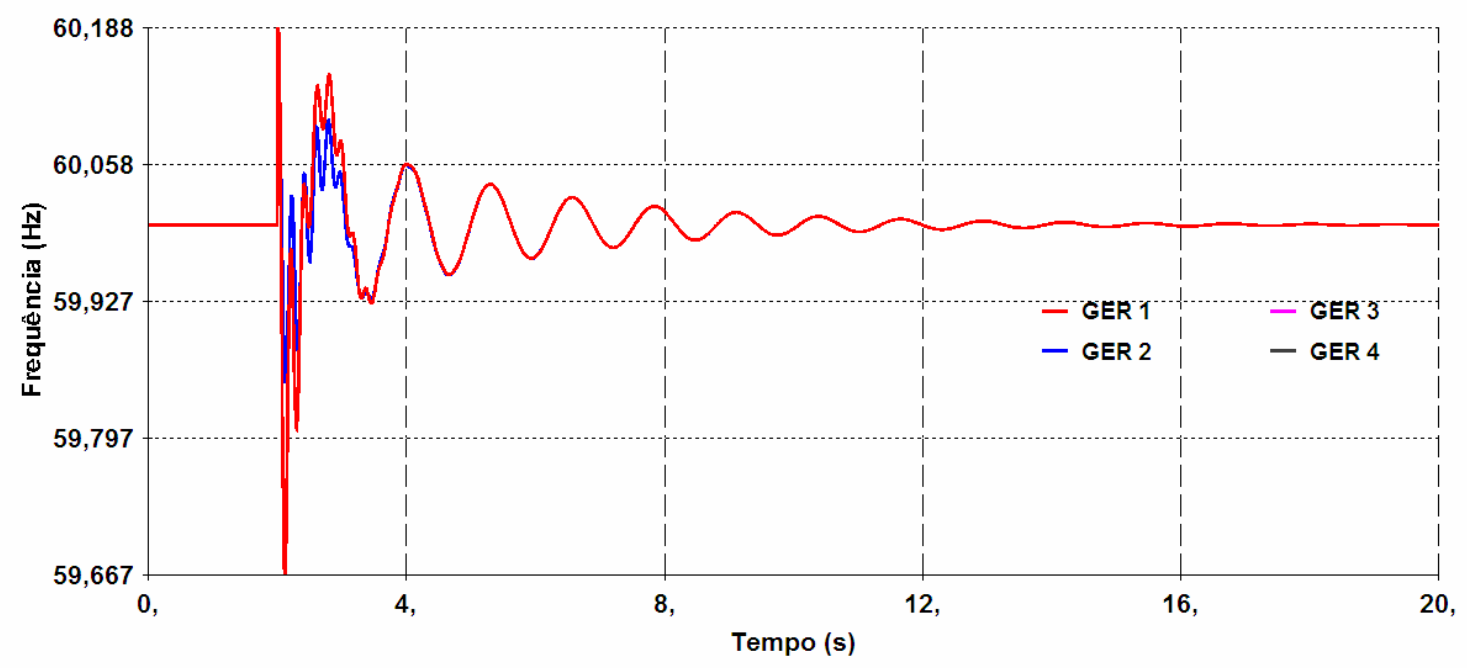

Figura 5.6- Simulação não linear do sistema com uma falta de $16 \mathrm{~ms}$ aplicada na barra $1 \mathrm{em} \mathrm{t}=2 \mathrm{~s}$ (potência incrementada em $15 \%$ com relação ao caso base).

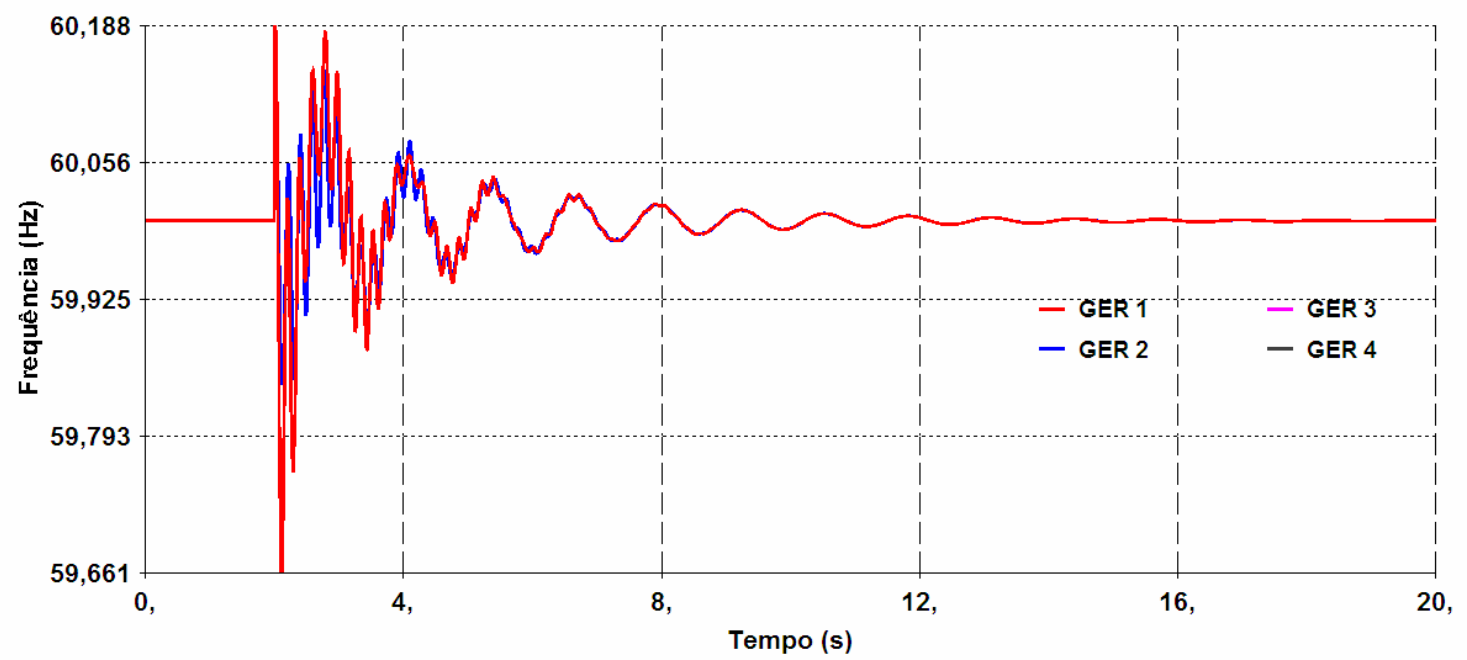

Figura 5.7- Simulação não linear do sistema com uma falta de $16 \mathrm{~ms}$ aplicada na barra $1 \mathrm{em} \mathrm{t}=2 \mathrm{~s}$ (potência incrementada em $15 \%$ com relação ao caso base).

Em todas essas situações o comportamento do sistema foi muito satisfatório, apresentando uma resposta significativamente bem amortecida, o que mostra que os PSSs ajustados pelo algoritmo proposto são bastante efetivos tanto nos amortecimentos de modos intra-planta como de modos locais. 


\section{Capítulo 6}

\section{CONCLUSÕES E PERSPECTIVAS FUTURAS}

Nesse trabalho, foram estudados o problema de oscilações eletromecânicas intraplanta em sistemas de potência e a solução usualmente empregada pela indústria para tal problema, que é o uso de controladores do tipo PSS, projetados por uma técnica de controle clássico e sintonizados de maneira empírica para o aumento do fator de amortecimento de tais oscilações. Verificou-se, no entanto, que a sintonia empírica dos parâmetros do PSS para um amortecimento eficaz das oscilações não é uma tarefa trivial, especialmente quando envolve múltiplas condições de operação e quando os geradores sujeitos às oscilações intra-planta participam também de outros modos eletromecânicos, tais como um modo local, por exemplo.

Por esta razão, o objetivo do trabalho foi o desenvolvimento de um procedimento automático de projeto de controladores (adaptado ao problema de oscilações eletromecânicas intra-planta) capaz de encontrar uma sintonia adequada dos parâmetros do PSS para amortecimento simultâneo de modos intra-planta e local em sistema de potência. A principal vantagem desse processo automático, quando comparado com os procedimentos convencionais de sintonia empírica (que requerem uma quantidade extensiva de trabalho de um projetista humano), é o fato de a intervenção do projetista ser minimizada, sendo o processo de tentativa-e-erro envolvido na sintonia do PSS realizado totalmente pelo computador (ficando o projetista responsável somente pelo suprimento dos parâmetros iniciais para a busca automática). 
88

O algoritmo proposto foi implementado utilizando-se o pacote YALMIP e as ferramentas de resolução de desigualdades matriciais lineares presentes no pacote SeDuMi, ambos disponíveis para o aplicativo Matlab ${ }^{\circledR}$. Para verificar a eficácia do algoritmo apresentado no capítulo 4 foram realizadas diversas simulações utilizando o modelo do sistema da Figura 5.1. As simulações foram efetuadas para o caso base e diversas variações na potência da carga, gerando vários pontos de operação para o sistema. A obtenção dos modelos linearizados e as análises de autovalores, autovetores e fatores de participação do sistema em estudo foram realizadas através do software PACDYN, e os resultados das sintonias automáticas realizadas pelo algoritmo proposto foram validados através de simulações não lineares realizadas com o software ANATEM.

Os resultados mostraram que o desempenho do algoritmo (em termos de quantidade de tempo necessário para encontrar uma solução para o problema em questão) é semelhante e, em alguns casos até mesmo bastante superior, ao de um projetista experiente. Portanto, o engenheiro encarregado da sintonia do PSS pode se concentrar em outras tarefas importantes, enquanto o computador executa o processo de sintonia, o que se traduz em um ganho significativo de produtividade para a empresa. É também razoável esperar que o funcionamento do projeto simultâneo pelo algoritmo proposto tenda a ser mais eficiente que as abordagens seqüenciais usuais para a sintonia do PSS, pois o mesmo é capaz de sintonizar os parâmetros de múltiplos PSSs simultaneamente, em oposição à sintonia passo-a-passo que pode ser realizada por um projetista humano.

Este trabalho de mestrado resultou em duas publicações aceitas em eventos científicos de renome, sendo uma no congresso IEEE Power and Energy Society General Meeting 2009, que será realizado na cidade de Calgary, no Canadá, e outra no XIII Encuentro Regional Iberoamericano de Cigré (ERIAC), a ser realizado na cidade de Puerto Iguazú, na Argentina. 
A sequiência deste trabalho prevê a aplicação do procedimento desenvolvido, para outros problemas de grande porte envolvendo oscilações eletromecânicas (tais como modos inter-área, por exemplo) e a adaptação do mesmo para o projeto de controladores suplementares para dispositivos FACTS. Também é previsto o estudo de técnicas de redução de modelos lineares para viabilizar a aplicação do algoritmo proposto a sistemas elétricos de grande porte, pois o esforço computacional envolvido na resolução de desigualdades matriciais lineares de dimensão elevada dificulta a aplicação deste algoritmo para tais sistemas. Alternativamente, pretende-se também explorar a esparsidade existente nos modelos lineares de sistemas de grande porte para acelerar o processo de resolução das desigualdades mencionadas, o que poderia igualmente viabilizar a aplicação do algoritmo a sistemas de dimensão elevada. 


\section{REFERÊNCIAS BIBLIOGRÁFICAS}

Anderson, P. M. e Fouad, A. A. (1994). Power system control and stability. IEEE Press.

Araújo, C. S., e Castro, J. C. (1991). Application of power system stabilisers in a plant with identical units. IEE Proceedings-C, vol. $138, \mathrm{n}^{\circ} 1$.

Bomfim, A. L. B., Taranto, G. N. e Falcão, D. M. (2000). "Simultaneous tuning of power system damping controllers using genetic algorithms," IEEE Trans. on Power Syst., vol. 15, no.1, pp. 163-169, Feb. 2000.

Boukarim, G. E., Wang, S., Chow, J., Taranto, G. N. e Martins, N. (2000). “A comparison of classical, robust, and decentralized control designs for multiple power system stabilizers," IEEE Trans. on Power Syst., vol. 15, no. 4, pp. 1287-1292, 2000.

Boyd, S., Ghaoui, L.E., Feron, E. e Balakrishnam, V. (1994). Linear matrix inequalities in system and control theory. Society for industrial and applied mathematics.

Bretas, N. G e Alberto, L. F. C (1999). Estabilidade transitória em sistemas eletroenergéticos. Publicações EESC-USP.

Cepel, Centro de pesquisas de energia elétrica. Rio de Janeiro, RJ, 2002. PACDYN- Manual do usuário. Disponível em: http:<//www.pacdyn.cepel.br> Acesso em 21 jan.2007. 
Crenshaw, M. L., Cutler, J. M., Wright, G. F. e Reid Jr., W. J. (1983). Power system stabilizer application in a two-unit plant analytical studies and fields tests. IEEE trans., february 1983, PAS 102, pp. 267-274.

Davison, E.J. e Ramesh, N. (1970). A note on the eigenvalues of a real matrix. IEEE Trans. Automatic Control, 15, pp. 252-253.

DeMello, F. P. e Concordia, C. (1969). Concepts of synchronous machine stability as affected by excitation control. IEEE Transactions on Power Systems, vol. 18, n. 4, pp. 1487-1496.

Klein, M., Rogers, G. J. e Kundur, P. (1991). A fundamental study of inter-area oscillations in power systems. IEEE Transactions on Power Systems, vol. 6, n. 3, pp. 914-921.

Kuiava, Rôman (2006). Controle robusto de dispositivos facts para o amortecimento de oscilações em sistemas elétricos de potencia. Dissertação de Mestrado, EESC-USP, São Carlos, S.P.

Kundur, P. (1994). Power system stability and control, McGraw-Hill, New York

Kundur, P., Paserba, J., Ajjarapu, V. et al. (2004). Definition and classification of power system stability. IEEE Transactions on Power Systems, vol. 19, n. 2, pp. 1387-1401. 
92

Larsen, E. V. e Swann, D. A. (1981). “Applying power system stabilizers, parts I II and III”. IEEE Trans. on Power App. and Syst., vol. PAS-100, no. 6, pp. 3017-3046, 1981.

Löfberg, J. (2004). A toolbox for modeling and optimization in Matlab. In Proceedings of the CACSD Conference, Taipei, Taiwan, 2004.

Oliveira, R. V., Ramos, R. A e Bretas, N. G. (2007) "A mixed procedure based on classical and modern control to design robust damping controllers," IEEE Trans. on Power Syst., vol. 22, pp. 1231-1239, 2007.

Pal, B. e Chaudhuri, B. (2005). Robust control in power systems. Springer Science + Business Media, Inc.

Pagola, F. L., Perez-Arriaga I. J. e Verghese G. C. (1989). On sensitivities, residues and participations: applications to oscillatory stability analysis and control. IEEE Trans. on Power Syst., vol. 4, no. 1, pp. 278-285, 1989.

Pérez-Arriaga, I. J., Verghese, G. C. e Schweppe, F. C. (1982). Selective modal analysis of very large systems with applications to electric power systems, IEEE Transactions on Power Apparatus and Systems.

Ramos, R. A. (2002). Procedimento de projeto de controladores robustos para o amortecimento de oscilações eletromecânicas em sistemas de potência. Tese de Doutorado, EESC-USP, São Carlos, S.P. 
Ramos, R. A., Alberto, L. F. C. e Bretas, N. G. (2004). “A New Methodology for the Coordinated Design of Robust Decentralized Power System Damping Controllers," IEEE Trans. on Power Syst., vol. 19, n.1, pp. 444-454, Feb. 2004.

Ramos, R. A., Castoldi, M. F., Rodrigues, C. R., Borges, R. C. e Bretas, N. G. (2009). “Tuning Power System Stabilizers to Damp Intra-plant Modes Using an Automatic Procedure,” publicação aceita no IEEE Power and Energy Society General Meeting 2009.

Ramos, R. A., Rodrigues, C. R., Castoldi, M. F., Borges, R. C. e Bretas, N. G. (2009). “Aplicação de um Procedimento Computadorizado de Sintonia Automática de PSS para Amortecimento de Modos Intra-Planta,” publicação aceita no XIII Encuentro Regional Iberoamericano de Cigré (ERIAC) 2009.

Rodrigues, C. R., Ramos, R. A., Borges, R. C. e Bretas, N. G. (2007). Uma alternativa para a avaliação da robustez de desempenho de estabilizadores de sistemas de potência. Latin-American Congress on Electricity Generation and Transmission

Rogers, G. (2000). Power system oscillations. Kluwer Academic Publishers.

Schleif, F. R., Feeley, R. K., Phillips, W. H., e Torluemke, R. W. (1979). A power system stabilizer application with local mode cancellation. IEEE trans., may/june 1979, PAS 98, pp. 1054-1059. 
94

Sturn, J. F. (1999). Using SeDuMi 1.02, a matlab toolbox for optimization over symmetric cones. Optimization methods and software, vol. 11-12, pp. 625-653, 1999.

Vasques, R. O. (2006). Projeto de controladores de amortecimento para sistemas elétricos de potência. Tese de Doutorado. EESC-USP, São Carlos, S.P.

Vidyasagar, M. (1993). Nonlinear systems analysis. Ed. 2, Prentice-Hall. 